\title{
Best Practices for Shielding Analyses of Activated Metals and Spent Resins from Reactor Operation
}

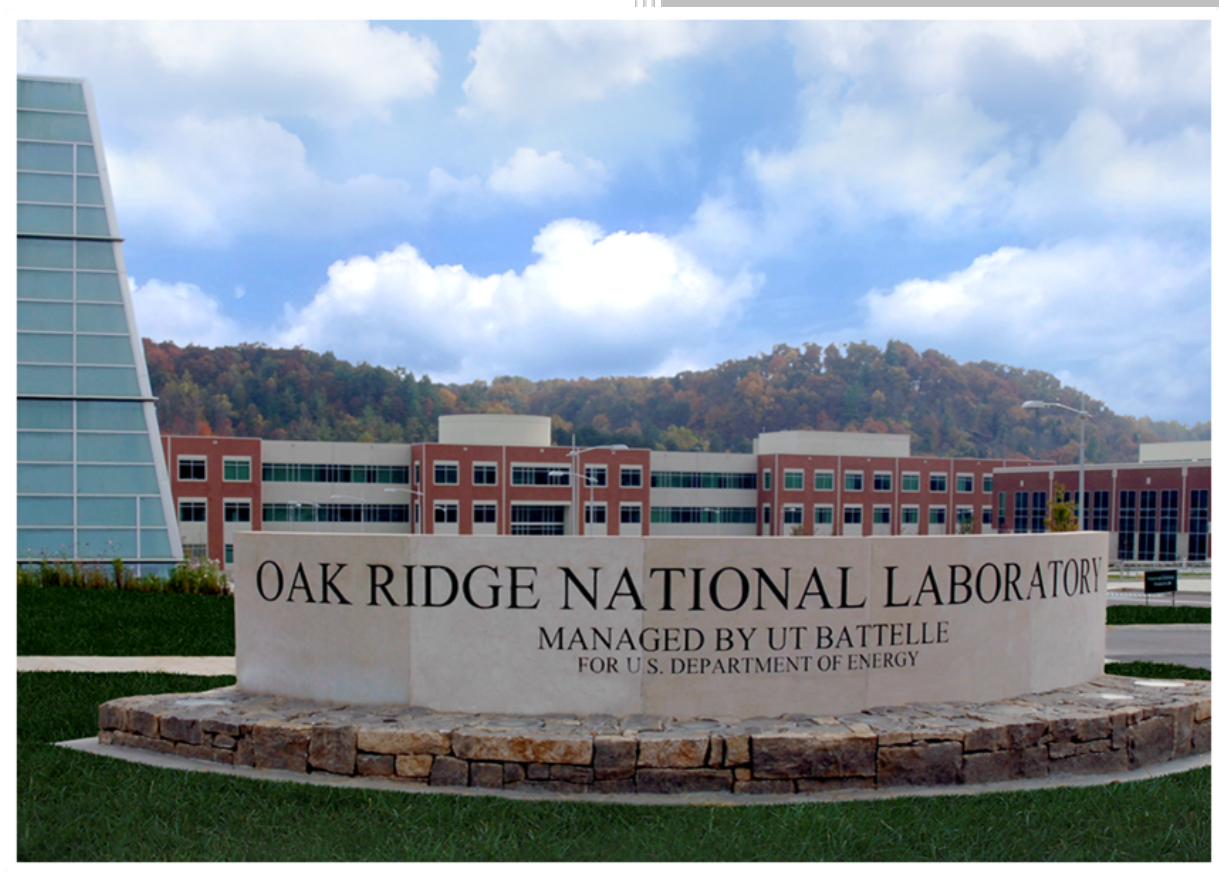

Approved for public release. Distribution is unlimited.

Georgeta Radulescu

Kaushik Banerjee

September 4, 2020 


\title{
DOCUMENT AVAILABILITY
}

Reports produced after January 1, 1996, are generally available free via US Department of Energy (DOE) SciTech Connect.

Website www.osti.gov

Reports produced before January 1, 1996, may be purchased by members of the public from the following source:

\author{
National Technical Information Service \\ 5285 Port Royal Road \\ Springfield, VA 22161 \\ Telephone 703-605-6000 (1-800-553-6847) \\ TDD 703-487-4639 \\ Fax 703-605-6900 \\ E-mail info@ntis.gov \\ Website http://classic.ntis.gov/
}

Reports are available to DOE employees, DOE contractors, Energy Technology Data Exchange representatives, and International Nuclear Information System representatives from the following source:

Office of Scientific and Technical Information

PO Box 62

Oak Ridge, TN 37831

Telephone 865-576-8401

Fax 865-576-5728

E-mail reports@osti.gov

Website http://www.osti.gov/contact.html

This report was prepared as an account of work sponsored by an agency of the United States Government. Neither the United States Government nor any agency thereof, nor any of their employees, makes any warranty, express or implied, or assumes any legal liability or responsibility for the accuracy, completeness, or usefulness of any information, apparatus, product, or process disclosed, or represents that its use would not infringe privately owned rights. Reference herein to any specific commercial product, process, or service by trade name, trademark, manufacturer, or otherwise, does not necessarily constitute or imply its endorsement, recommendation, or favoring by the United States Government or any agency thereof. The views and opinions of authors expressed herein do not necessarily state or reflect those of the United States Government or any agency thereof. 
Reactor and Nuclear Systems Division

Georgeta Radulescu

Kaushik Banerjee

Date Published: September 4, 2020

Prepared by

OAK RIDGE NATIONAL LABORATORY

Oak Ridge, TN 37831-6283

managed by

UT-BATTELLE, LLC

for the

US DEPARTMENT OF ENERGY

under contract DE-AC05-00OR22725 



\section{CONTENTS}

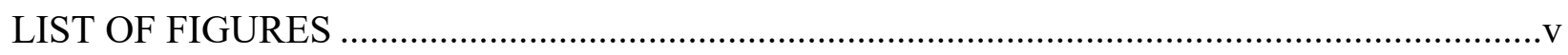

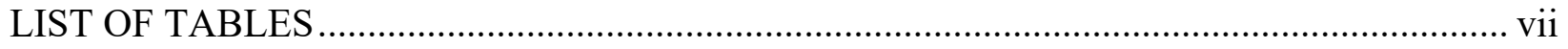

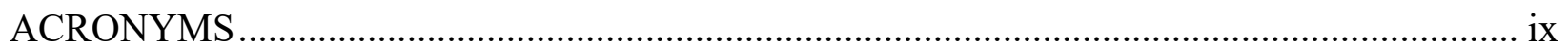

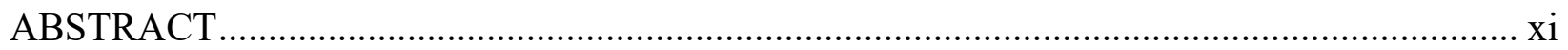

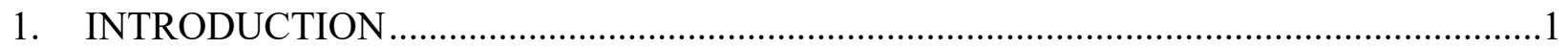

2. REVIEW OF SHIELDING ANALYSIS APPROACHES FOR GTCC IN SAFETY

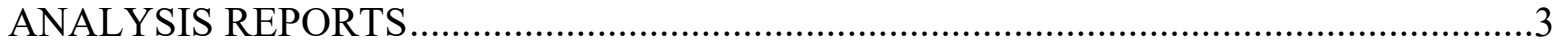

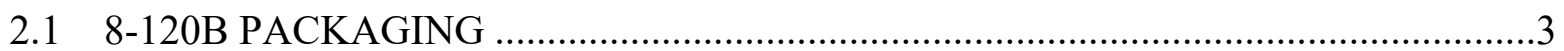

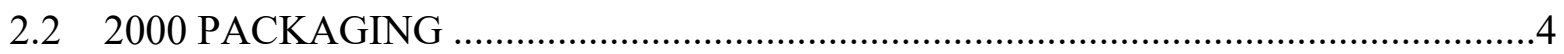

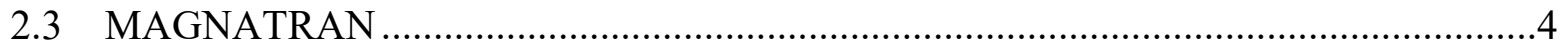

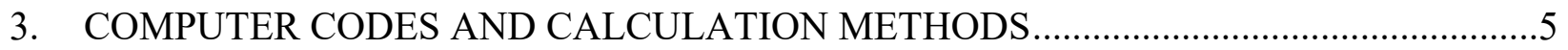

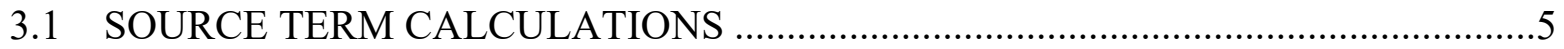

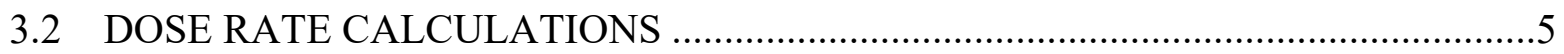

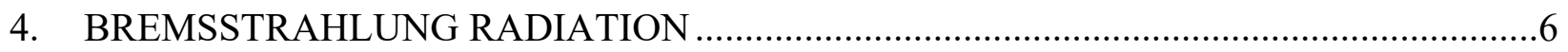

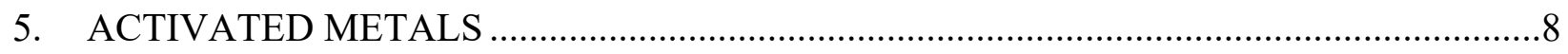

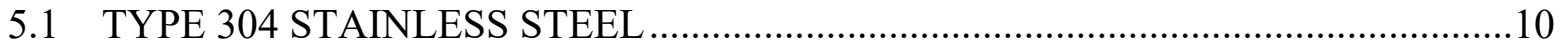

5.1.1 Average Elemental Concentrations in Type 304 Stainless Steel ......................12

5.1.2 Minimum Initial Cobalt Impurity Concentration and Average

Concentrations for the Remainder of Chemical Elements in Type 304

Stainless Steel.........................................................................................

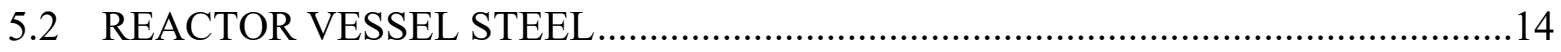

5.2.1 Average Elemental Concentrations in Vessel Steel ........................................16

5.2.2 Minimum Initial Cobalt Impurity Concentration and Average

Concentrations for the Remainder of Chemical Elements in Vessel Steel .......17

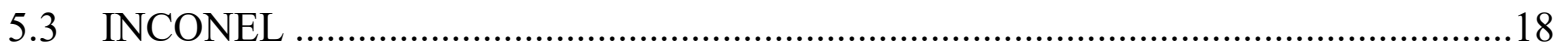

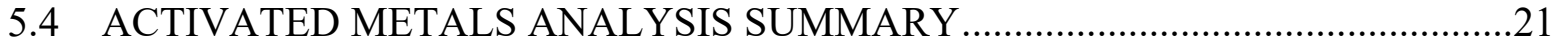

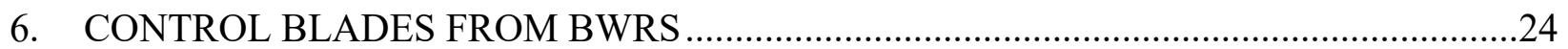

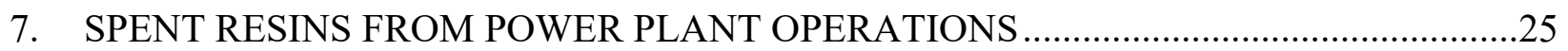

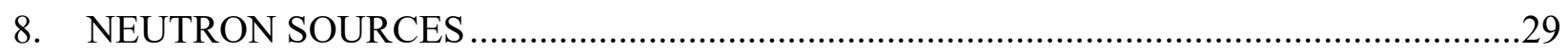

9. ANALYSIS OF SOURCE GEOMETRY AND SPATIAL DISTRIBUTION MODELS......31

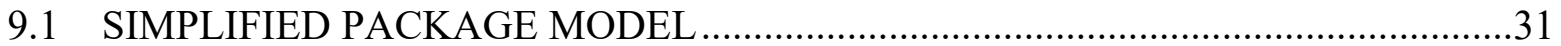

9.2 SELF-SHIELDING EFFECTS ASSOCIATED WITH ANALYSIS MODELS ...........33

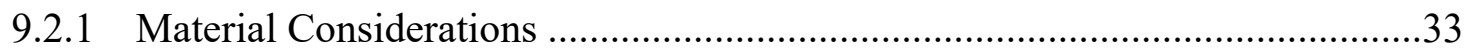

9.2.2 Self-Shielding Effects Associated with Waste Geometry Model ......................34

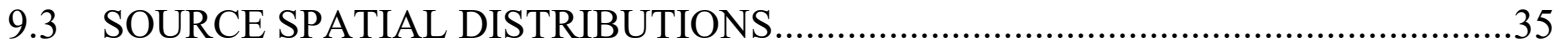

9.3.1 Spatial Distribution of Activation Products in Reactor Vessel and

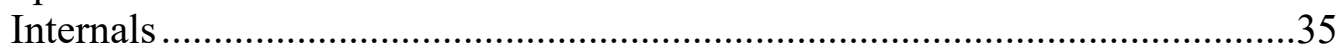

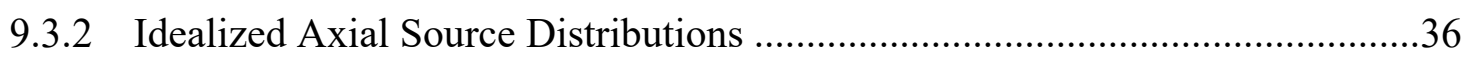

9.3.3 Idealized Radial Source Distributions ................................................................

10. NEUTRON-ACTIVATED CORROSION PRODUCTS ON REACTOR INTERNAL

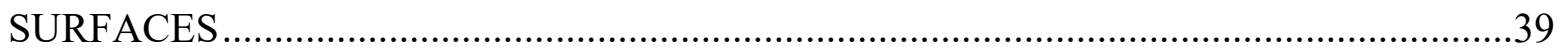

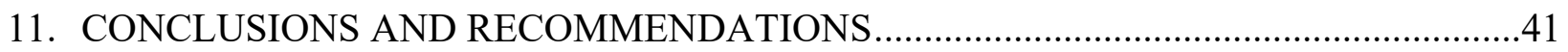

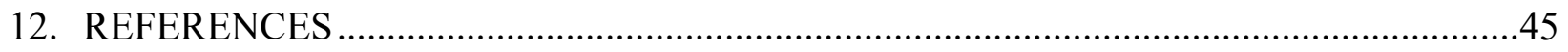





\section{LIST OF FIGURES}

Figure 1. Illustration of bremsstrahlung radiation sources assuming $\mathrm{UO}_{2}$ and $\mathrm{H}_{2} \mathrm{O}$ as the matrix options.

Figure 4. Fractional (a) activity and (b) decay heat for ${ }^{60} \mathrm{Co}$ and the remainder of radionuclides in irradiated Type 304 stainless steel with average initial elemental concentrations as a function of decay time.

Figure 5. Fractional external package dose rates for ${ }^{60} \mathrm{Co}$ and the remainder of radionuclides in irradiated Type 304 stainless steel with average initial elemental concentrations as a function of decay time, assuming (a) $1 \mathrm{~cm}$ and (b) $10 \mathrm{~cm}$ thick steel cask shield.

Figure 6. Fractional (a) activity and (b) decay heat for ${ }^{60} \mathrm{Co}$ and the remainder of radionuclides as a function of decay time in irradiated Type 304 stainless steel, assuming minimum initial cobalt impurity concentration and average concentrations for the remainder of chemical elements.

Figure 7. Fractional external package dose rates for ${ }^{60} \mathrm{Co}$ and the remainder of radionuclides as a function of decay time for average Type 304 stainless steel compositions, assuming (a) $1 \mathrm{~cm}$ and (b) $10 \mathrm{~cm}$ thick steel cask shell.

Figure 8. Fractional (a) activity and (b) decay heat for ${ }^{60} \mathrm{Co}$ and the remainder of radionuclides as a function of decay time for average vessel steel composition.

Figure 9. Fractional external dose rates for ${ }^{60} \mathrm{Co}$ and the remainder of radionuclides as a function of decay time for average vessel steel composition, assuming (a) $1 \mathrm{~cm}$ and (b) $10 \mathrm{~cm}$ thick steel cask shell.

Figure 10. Fractional (a) activity and (b) decay heat for ${ }^{60} \mathrm{Co}$ and the remainder of radionuclides in irradiated vessel steel as a function of decay time, assuming minimum initial cobalt impurity concentration and average concentrations for the remainder of chemical elements.

Figure 11. Fractional external dose rates for ${ }^{60} \mathrm{Co}$ and the remainder of radionuclides in irradiated vessel steel as a function of decay time assuming (a) $1 \mathrm{~cm}$ and (b) 10 $\mathrm{cm}$ thick steel cask shell—minimum initial cobalt impurity concentration and average concentrations for the remainder of chemical elements.

Figure 12. Fractional (a) activity and (b) decay heat for ${ }^{60} \mathrm{Co}$ and the remainder of radionuclides in irradiated Inconel as a function of decay time.

Figure 13. Fractional external dose rates for ${ }^{60} \mathrm{Co}$ and the remainder of radionuclides in irradiated Inconel as a function of decay time, assuming (a) $1 \mathrm{~cm}$ and (b) $10 \mathrm{~cm}$ thick steel cask shell.

Figure 14. Ratio of ${ }^{60} \mathrm{Co}$ dose rate to total dose rate as a function of decay time for activated metals.

Figure 15. Fractional external dose rates for ${ }^{137} \mathrm{Cs} /{ }^{137 m} \mathrm{Ba}$ and ${ }^{60} \mathrm{Co}$ on the Crystal River spent resin described in NUREG/CR-6567, assuming the thickness of the cask steel shell is (a) $1 \mathrm{~cm}$ and (b) $10 \mathrm{~cm}$.

Figure 16. Fractional external package dose rates due to ${ }^{137} \mathrm{Cs} /{ }^{137 m} \mathrm{Ba},{ }^{60} \mathrm{Co},{ }^{134} \mathrm{Cs},{ }^{65} \mathrm{Zn}$, and ${ }^{58} \mathrm{Co}$ on the spent resins described in NUREG/CR-2830, assuming the thickness of the cask steel shell is (a) $1 \mathrm{~cm}$ and (b) $10 \mathrm{~cm}$.

Figure 19. Probability density functions assumed for the source strength axial distribution. 
Figure 20. Source distributions assumed for the radial source profile.

Figure 21. Effects of radial source distributions pdf 4, pdf 5, and pdf 6 relative to the uniform source distribution (pdf 1) at detector locations 1 through 9.

Figure 22. Ratio of dose rate based on a surface source model to dose rate based on a uniform volumetric source model as a function of detector location for various neutron-activated corrosion product sources. 


\section{LIST OF TABLES}

Table 1. Packages currently authorized for shipment of reactor-related GTCC..........................3

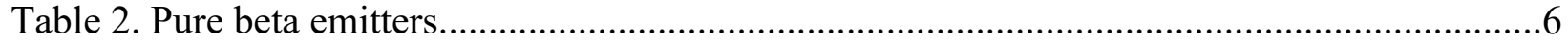

Table 3. Type 304 stainless steel composition summary from NUREG/CR-3474 .....................11

Table 7. Fractional activities, decay heat, and dose rates due to Co-60 and due to the other radionuclides in irradiated vessel steel-average initial nuclide concentrations

Table 8. Fractional activities, decay heat, and external package dose rates due to ${ }^{60} \mathrm{Co}$ and the remainder of radionuclides in irradiated vessel steel-minimum initial cobalt impurity concentration, average concentrations for the remainder of chemical elements

Table 9. Inconel composition from NUREG/CR-3474

Table 10. Fractional activities, decay heat, and dose rates because of ${ }^{60} \mathrm{Co}$ and the other radionuclides in irradiated Inconel.

Table 11. Main radionuclides with a half-life greater than 1 day identified in reactoractivated metals

Table 12. Important radionuclides in irradiated $\mathrm{Hf}$ and their half-lives and gamma emissions

Table 13. Levels $(\mu \mathrm{Ci} / \mathrm{g})$ of radionuclides on resin samples from various power plants

Table 14. Activity, decay heat, and dose rate fractions for ${ }^{137} \mathrm{Cs} /{ }^{137 m} \mathrm{Ba}$ and ${ }^{60} \mathrm{Co}$ on the Crystal River spent resin described in NUREG/CR-6567

Table 15. Dose rate fractions for main radionuclides on spent resins with maximum loading (NUREG/CR-2830) ..............................................................................28

Table 16. Alpha-emitting nuclide levels on a resin sample and actinide neutron and gamma sources.

Table 17. EIS-0375 radionuclide inventory assumed for activation metals shipments and

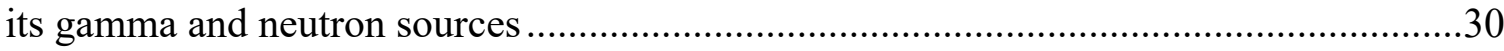

Table 18. Characteristics of the simplified cask model ..........................................................31

Table 19. Description of dose rate detector locations for the cask at NCT .................................33

Table 20. External cask dose rate for various materials normalized to dose rate based on Al material

Table 21. Effects of geometry models Case 1, 2, and 3 on external package dose rate relative to Case 4- uniform volumetric source distribution.

Table 22. Effects on cask external dose rate of pdf 2 and pdf 3 axial source strength distributions relative to uniform source distribution pdf 1

Table 23. Reference fractional radioactivity levels on internal surfaces at reactor shutdown. 



\section{ACRONYMS}

$\begin{array}{ll}\text { ASME } & \text { American Society of Mechanical Engineers } \\ \text { BWR } & \text { boiling water reactor } \\ \text { CoC } & \text { Certificate of Compliance } \\ \text { CFR } & \text { Code of Federal Regulations } \\ \text { EIS } & \text { environmental impact statement } \\ \text { GE } & \text { General Electric } \\ \text { GTCC } & \text { Greater-Than-Class C } \\ \text { LWR } & \text { light water reactor } \\ \text { NCT } & \text { normal conditions of transport } \\ \text { NRC } & \text { US Nuclear Regulatory Commission } \\ \text { ORNL } & \text { Oak Ridge National Laboratory } \\ \text { pdf } & \text { probability density function } \\ \text { ppm } & \text { parts per million } \\ \text { PWR } & \text { pressurized water reactor } \\ \text { SAR } & \text { safety analysis report } \\ \text { SD } & \text { standard deviation }\end{array}$





\begin{abstract}
This report investigated best practices for performing shielding evaluations of Type B waste packages, as defined in 10 CFR Part 71 regulations on packaging and transportation of radioactive material, or packages for which the contents are not defined before loading and may include a broad range of nuclides, geometries, and non-fuel materials. The following non-fuel waste streams were analyzed:
\end{abstract}

- Activated metals from decommissioned commercial power reactors, including Type 304 stainless steel, reactor vessel steel, and Inconel.

- Control blades from boiling water reactors.

- Neutron-activated corrosion products on surfaces of activated metals.

- Spent resins from power plant operations.

Measured elemental compositions, including major constituents and impurities, for steel and Inconel samples from commercial power reactors were used in activation calculations to determine radionuclide inventories in activated metals. For a simplified cask model, ${ }^{60} \mathrm{Co}$ contribution to the total external package dose rate at 30 days after shutdown varied from approximately $60 \%$ to $95 \%$, depending on the activated metal, initial cobalt impurity concentration in the metal, and the thickness of the overpack gamma shield. Its maximum contribution to the total external package dose rate of approximately $100 \%$ was reached within the time interval of 2 to 5 years after shutdown and was maintained for up to 45 to 60 years after shutdown, depending on material, initial cobalt impurity concentration, and shield thickness. Thereafter, the ${ }^{60} \mathrm{Co}$ contribution to external package dose rate decreased with increasing decay time. Cobalt-60 is primarily produced by neutron reactions with the cobalt impurity in steel and Inconel. Other important radionuclides in activated metals contributing to package external dose rate are radionuclides with relatively short decay times, including ${ }^{51} \mathrm{Cr},{ }^{59} \mathrm{Fe},{ }^{58} \mathrm{Co}$, and ${ }^{54} \mathrm{Mn}$. These radionuclides may be represented as an equivalent ${ }^{60} \mathrm{Co}$ activity/source because ${ }^{60} \mathrm{Co}$ gamma ray emissions are bounding in terms of source strength and energy to other important radionuclides identified in the analyzed activated metals.

Approaches for modeling the neutron-activated corrosion products that may be attached to activated reactor components were analyzed in this report. It was demonstrated that a surface source is more conservative than a uniform volumetric source for the treatment of neutronactivated corrosion products with respect to external package dose rates.

An analysis of the maximum radionuclide loadings reported on spent resins identified the radionuclides ${ }^{137} \mathrm{Cs},{ }^{60} \mathrm{Co},{ }^{134} \mathrm{Cs},{ }^{65} \mathrm{Zn}$, and ${ }^{58} \mathrm{Co}$ as the primary contributors to external package dose rate. For a resin cooled for 3.08 years, the external package dose rate was entirely produced by the reported ${ }^{137} \mathrm{Cs}$ and ${ }^{60} \mathrm{Co}$ inventory. The neutron sources from actinides found on spent resins or activated metals produced negligible dose rates and may be ignored in dose rate analyses.

Effects of idealized waste material, source geometry, and spatial material/source distributions on external package dose rates were determined based on dose rate results for a simplified cask model under normal conditions of transport. Type 304 stainless steel, zirconium, and aluminum 
with adjusted mass densities based on a maximum content weight were analyzed for material modeling effects on external package dose rate. These materials produced identical external package dose rates within the statistical uncertainties of the dose rate estimates. Among four different source geometry configurations with homogeneous material of different mass densities, uniform volumetric source distribution, and the same source strength, the geometry configuration with lowest mass density (i.e., minimum self-shielding effect among the four cases) was most conservative. Spatial source distributions that better represent localized peak ${ }^{60} \mathrm{Co}$ activity values were more conservative than a uniform volumetric source distribution, assuming the same weight and total source strength per package. The increase in external dose rate caused by localized source peaks can be as much as the ratio between source peak activity density to average activity density, depending on the location of the activated metal with peak activity density. Therefore, the shielding analysis may be simplified if localized peak activities and the average activity per package can be measured/determined and documented at the time of cask loading. For simplicity, external package dose rates may be determined based on average source activity and a uniform volumetric source distribution. The dose rate results from that calculation model multiplied by the ratio of peak activity density to average activity density will produce maximum dose rate values for conservative estimates. 


\section{INTRODUCTION}

The US Code of Federal Regulations (CFR) Part 71, Title 10, "Packaging and Transportation of Radioactive Material" [1] provides regulatory requirements for transportation of radioactive materials. Performance requirements as well as procedures and standards for approval of packaging and shipping procedures by the Nuclear Regulatory Commission are provided to ensure that a transportation package contains the radioactive material, prevents unusual occurrences, and reduces external radiation to safety levels. Shielding-specific regulatory requirements provide limits to the dose rate external to a transportation package under normal conditions of transport (\$71.47) and hypothetical accident conditions (\$71.51). The scope of this report is to investigate best practices for performing a shielding evaluation of Type B waste packages, as defined in 10 CFR Part 71, or a package for which the contents are not well defined before loading. The contents may include a broad range of nuclides, geometries, and non-fuel materials. These waste contents are identified as Greater-Than-Class C (GTCC), and their disposal is controlled by 10 CFR Part 61 [2] because of the presence of very long-lived isotopes. Most GTCC materials consist of irradiated and surface-contaminated metal, usually stainless steel, resulting from reactor decommissioning. The analyses in this report are limited to GTCC materials related to commercial nuclear power reactors, including activated metals and spent resins. The GTCC material is referred to as waste herein.

Transportation package contents may include a broad range of nuclides, geometries, and materials that may not be well defined before loading. Safety analysis reports (SARs) often state that the maximum quantity of non-fuel material permitted in a transportation package is based on radiochemical assay of samples and dose rate measurements in the waste containers. Therefore, shielding analysis methods are typically focused on the intended package contents $[3,4,5,6]$. These methods aim to (1) identify all radionuclides important to external package dose rate and (2) determine the contributions to external package dose rates of each of the important radionuclides identified in the waste. The contribution to external package dose rate of $1 \mathrm{Ci}$ of radionuclide or $1 \mathrm{Ci}$ of radionuclide per gram of waste is typically determined. The maximum quantity of material permitted in the package is then determined based on individual nuclide contributions to the external package dose rates and regulatory (e.g., 10 CFR Part 71) dose rate limits. Other analysis methods intended to address a variety of waste contents and changes with decay time of radionuclide compositions developed payload limits for monoenergetic gamma rays and provided loading procedures to be used when loading the waste $[7,8]$. The materials, geometry shapes, and spatial source distributions of individual waste pieces loaded into a transportation cask may exhibit variations that cannot be easily characterized and/or considered in safety analysis models. Therefore, the maximum quantity of material permitted in the package is typically determined from dose rate calculations using bounding material, geometry, and spatial source distribution models.

Research was performed in this work to identify radioisotopes in various non-fuel waste streams produced from reactor operations that are major contributors to external package dose rates. The effects of several idealized source geometry and spatial distributions on external package dose rates were determined. The radiation source term and dose rate analyses presented in this report are intended to illustrate bounding analysis approaches that can be used to reduce the complexity of these analyses. 
The following non-fuel waste streams were analyzed:

- activated metals, including Type 304 stainless steel, reactor vessel steel, and Inconel from decommissioned commercial power reactors,

- control blades from boiling water reactors (BWRs),

- neutron-activated corrosion products on surfaces of activated metals, and

- spent resins from power plant operations.

Section 2 provides a brief summary of relevant information for selected packages designed for the shipment of reactor-related GTCC illustrating various shielding analysis approaches. The computer codes used to calculate radiation source terms and external package dose rates are briefly described in Section 3. Section 4 discusses methods for calculating the bremsstrahlung radiation produced by the slowing down of beta radiation in materials. Cobalt- 60 contents of activated steel and Inconel are evaluated with respect to their contribution to external package dose rates as a function of decay time in Section 5. Radiation sources from activated BWR control blades are analyzed in Section 6. Section 7 analyzes the importance to dose rate of radionuclides on spent resins from power plant operation. The importance of neutron sources to external package dose rates is analyzed in Section 8. The effects of idealized source geometry models and source distributions on external package dose rates are analyzed in Section 9. Section 10 evaluates the effects on external package dose rate of the spatial representation (i.e., uniform volumetric vs. surface source) of neutron-activated corrosion products found on surfaces of activated metals. Conclusions and recommendations are provided in Section 11. 


\section{REVIEW OF SHIELDING ANALYSIS APPROACHES FOR GTCC IN SAFETY ANALYSIS REPORTS}

This section provides a brief summary of relevant information for three selected packages designed for the shipment of reactor-related GTCC illustrating various shielding analysis approaches. The methods used to perform the shielding analyses of the three selected packages are representative of the range of methods typically used in GTCC shielding analyses. Table 1 presents a list that includes, but it is not limited to, currently US Nuclear Regulatory Commission authorized packages for shipment of reactor-related GTCC [9]. The contents of these packages include solid, irradiated, and contaminated hardware and solid, particulate debris or filter media. The authorized contents for some of these packages may include other waste streams, including spent nuclear fuel, transuranic waste, and sealed sources.

Table 1. Packages currently authorized for shipment of reactor-related GTCC

\begin{tabular}{ll}
\hline Package ID number & \multicolumn{1}{c}{ Package model number } \\
\hline USA/9168/B(U)-96 & $8-120 \mathrm{~B}$ \\
USA/9184/B(U) & PAS-1 \\
USA/9204/B(U)F-96 & $10-160 \mathrm{~B}$ \\
USA/9228/B(U)-96 & 2000 \\
USA/9233/B(U)-96 & TN-RAM \\
USA/9235/B(U)F-96 & NAC-STC \\
USA/9261/B(U)F-96 & HI-STAR 100 HB GTCC \\
USA/9270/B(U)F-96 & UMS Universal Transport Cask Package \\
USA/9316/B(U)-96 & AOS-025A, AOS-050A, AOS-100A, AOS-100B, and AOS-100A-S \\
USA/9321/B(U)-96 & 3-60B \\
USA/9356/B(U)F-96 & MAGNATRAN \\
USA/9365/B(U)-96 & RT-100
\end{tabular}

\subsection{8-120B PACKAGING}

Model 8-120B packaging is authorized for shipments of irradiated hardware components and ${ }^{60} \mathrm{Co}$ sources [10]. Irradiated hardware may include activated stainless steel, carbon steel, nickel alloys, and zirconium alloys, as well as irradiated by-products such as control rods and/or control blades containing either hafnium or boron carbide. The minimum cooling time of the package contents is 30 days. The package contents may vary from small concentrated sources to large sources. SAR analyses have been performed for idealized sources configurations that bound any actual source configuration that may occur. Nearly every radionuclide may be transported using the $8-120 \mathrm{~B}$ packaging.

The safety analyses determined the maximum quantity of material permitted in the package. Cobalt-60 and ${ }^{137} \mathrm{Cs}$ sources were analyzed separately. For other gamma emitters, analyses used 8 gamma energy levels ranging from $0.5 \mathrm{MeV}$ to $3.5 \mathrm{MeV}$. Payload source strength was determined as a function of the gamma energy. Limits were determined in terms of source 
strength (photons/s) for the point-source configurations and in in terms of source strength per gram of waste (photons/s/g) for the distributed-source cases. To determine the maximum sourcestrength limit for point sources, the regulatory dose rate limit for each surface was divided by the highest per-unit source gamma dose rate for that surface. The lowest of the allowable source strengths was then selected as the limiting gamma-source strength for that case. For the distributed-source cases, the allowable source strength was divided by the modeled-source region mass to yield the allowable source-strength density in photons $/ \mathrm{s} / \mathrm{g}$. A sum-of-fractions approach was used to quantify payloads that emit gamma rays at multiple energies. Neutron sources were limited to less than $10,000 \mathrm{n} / \mathrm{s}$. Pure beta emitters with beta energies greater than $3.5 \mathrm{MeV}$ are not authorized for shipment.

\subsection{PACKAGING}

Model 2000 packaging is authorized for shipments of irradiated hardware components composed of stainless steels, carbon steels, nickel alloys and zirconium alloys and irradiated byproducts such as control rods and/or control blades containing either hafnium or boron carbide. The 2000 package SAR [11] provides a list of radionuclides present in irradiated hardware and byproduct contents that contribute to external dose rates. Other radionuclides that are not important for shielding may be loaded, and their limits are based on the package thermal limit of $1500 \mathrm{~W}$. External dose rates were calculated individually for $1 \mathrm{Ci}$ of activity with the energy spectrum from each of the listed radionuclides. The energy spectrum for each radionuclide was taken from the ORIGEN-S data libraries. The dose rate contribution from a specific radionuclide at a regulatory dose rate location was calculated by multiplying the total activity for the radionuclide by its respective dose rate per curie. The total dose rate from a payload of irradiated hardware and byproduct was calculated by summing the dose rate contributions from each radionuclide included in the shipment. The maximum activity of each radionuclide was limited by the minimum of either (1) the activity equivalent to the $1,500 \mathrm{~W}$ thermal limit of the cask or (2) the activity resulting in a normal-condition-of-transport (NCT) side-surface dose rate equal to $90 \%$ of the regulatory limit (180 $\mathrm{mrem} / \mathrm{h})$.

\subsection{MAGNATRAN}

The MAGNATRAN packaging is authorized for shipments of GTCC waste consisting of solid, irradiated, and contaminated hardware. The specific Curie content source of the GTCC waste is limited to a maximum activity density of $2.7 \mathrm{Ci}{ }^{60} \mathrm{Co} / \mathrm{lb}$ averaged over the $\mathrm{GTCC}$ waste, with a maximum localized peak activity density of $16.1 \mathrm{Ci}{ }^{60} \mathrm{Co} / \mathrm{lb}$ and a total ${ }^{60} \mathrm{Co}$ activity of $85,760 \mathrm{Ci}$ at transport. The maximum allowed weight of this waste is 55,000 lbs. The source term for the GTCC waste was based on measured activity densities of 3 key isotopes in January $2008:{ }^{63} \mathrm{Ni}(6$ $\mathrm{Ci} / \mathrm{lb}),{ }^{60} \mathrm{Co}(13 \mathrm{Ci} / \mathrm{lb})$, and ${ }^{55} \mathrm{Fe}(5 \mathrm{Ci} / \mathrm{lb})$ because additional radioisotopes typical of $\mathrm{GTCC}$ material do not significantly contribute to cask dose rates. These activity densities were input into ORIGEN-S and decayed to 12 years (assumed time between measurement and actual shipment offsite). External package dose rates were determined for $2.68 \mathrm{Ci}{ }^{60} \mathrm{Co} / \mathrm{lb}$. A localized increase in the ${ }^{60} \mathrm{Co}$ content by a factor of $6(16.1 \mathrm{Ci} / \mathrm{lb})$ was considered. Dose rate was multiplied by 6 , which is equivalent to a global source increase by a factor of 6 [6]. 


\section{COMPUTER CODES AND CALCULATION METHODS}

The analyses in this report are based on source term and dose rate calculations performed with the SCALE 6.2.3 [12] computer code system. Details of the source term and dose rate calculation methods are provided in this section. Unless otherwise noted, the decay data used throughout this report were taken from the $8^{\text {th }}$ Edition of the Table of Isotopes (1999) [13].

\subsection{SOURCE TERM CALCULATIONS}

The ORIGEN module in the SCALE 6.2.3 computer code system calculates time-dependent concentrations, activities, and radiation source terms for many isotopes simultaneously generated or depleted by neutron transmutation, fission, and radioactive decay. This module was used to perform neutron activation and decay calculations for the analyses in this report. Neutronspectrum-dependent ORIGEN libraries were created with the COUPLE module in the SCALE 6.2.3 code system.

The TRITON/NEWT (T-DEPL) analysis sequence was used to perform depletion calculations and determine nuclide concentrations and associated radiation sources for the activation sources of a control blade exposed to the neutron flux from a BWR fuel assembly. This TRITON sequence invokes SCALE functional modules for resonance processing, 2D discrete ordinates transport calculations (NEWT), burnup-dependent cross section preparation (COUPLE), and depletion calculations (ORIGEN). TRITON can simulate the depletion of multiple mixtures in a fuel assembly model. This is a very useful and powerful feature in a nuclide inventory analysis, because it allows a more appropriate representation of the local flux distribution and neutronic environment for a specific measured fuel rod in the assembly.

\subsection{DOSE RATE CALCULATIONS}

Dose rate calculations were performed with the MAVRIC shielding analysis sequence in SCALE, which employs the state-of-the-art hybrid variance reduction capabilities $[14,15]$ developed at Oak Ridge National Laboratory (ORNL) to generate high-fidelity dose results. A variance reduction method referred to as forward-weighted consistent adjoint driven importance sampling was used to estimate external package dose rates. This method (respWeighting) performs both forward and adjoint discrete ordinates calculations with the Denovo discrete ordinates code [16] to determine energy- and space-dependent source biasing and particle importance parameters.

The American National Standards Institute/American Nuclear Society (ANSI/ANS) 6.1.1-1977 neutron and photon flux-to-dose-rate conversion factors [17] were applied to the particle flux estimated by the Monte Carlo method to obtain the dose rate. 


\section{BREMSSTRAHLUNG RADIATION}

Many radionuclides decay by electron capture (e.g., ${ }^{55} \mathrm{Fe},{ }^{37} \mathrm{Ar}$, and ${ }^{49} \mathrm{~V}$ ) or by emitting beta particles (i.e., energetic electrons in $\beta^{-}$decay and positrons in $\beta^{+}$decay) with negligible gamma emissions. Beta decay also produces antineutrinos and neutrinos that have negligible interaction cross sections and are undetectable. However, beta particles lose their energy continuously as they pass through matter, emitting bremsstrahlung radiation over their range. The bremsstrahlung spectrum depends on electron interactions with the medium that contains the beta emitter radionuclide. High-energy betas interacting with dense, high-Z, materials will more likely produce bremsstrahlung radiation. Pure beta emitters are presented in Table 2 along with their half-lives and end point energies [18]. The end point energy of beta particles indicates the maximum energy of bremsstrahlung radiation that can be emitted. Most of these pure beta emitters have end point energies less than $300 \mathrm{keV}$; i.e., their bremsstrahlung radiation is near the $\mathrm{X}$-ray energy range and would probably be entirely absorbed in waste and shielding materials. However, ${ }^{45} \mathrm{Ca},{ }^{204} \mathrm{Tl},{ }^{32} \mathrm{P}$, and ${ }^{90} \mathrm{Y}$ nuclides have much higher end point energies, and their bremsstrahlung radiation may contribute to the external cask dose rate.

Table 2. Pure beta emitters

\begin{tabular}{lcc}
\hline Nuclide $^{\mathrm{a}}$ & Half-life $^{\mathrm{a}}$ & ${\text { End point energy }(\mathbf{M e V})^{\mathrm{a}}}^{{ }^{3} \mathrm{H}}$ \\
${ }^{14} \mathrm{C}$ & $12.26 \mathrm{y}$ & 0.0186 \\
${ }^{32} \mathrm{P}$ & $5,730 \mathrm{y}$ & 0.156 \\
${ }^{35} \mathrm{~S}$ & $14.28 \mathrm{~d}$ & 1.71 \\
${ }^{36} \mathrm{Cl}$ & $24.4 \mathrm{~d}$ & 0.248 \\
${ }^{45} \mathrm{Ca}$ & $3.08 \mathrm{E}+05 \mathrm{y}$ & 0.167 \\
${ }^{63} \mathrm{Ni}$ & $165 \mathrm{~d}$ & 0.714 \\
${ }^{90} \mathrm{Sr} /{ }^{90} \mathrm{Y}$ & $92 \mathrm{y}$ & 0.252 \\
${ }^{99} \mathrm{Tc}$ & $27.7 \mathrm{y} / 64 \mathrm{~h}$ & $0.546 / 2.27$ \\
${ }^{147} \mathrm{Pm}$ & $2.12 \mathrm{E}+05 \mathrm{y}$ & 0.292 \\
${ }^{204} \mathrm{Tl}$ & $2.62 \mathrm{y}$ & 0.224 \\
& $3.81 \mathrm{y}$ & 0.766 \\
\hline
\end{tabular}

${ }^{\text {a }}$ Ref. [18].

Photon sources calculated with ORIGEN include bremsstrahlung radiation. The option for the medium in ORIGEN calculations is either $\mathrm{UO}_{2}$ (the default option), water matrix, or no material. A case-specific material is not available in ORIGEN. Bremsstrahlung sources in photons $/ \mathrm{s} / \mathrm{Ci}$ for ${ }^{63} \mathrm{Ni}$ and ${ }^{90} \mathrm{Sr} /{ }^{90} \mathrm{Y}$ calculated with ORIGEN using the $\mathrm{UO}_{2}$ and $\mathrm{H}_{2} \mathrm{O}$ matrix options are shown in Figure 1. The source intensity of the bremsstrahlung radiation produced in the high-density $\mathrm{UO}_{2}$ matrix is higher than that produced by assuming a water matrix. The $\mathrm{UO}_{2}$ matrix option may be too conservative for beta emitters present in low-mass density or low-Z materials. If the ORIGEN code is not used, another method may be used to generate the bremsstrahlung radiation source term for pure beta emitters. An analytical formula has been used in the 8-120B SAR [19] to generate bremsstrahlung radiation source term for pure beta emitters with high activities and peak beta energies from $0.3 \mathrm{MeV}$ to $3.5 \mathrm{MeV}$. That is, significant 8-120B beta emitters were represented as an equivalent gamma emitter and treated like any other gamma energy line. Another method for determining bremsstrahlung radiation sources caused by pure beta emitters in a waste material would be a coupled electron-photon calculation with Monte Carlo N-Particle (MCNP) code [20]. This method has also been used to validate the analytical formula for bremsstrahlung radiation source terms from pure emitters for 8-120B shielding analyses [19]. 


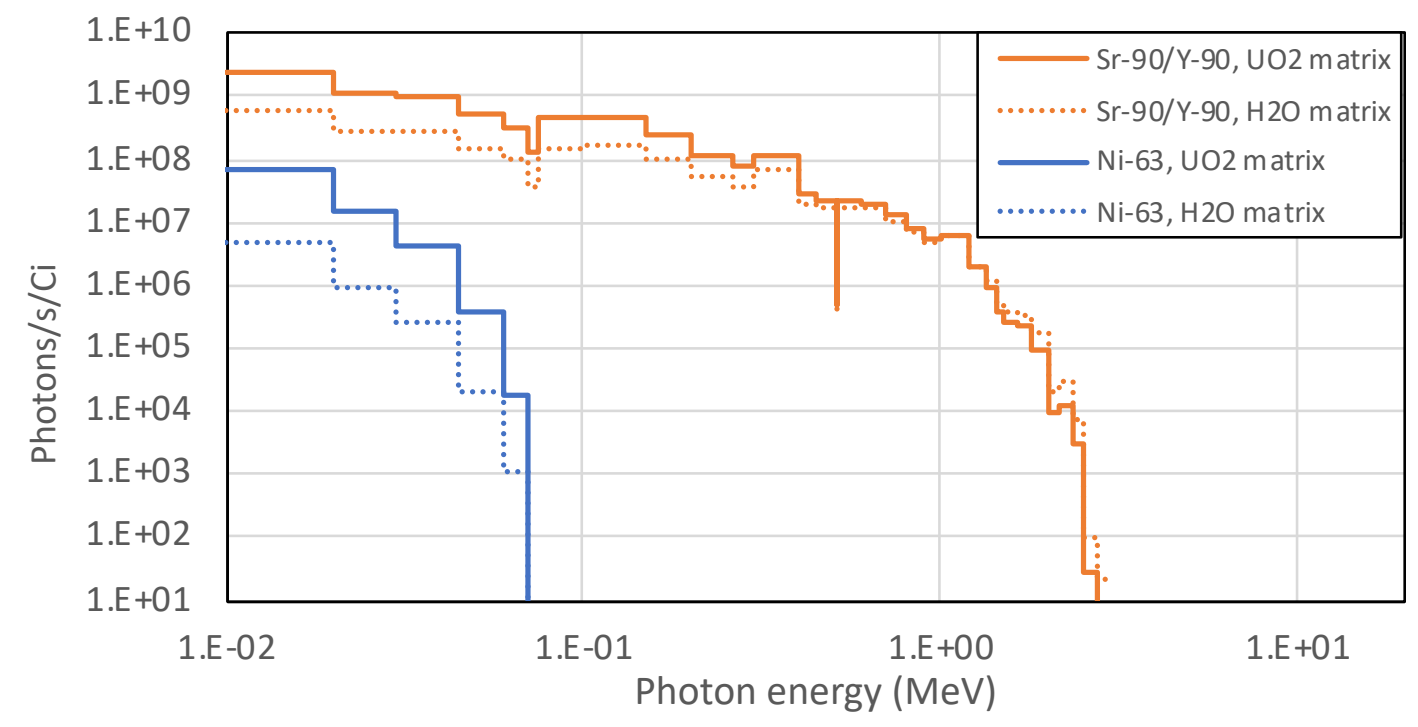

Figure 1. Illustration of bremsstrahlung radiation sources assuming $\mathrm{UO}_{2}$ and $\mathrm{H}_{2} \mathrm{O}$ as the matrix options. 


\section{ACTIVATED METALS}

The contribution of the major gamma emitter, ${ }^{60} \mathrm{Co}$, present in activated metals to cask external dose rate as a function of decay time was analyzed in this section. Previous studies [21] indicate that cobalt impurity in structural materials is the most significant source of ${ }^{60} \mathrm{Co}$ in light water reactor (LWR) activated steel. The ${ }^{60} \mathrm{Co}$ radioisotope $\left(\mathrm{T}_{1 / 2}=5.271\right.$ years $)$ is an activation product primarily produced by thermal neutron capture ${ }^{59} \mathrm{Co}(\mathrm{n}, \gamma){ }^{60} \mathrm{Co}$ in the cobalt impurity found in reactor structural materials. Depending on the neutron spectrum, a small ${ }^{60} \mathrm{Co}$ quantity (e.g., $<1 \%$ ) may be produced by threshold neutron reactions ${ }^{60} \mathrm{Ni}(\mathrm{n}, \mathrm{p}){ }^{60} \mathrm{Co}$, and ${ }^{63} \mathrm{Cu}(\mathrm{n}, \alpha){ }^{60} \mathrm{Co}$. Cobalt60 decay produces two gamma rays of $1.173 \mathrm{MeV}$ and $1.333 \mathrm{MeV}$ with close to $100 \%$ abundance.

Most reactor internal structural materials are constructed of Type 304L stainless steel [21]. A reactor pressure vessel is typically constructed of carbon steel and is clad on the inner surface with stainless steel or Inconel [22, 23]. Properties of alloys are specified by various material standards such as American Society of Mechanical Engineers (ASME) standards. However, concentration limits of trace elements are not specified in these standards and the manufacturer is not required to report them. Measured elemental compositions, including major constituents and impurities, for stainless steel were taken from NUREG/CR-3474 [21]. This publication provides measured material compositions of samples of carbon steel, stainless steel 304L, stainless steel 316, and Inconel obtained from various power plants. Sample elemental compositions were determined by two main techniques: instrumental neutron activation and energy dispersive x-ray fluorescence. The greatest cobalt impurity levels were measured in Type 304 stainless steel with up to $2,570 \mathrm{ppm}$, and the lowest cobalt impurity levels were measured in carbon steel, ranging from 93 to $151 \mathrm{ppm}$. The cobalt impurity levels in the three Type 316 stainless steel samples analyzed varied from 1,340 to $1,630 \mathrm{ppm}$. The reported cobalt impurity concentration in the Inconel sample was $574 \mathrm{ppm}$. The Type 316 stainless steel was not analyzed in this report because stainless steel Types 304 and 316 have similar initial elemental compositions and cobalt impurity concentrations [21]. Therefore, the results for Type 304 stainless steel are applicable to the Type 316 stainless steel.

Cobalt base alloys, often called Stellite ${ }^{\circledR}$, have been used as cladding material for some reactor components [24, 25] (e.g., latch assemblies and control rod rollers), because of their wear resistance. The cobalt content in these alloys is approximately 50\% [25]. Many of these components have later been replaced with steel because significant amounts of ${ }^{60} \mathrm{Co}$ (as much as $43 \%$ of ${ }^{60} \mathrm{Co}$ in the plant) were released into the primary coolant because of the Stellite corrosion [26]. Because of the large cobalt content, Stellite radiation source would be dominated by ${ }^{60} \mathrm{Co}$ and the ${ }^{60} \mathrm{Co}$-specific activity in activated Stellite would be very high compared to any other activated metal. Therefore, activated Stellite is not analyzed in this report.

Material compositions, including major constituents and impurities, were used in ORIGEN activation calculations to determine radionuclide activity, radiation source terms, and decay heat as a function of decay time up to 100 years after reactor shutdown. Neutron spectra at the various locations of structural materials and the pressure vessel in LWRs were not available for these activation analyses. The energy-dependent neutron spectrum shown in Figure 2 and a 30-year, full-power irradiation period, were assumed in all activation calculations. This neutron spectrum 
from a PWR fuel assembly is representative of a broad neutron energy range, including thermal, epithermal, and fast neutron energies. The variations in the neutron spectrum as a function of reactor type, location in the reactor, and neutron flux are assumed not to have significant effects on the conclusions of this report because (1) in general, the most important type of activation reaction is thermal neutron capture [21], and (2) the results presented in this report are provided as fractional contributions of individual radionuclides to external package total dose rate (i.e., dose rate ratios).

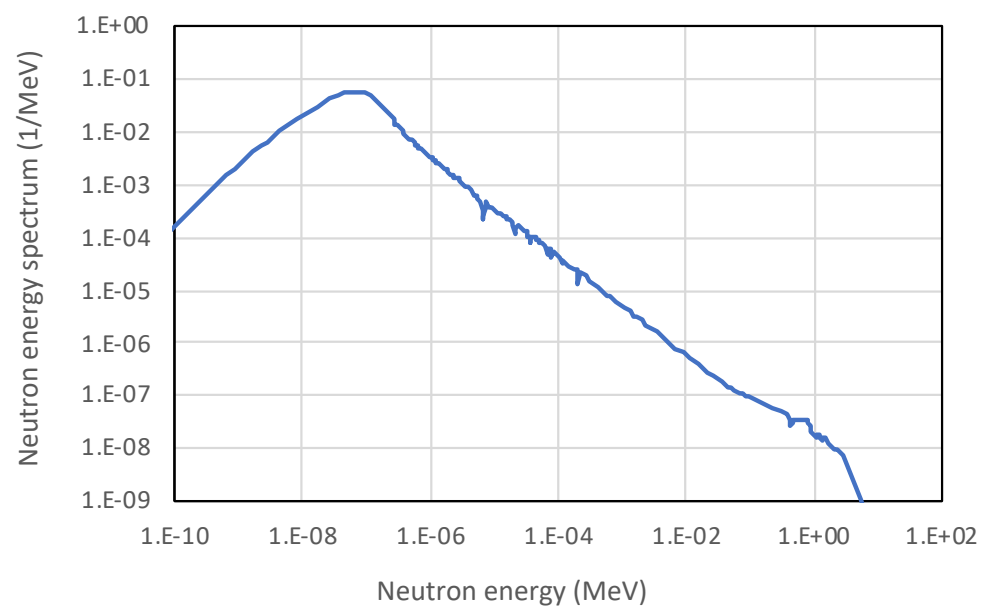

Figure 2. Neutron energy spectrum used in activation calculations.

The radiation source terms from the ORIGEN neutron activation calculations were then used in dose rate calculations to determine total external package dose rate and the contribution of the major activation product ${ }^{60} \mathrm{Co}$ to the total dose rate as a function of decay time. The bremsstrahlung radiation was calculated assuming the default slowing down medium $\left(\mathrm{UO}_{2}\right)$ for beta radiation in ORIGEN. The dose rate calculations used the generic cylindrical drum-like cask model illustrated in Figure 3. This simple steel cask model was used to calculate external package dose rate, assuming two different gamma shield thicknesses, $1 \mathrm{~cm}$ and $10 \mathrm{~cm}$. The assumed total waste weight was $1,500 \mathrm{~kg}$, which yields a uniform mass density of $3.4 \mathrm{~g} / \mathrm{cm}^{3}$ for the waste. 


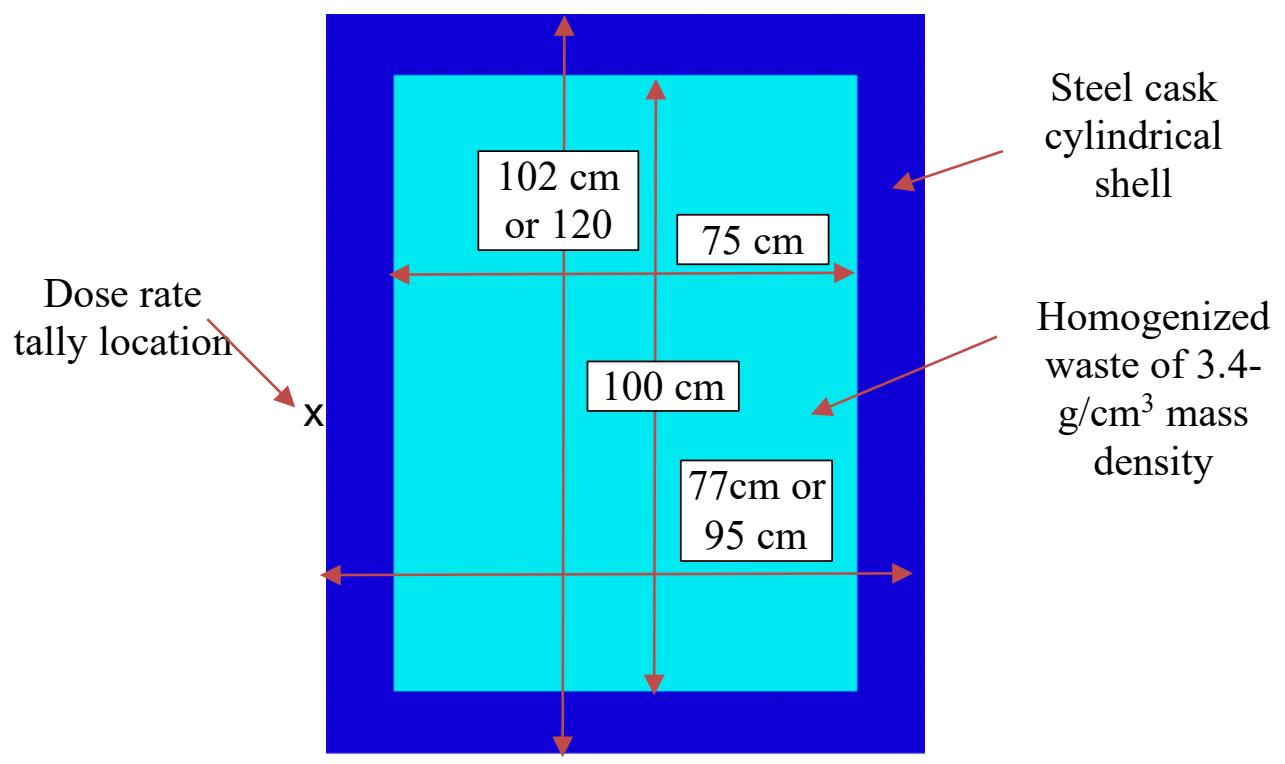

Figure 3. Cask model used in activated metal dose rate analyses.

X-rays and low-energy gamma rays have a very high probability of being absorbed in waste and cask structural materials and only more energetic gamma rays have higher probabilities of emerging from the cask into surrounding air. Therefore, only radionuclides emitting energetic gamma radiation are expected to have major contributions to dose rate in the external regions of a transport cask. The two different thickness values for the cask shielding material were used to show that the contribution of radionuclides with energetic gamma rays (e.g., ${ }^{60} \mathrm{Co}$ ) to external package dose rate increases with increasing shield thickness relative to the contributions of nuclides emitting less energetic gamma rays. The statistical uncertainty of the calculated dose rate values was approximately $0.1 \%$.

\subsection{TYPE 304 STAINLESS STEEL}

The chemical composition of Type 304 stainless steel provided in NUREG/CR-3474 [21] is presented in Table 3. This chemical composition, including major constituents and impurities, is based on 13 samples collected from various US power plants. Analyses were performed for two scenarios: (1) average initial nuclide concentrations and (2) minimum initial cobalt impurity concentration and average concentrations for the remainder of nuclides. 
Table 3. Type 304 stainless steel composition summary from NUREG/CR-3474

\begin{tabular}{|c|c|c|c|c|c|c|}
\hline Element & Unit & Average & $\mathrm{SD}^{a}(\%)$ & Range & Range factor $^{b}$ & No. of samples \\
\hline $\mathrm{Li}$ & $\mathrm{ppm}^{c}$ & 0.13 & - & - & - & 1 \\
\hline $\mathrm{N}$ & $\mathrm{ppm}$ & $452 \pm 64$ & 14 & 402 to 526 & 1.3 & 3 \\
\hline $\mathrm{Na}$ & ppm & $9.7 \pm 12.2$ & 126 & 3 to 37 & 12.3 & 7 \\
\hline $\mathrm{Al}$ & ppm & 100 & - & $<50$ to 200 & $>4$ & 6 \\
\hline $\mathrm{Cl}$ & ppm & 70 & - & $<50$ to 130 & $>2.6$ & 5 \\
\hline $\mathrm{K}$ & ppm & $<3$ & _- & - & - & 3 \\
\hline $\mathrm{Ca}$ & ppm & 19 & - & - & - & 1 \\
\hline Sc & ppm & $<0.03$ & - & - & - & 1 \\
\hline $\mathrm{Ti}$ & ppm & $<600$ & - & - & - & 10 \\
\hline $\mathrm{V}$ & ppm & $456 \pm 235$ & 52 & 140 to 690 & 4.90 & 9 \\
\hline $\mathrm{Cr}$ & $\%$ & $18.4 \pm 1.1$ & 6 & 16.5 to 20.2 & 1.2 & 13 \\
\hline Mn & $\%$ & $1.53 \pm 0.27$ & 18 & 1.11 to 1.76 & 1.6 & 13 \\
\hline $\mathrm{Fe}$ & $\%$ & $70.6 \pm 2.6$ & 4 & 68.0 to 76.7 & 1.1 & 13 \\
\hline Co & ppm & $1414 \pm 800$ & 57 & 229 to 2570 & 11.2 & 8 \\
\hline $\mathrm{Ni}$ & $\%$ & $10.0 \pm 0.7$ & 7 & 8.8 to 11.0 & 1.3 & 13 \\
\hline $\mathrm{Cu}$ & ppm & $3080 \pm 2270$ & 74 & 300 to 8150 & 27.2 & 13 \\
\hline $\mathrm{Zn}$ & $\mathrm{ppm}$ & $457 \pm 717$ & 157 & $<15$ to 2230 & $>150$ & 12 \\
\hline $\mathrm{Ga}$ & ppm & $129 \pm 143$ & 111 & $<40$ to 450 & $>11.3$ & 13 \\
\hline As & ppm & $194 \pm 259$ & 133 & $<57$ to 1010 & $>17.7$ & 13 \\
\hline $\mathrm{Se}$ & ppm & $\sim 35$ & - & $<2$ to 70 & $>35$ & 13 \\
\hline $\mathrm{Br}$ & ppm & $\sim 2$ & - & $<0.9$ to 8.0 & $>8.9$ & 8 \\
\hline $\mathrm{Rb}$ & ppm & $<10$ & - & - & - & 9 \\
\hline $\mathrm{Sr}$ & ppm & 0.2 & - & - & - & 1 \\
\hline $\mathrm{Y}$ & ppm & $<5$ & - & - & - & 12 \\
\hline $\mathrm{Zr}$ & $\mathrm{ppm}$ & $\sim 10$ & - & $<4$ to 20 & $>5$ & 13 \\
\hline $\mathrm{Nb}$ & ppm & $89 \pm 90$ & 101 & $<5$ to 300 & $>60$ & 13 \\
\hline Mo & ppm & $2600 \pm 1500$ & 58 & 80 to 5500 & 68.8 & 13 \\
\hline $\mathrm{Ag}$ & ppm & $<2$ & - & - & - & 8 \\
\hline $\mathrm{Sb}$ & ppm & $12.3 \pm 3.8$ & 31 & 6.9 to 17.0 & 2.5 & 8 \\
\hline Cs & ppm & $<0.3$ & - & - & - & 5 \\
\hline $\mathrm{Ba}$ & ppm & $<500$ & - & - & - & 8 \\
\hline $\mathrm{La}$ & ppm & $\sim 0.02$ & - & $<0.05$ to 2.1 & $>42.0$ & 8 \\
\hline $\mathrm{Ce}$ & ppm & $371 \pm 212$ & 57 & $<2$ to 550 & $>275.0$ & 8 \\
\hline $\mathrm{Sm}$ & ppm & $\sim 0.1$ & - & $<0.05$ to 0.15 & $>3$ & 7 \\
\hline $\mathrm{Eu}$ & ppm & $\sim 0.02$ & - & - & - & inferred \\
\hline $\mathrm{Tb}$ & ppm & $0.47 \pm 0.25$ & 53 & 0.22 to 0.71 & 3.2 & 3 \\
\hline Dy & ppm & $<1$ & - & - & - & 5 \\
\hline Ho & ppm & $<1$ & - & - & - & 3 \\
\hline $\mathrm{Yb}$ & ppm & $<2$ & - & - & - & 5 \\
\hline $\mathrm{Lu}$ & ppm & $<0.8$ & - & - & - & 7 \\
\hline $\mathrm{Hf}$ & ppm & $<2$ & - & - & - & 3 \\
\hline W & ppm & $186 \pm 149$ & 80 & 7.2 to 520 & 72 & 8 \\
\hline $\mathrm{Pb}$ & ppm & $67 \pm 50$ & 75 & $<10$ to 139 & $>13.9$ & 9 \\
\hline Th & ppm & $<1$ & - & - & - & 3 \\
\hline $\mathrm{U}$ & ppm & $<2$ & - & - & - & 3 \\
\hline
\end{tabular}

${ }^{a}$ Relative standard deviation (SD) expressed as a percentage of the average value.

${ }^{b}$ Ratio of the highest to the lowest value measured.

'Parts per million (ppm). 


\subsubsection{Average Elemental Concentrations in Type 304 Stainless Steel}

Fractional activities, decay heat, and external package dose rates for ${ }^{60} \mathrm{Co}$ and the remainder of radionuclides in irradiated Type 304 stainless steel based on average chemical element concentrations (i.e., 1,414 ppm cobalt impurity) are presented in Table 4 and illustrated in Figure 4 and Figure 5 . Cobalt- 60 activity was approximately $10 \%$ of the total activity at shutdown, reached approximately $50 \%$ of the total activity at 10 years after shutdown, and decreased to negligible levels beyond 60 years after shutdown. However, ${ }^{60} \mathrm{Co}$ is the major decay heat contributor within the time interval from 30 days to 45 years after reactor shutdown and a major contributor to the external dose rate within the time interval from 30 days to up to 100 years after reactor shutdown. Additionally, the ${ }^{60} \mathrm{Co}$ contribution to external dose rate within the time interval from 2 to 60 years after shutdown was 99 to $100 \%$.

Table 4. Fractional activity, decay heat, and external package dose rate from ${ }^{60} \mathrm{Co}$ and the remainder of radionuclides in irradiated Type 304 stainless steel, assuming average initial elemental concentrations

\begin{tabular}{|c|c|c|c|c|c|c|c|c|}
\hline & \multirow{2}{*}{\multicolumn{2}{|c|}{ Activity fraction }} & \multirow{2}{*}{\multicolumn{2}{|c|}{ Decay heat fraction }} & \multicolumn{4}{|c|}{$1 \mathrm{~cm}$ thick shield $10 \mathrm{~cm}$ thick shield } \\
\hline & & & & & \multicolumn{4}{|c|}{ Dose rate fraction } \\
\hline & ${ }^{60} \mathrm{Co}$ & Remainder & ${ }^{60} \mathrm{Co}$ & Remainder & ${ }^{60} \mathrm{Co}$ & Remainder & ${ }^{60} \mathrm{Co}$ & Remainder \\
\hline 0.0 & $1.01 \mathrm{E}-01$ & $8.99 \mathrm{E}-01$ & $2.06 \mathrm{E}-01$ & 7.94E-01 & 0.27 & 0.73 & 0.23 & 0.77 \\
\hline 0.09 & $2.59 \mathrm{E}-01$ & 7.41E-01 & 8.73E-01 & $1.27 \mathrm{E}-01$ & 0.89 & 0.11 & 0.95 & 0.05 \\
\hline 0.27 & 3.84E-01 & $6.16 \mathrm{E}-01$ & $9.66 \mathrm{E}-01$ & $3.40 \mathrm{E}-02$ & 0.93 & 0.07 & 0.97 & 0.03 \\
\hline 2 & $4.20 \mathrm{E}-01$ & $5.80 \mathrm{E}-01$ & $9.86 \mathrm{E}-01$ & $1.45 \mathrm{E}-02$ & 0.99 & 0.01 & 0.99 & 0.01 \\
\hline 5 & 4.81E-01 & 5.19E-01 & 9.95E-01 & $5.11 \mathrm{E}-03$ & 1.00 & 0.00 & 1.00 & 0.00 \\
\hline 10 & $5.19 \mathrm{E}-01$ & 4.81E-01 & $9.95 \mathrm{E}-01$ & 4.65E-03 & 1.00 & 0.00 & 1.00 & 0.00 \\
\hline 15 & 4.67E-01 & 5.33E-01 & $9.93 \mathrm{E}-01$ & $6.94 \mathrm{E}-03$ & 1.00 & 0.00 & 1.00 & 0.00 \\
\hline 25 & 2.39E-01 & $7.61 \mathrm{E}-01$ & $9.78 \mathrm{E}-01$ & $2.18 \mathrm{E}-02$ & 1.00 & 0.00 & 1.00 & 0.00 \\
\hline 45 & $2.58 \mathrm{E}-02$ & $9.74 \mathrm{E}-01$ & $7.89 \mathrm{E}-01$ & $2.11 \mathrm{E}-01$ & 1.00 & 0.00 & 1.00 & 0.00 \\
\hline 60 & $4.06 \mathrm{E}-03$ & $9.96 \mathrm{E}-01$ & $3.67 \mathrm{E}-01$ & $6.33 \mathrm{E}-01$ & 0.99 & 0.01 & 1.00 & 0.00 \\
\hline 75 & $6.27 \mathrm{E}-04$ & $9.99 \mathrm{E}-01$ & $8.21 \mathrm{E}-02$ & $9.18 \mathrm{E}-01$ & 0.93 & 0.07 & 0.97 & 0.03 \\
\hline 100 & $2.77 \mathrm{E}-05$ & $1.00 \mathrm{E}+00$ & $3.94 \mathrm{E}-03$ & $9.96 \mathrm{E}-01$ & 0.35 & 0.65 & 0.59 & 0.41 \\
\hline
\end{tabular}

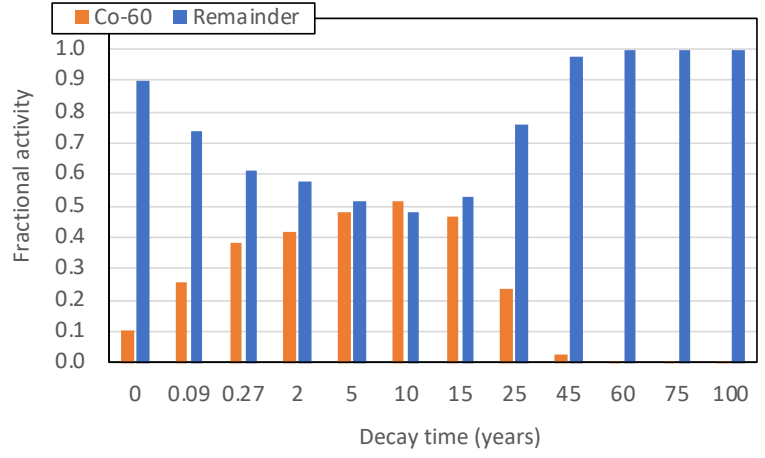

(a)

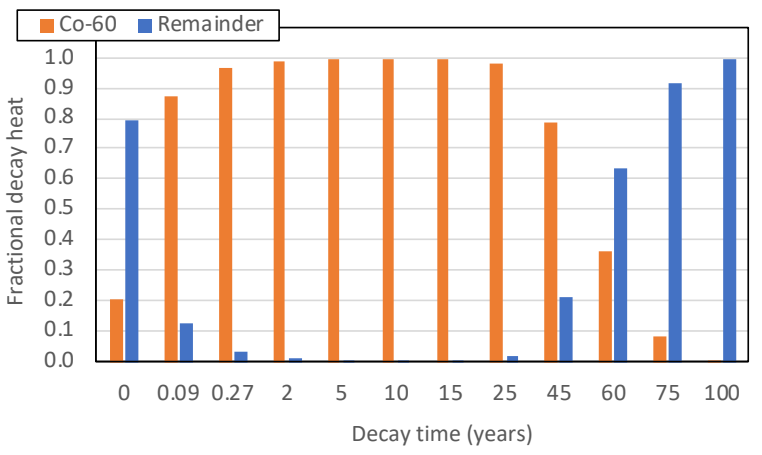

(b)

Figure 4. Fractional (a) activity and (b) decay heat for ${ }^{60} \mathrm{Co}$ and the remainder of radionuclides in irradiated Type 304 stainless steel with average initial elemental concentrations as a function of decay time. 


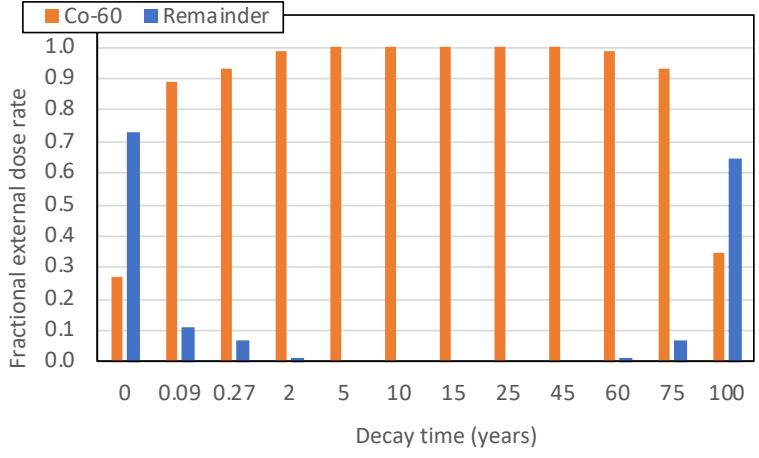

(a)

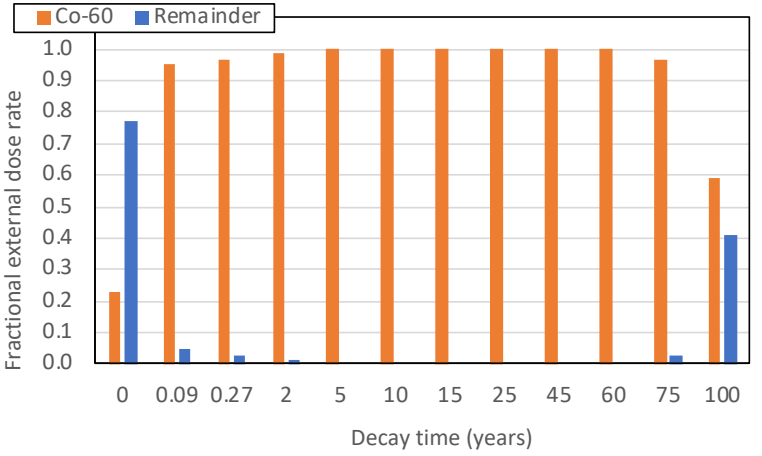

(b)

Figure 5. Fractional external package dose rates for ${ }^{60} \mathrm{Co}$ and the remainder of radionuclides in irradiated Type 304 stainless steel with average initial elemental concentrations as a function of decay time, assuming (a) $1 \mathrm{~cm}$ and (b) $10 \mathrm{~cm}$ thick steel cask shield.

\subsubsection{Minimum Initial Cobalt Impurity Concentration and Average Concentrations for the Remainder of Chemical Elements in Type 304 Stainless Steel}

A study was also performed for the Type 304 stainless steel composition, assuming minimum initial cobalt impurity concentration (i.e., $229 \mathrm{ppm}$ ) and average concentrations for the remainder of chemical elements in steel composition. Fractional activities, decay heat, and external package dose rates due to ${ }^{60} \mathrm{Co}$ and the remainder of radionuclides are presented in Table 5 and illustrated in Figure 6 and Figure 7. Cobalt- 60 had significant contributions to the total external package dose rate from 30 days to 75 years after shutdown. Even with this much lower cobalt impurity concentration, the ${ }^{60} \mathrm{Co}$ contribution to external package dose rate was $99 \%$ to $100 \%$ within the time interval 5 years to 25 years after shutdown for the steel shield with a thickness of $1 \mathrm{~cm}$ and within the time interval 5 years to 45 years after shutdown for the steel shield with a thickness of $10 \mathrm{~cm}$.

Table 5. Fractional activities, decay heat, and external package dose rates from ${ }^{60} \mathrm{Co}$ and the remainder of radionuclides in irradiated Type 304 stainless steel, assuming minimum initial cobalt impurity concentration and average concentrations for the remainder of chemical elements

\begin{tabular}{|c|c|c|c|c|c|c|c|c|}
\hline \multirow{3}{*}{$\begin{array}{c}\text { Decay time } \\
\text { (years) }\end{array}$} & \multirow{2}{*}{\multicolumn{2}{|c|}{ Activity fraction }} & \multirow{2}{*}{\multicolumn{2}{|c|}{ Decay heat fraction }} & \multicolumn{2}{|c|}{$1 \mathrm{~cm}$ thick shield } & \multicolumn{2}{|c|}{$10 \mathrm{~cm}$ thick shield } \\
\hline & & & & & \multicolumn{4}{|c|}{ Dose rate fraction } \\
\hline & ${ }^{60} \mathrm{Co}$ & Remainder & ${ }^{60} \mathrm{Co}$ & Remainder & ${ }^{60} \mathrm{Co}$ & Remainder & ${ }^{60} \mathrm{Co}$ & Remainder \\
\hline 0.0 & $1.55 \mathrm{E}-02$ & $9.84 \mathrm{E}-01$ & $3.32 \mathrm{E}-02$ & $9.67 \mathrm{E}-01$ & 0.05 & 0.95 & 0.04 & 0.96 \\
\hline 0.09 & $5.09 \mathrm{E}-02$ & $9.49 \mathrm{E}-01$ & $5.08 \mathrm{E}-01$ & 4.92E-01 & 0.55 & 0.45 & 0.71 & 0.29 \\
\hline 0.27 & $8.79 \mathrm{E}-02$ & $9.12 \mathrm{E}-01$ & $8.09 \mathrm{E}-01$ & $1.91 \mathrm{E}-01$ & 0.66 & 0.34 & 0.80 & 0.20 \\
\hline 2 & $1.01 \mathrm{E}-01$ & 8.99E-01 & $9.11 \mathrm{E}-01$ & 8.93E-02 & 0.94 & 0.06 & 0.97 & 0.03 \\
\hline 5 & $1.26 \mathrm{E}-01$ & $8.74 \mathrm{E}-01$ & $9.68 \mathrm{E}-01$ & $3.24 \mathrm{E}-02$ & 0.99 & 0.01 & 1.00 & 0.00 \\
\hline 10 & $1.43 \mathrm{E}-01$ & $8.57 \mathrm{E}-01$ & $9.71 \mathrm{E}-01$ & $2.89 \mathrm{E}-02$ & 1.00 & 0.00 & 1.00 & 0.00 \\
\hline 15 & $1.19 \mathrm{E}-01$ & $8.81 \mathrm{E}-01$ & $9.56 \mathrm{E}-01$ & 4.41E-02 & 1.00 & 0.00 & 1.00 & 0.00 \\
\hline 25 & 4.57E-02 & $9.54 \mathrm{E}-01$ & $8.72 \mathrm{E}-01$ & $1.28 \mathrm{E}-01$ & 1.00 & 0.00 & 1.00 & 0.00 \\
\hline 45 & 4.03E-03 & $9.96 \mathrm{E}-01$ & $3.63 \mathrm{E}-01$ & $6.37 \mathrm{E}-01$ & 0.97 & 0.03 & 0.99 & 0.01 \\
\hline 60 & $6.23 \mathrm{E}-04$ & $9.99 \mathrm{E}-01$ & $8.09 \mathrm{E}-02$ & $9.19 \mathrm{E}-01$ & 0.84 & 0.16 & 0.94 & 0.06 \\
\hline 75 & $9.59 \mathrm{E}-05$ & $1.00 \mathrm{E}+00$ & $1.34 \mathrm{E}-02$ & 9.87E-01 & 0.44 & 0.56 & 0.67 & 0.33 \\
\hline 100 & $4.24 \mathrm{E}-06$ & $1.00 \mathrm{E}+00$ & $5.98 \mathrm{E}-04$ & $9.99 \mathrm{E}-01$ & 0.06 & 0.94 & 0.07 & 0.93 \\
\hline
\end{tabular}




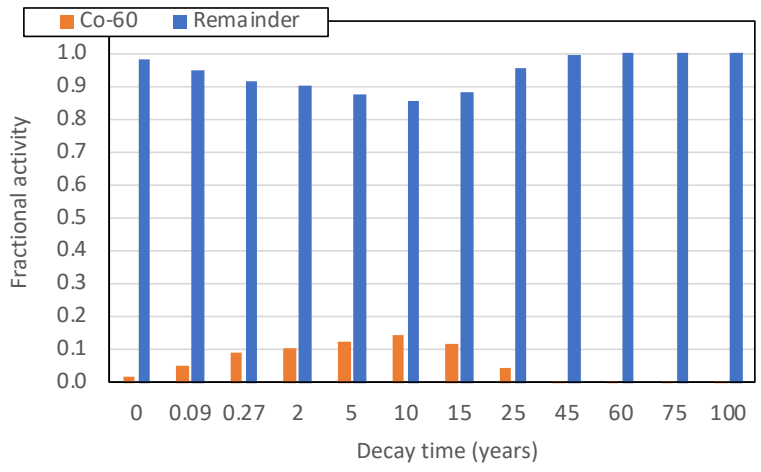

(a)

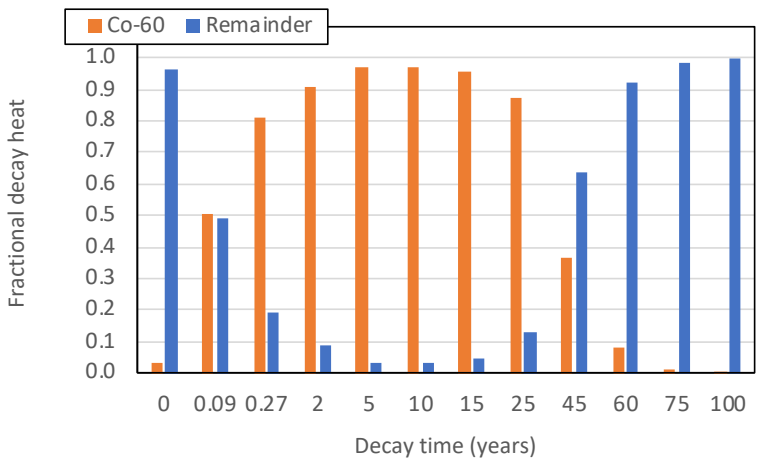

(b)

Figure 6. Fractional (a) activity and (b) decay heat for ${ }^{60} \mathrm{Co}$ and the remainder of radionuclides as a function of decay time in irradiated Type 304 stainless steel, assuming minimum initial cobalt impurity concentration and average concentrations for the remainder of chemical elements.

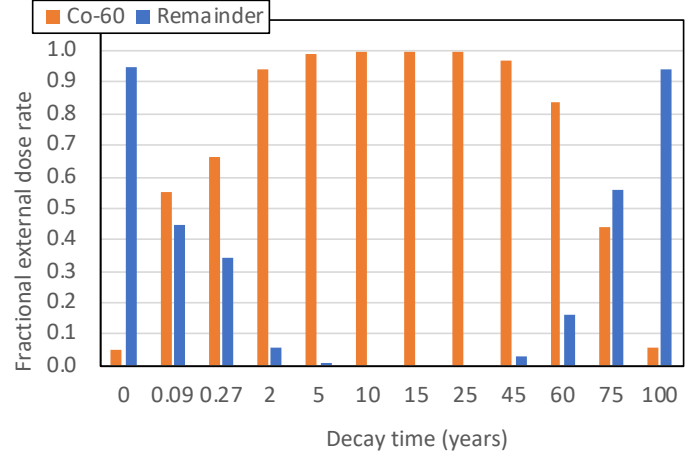

(a)

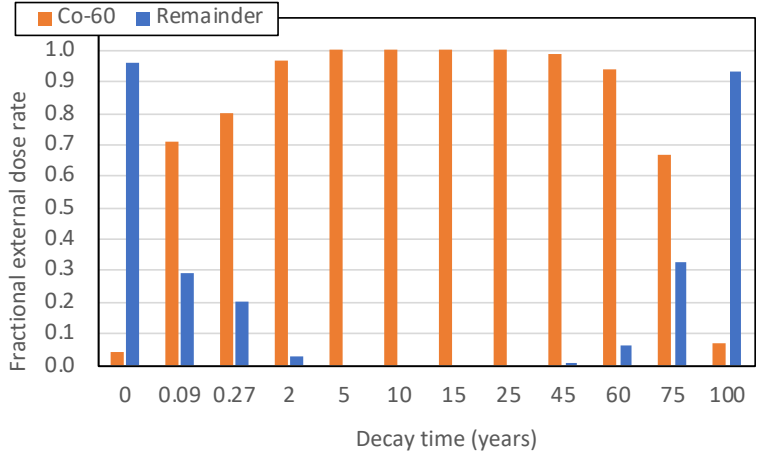

(b)

Figure 7. Fractional external package dose rates for ${ }^{60} \mathrm{Co}$ and the remainder of radionuclides as a function of decay time for average Type 304 stainless steel compositions, assuming (a) $1 \mathrm{~cm}$ and (b) $10 \mathrm{~cm}$ thick steel cask shell.

\subsection{REACTOR VESSEL STEEL}

Vessel steel chemical composition is presented in Table 6. This composition is based on ten samples collected from various power plants [21]. The reactor vessel steel contained $98 \%$ iron by weight, which indicates a carbon steel composition. The measured average cobalt impurity concentration in the reactor vessel steel was very low (122 ppm) compared to that measured in Type 304 stainless steel (1,414 ppm) and Type 316 stainless steel (1,630 ppm). 
Table 6. Vessel steels composition summary from NUREG/CR-3474

\begin{tabular}{|c|c|c|c|c|c|c|}
\hline Element & Unit & Average & $\mathrm{SD}^{a}(\%)$ & Range & Range factor ${ }^{b}$ & No. of samples \\
\hline $\mathrm{Li}$ & $\mathrm{ppm}^{c}$ & 0.30 & - & - & - & 1 \\
\hline $\mathrm{N}$ & $\mathrm{ppm}$ & 84 & - & - & - & 1 \\
\hline $\mathrm{Na}$ & ppm & $23 \pm 24$ & 102 & 6.6 to 40 & 6.1 & 2 \\
\hline $\mathrm{Al}$ & ppm & $330 \pm 400$ & 86 & $<50$ to 613 & $>12$ & 2 \\
\hline $\mathrm{Cl}$ & ppm & 40 & - & - & - & 1 \\
\hline $\mathrm{K}$ & ppm & $12 \pm 12$ & 100 & $<3$ to 20 & $>6.7$ & 2 \\
\hline $\mathrm{Ca}$ & ppm & 14 & - & - & - & 1 \\
\hline $\mathrm{Sc}$ & $\mathrm{ppm}$ & 0.26 & - & - & _- & 1 \\
\hline $\mathrm{Ti}$ & ppm & $<2$ & - & - & - & 1 \\
\hline $\mathrm{V}$ & ppm & $<80$ & - & $<30$ to 90 & $>3$ & 10 \\
\hline $\mathrm{Cr}$ & $\%$ & $0.17 \pm 0.13$ & 76 & 0.06 to 0.36 & 6 & 10 \\
\hline Mn & $\%$ & $1.02 \pm 0.41$ & 40 & 0.02 to 1.49 & 75 & 10 \\
\hline $\mathrm{Fe}$ & $\%$ & 98 & - & - & - & 10 \\
\hline Co & ppm & $122 \pm 41$ & 34 & 93 to 151 & 1.6 & 2 \\
\hline $\mathrm{Ni}$ & $\%$ & $0.66 \pm 0.13$ & 20 & $<0.3$ to 0.76 & $>2.5$ & 10 \\
\hline $\mathrm{Cu}$ & ppm & $1274 \pm 400$ & 31 & 675 to 1900 & 2.8 & 10 \\
\hline $\mathrm{Zn}$ & ppm & $\sim 100$ & - & $<4$ to 210 & $>52$ & 10 \\
\hline $\mathrm{Ga}$ & ppm & $\sim 80$ & - & $<20$ to 300 & $>15$ & 10 \\
\hline As & ppm & $532 \pm 1085$ & 204 & $<50$ to 3600 & $>72.0$ & 10 \\
\hline $\mathrm{Se}$ & ppm & 0.7 & - & - & - & 1 \\
\hline $\mathrm{Br}$ & ppm & 0.85 & - & - & - & 1 \\
\hline $\mathrm{Rb}$ & ppm & $48 \pm 35$ & 73 & 23 to 72 & 3.1 & 2 \\
\hline $\mathrm{Sr}$ & ppm & 0.15 & - & - & - & 1 \\
\hline $\mathrm{Y}$ & ppm & $<20$ & - & - & - & 10 \\
\hline $\mathrm{Zr}$ & ppm & $<10$ & - & - & - & 10 \\
\hline $\mathrm{Nb}$ & ppm & $18.8 \pm 12.2$ & 65 & $<8$ to 40 & $>5$ & 10 \\
\hline Mo & ppm & $0.56 \pm 0.05$ & 9 & 0.45 to 0.63 & 1.4 & 10 \\
\hline $\mathrm{Ag}$ & ppm & $<2$ & - & - & - & 1 \\
\hline $\mathrm{Sb}$ & ppm & $11 \pm 7$ & 64 & 6.1 to 16 & 2.6 & 2 \\
\hline Cs & ppm & $<0.2$ & - & - & - & 1 \\
\hline $\mathrm{Ba}$ & ppm & 0.10 & - & - & - & 1 \\
\hline $\mathrm{La}$ & ppm & 273 & - & - & - & 1 \\
\hline $\mathrm{Ce}$ & ppm & $<1$ & - & - & - & 1 \\
\hline $\mathrm{Sm}$ & $\mathrm{ppm}$ & 0.017 & - & - & - & 1 \\
\hline $\mathrm{Eu}$ & ppm & 0.031 & - & - & - & 1 \\
\hline $\mathrm{Tb}$ & ppm & 0.45 & - & - & - & 1 \\
\hline Ho & $\mathrm{ppm}$ & $<0.8$ & - & - & - & 2 \\
\hline $\mathrm{Yb}$ & ppm & $<1$ & - & - & - & 2 \\
\hline $\mathrm{Lu}$ & ppm & $<0.2$ & - & - & - & 2 \\
\hline $\mathrm{Hf}$ & ppm & 0.21 & - & - & - & 1 \\
\hline $\mathrm{Ta}$ & ppm & 0.13 & - & - & - & 1 \\
\hline $\mathrm{W}$ & ppm & $5.5 \pm 0.6$ & 11 & - & - & 2 \\
\hline $\mathrm{Pb}$ & ppm & $820 \pm 2430$ & 296 & - & - & 10 \\
\hline Th & ppm & 0.18 & - & - & - & 1 \\
\hline $\mathrm{U}$ & ppm & 0.20 & - & - & - & 1 \\
\hline
\end{tabular}

${ }^{a}$ Relative standard deviation (SD) expressed as a percentage of the average value.

${ }^{b}$ Ratio of the highest to the lowest value measured.

'Parts per million (ppm). 


\subsubsection{Average Elemental Concentrations in Vessel Steel}

Fractional activities, decay heat, and dose rates due to ${ }^{60} \mathrm{Co}$ and the other radionuclides in vessel steel based on the average chemical element concentrations (i.e., 122 ppm cobalt impurity) are presented in Table 7 and illustrated in Figure 8 and Figure 9. Cobalt-60 activity was approximately $0.2 \%$ of the total activity at shutdown, reached approximately $22 \%$ of the total activity at 22 years after shutdown, and decreased to negligible levels beyond 60 years after shutdown. However, ${ }^{60} \mathrm{Co}$ was a major decay heat contributor within the time interval from 30 days to 60 years after reactor shutdown and also a major contributor to the external dose rate within the time interval from 30 days to up to 75 years after reactor shutdown, depending on the cask steel shell thickness. The ${ }^{60} \mathrm{Co}$ contribution to external package dose rate was $98 \%$ to $100 \%$ within the time interval 5 years to 60 years after shutdown.

Table 7. Fractional activities, decay heat, and dose rates due to $\mathrm{Co}-60$ and due to the other radionuclides in irradiated vessel steel-average initial nuclide concentrations

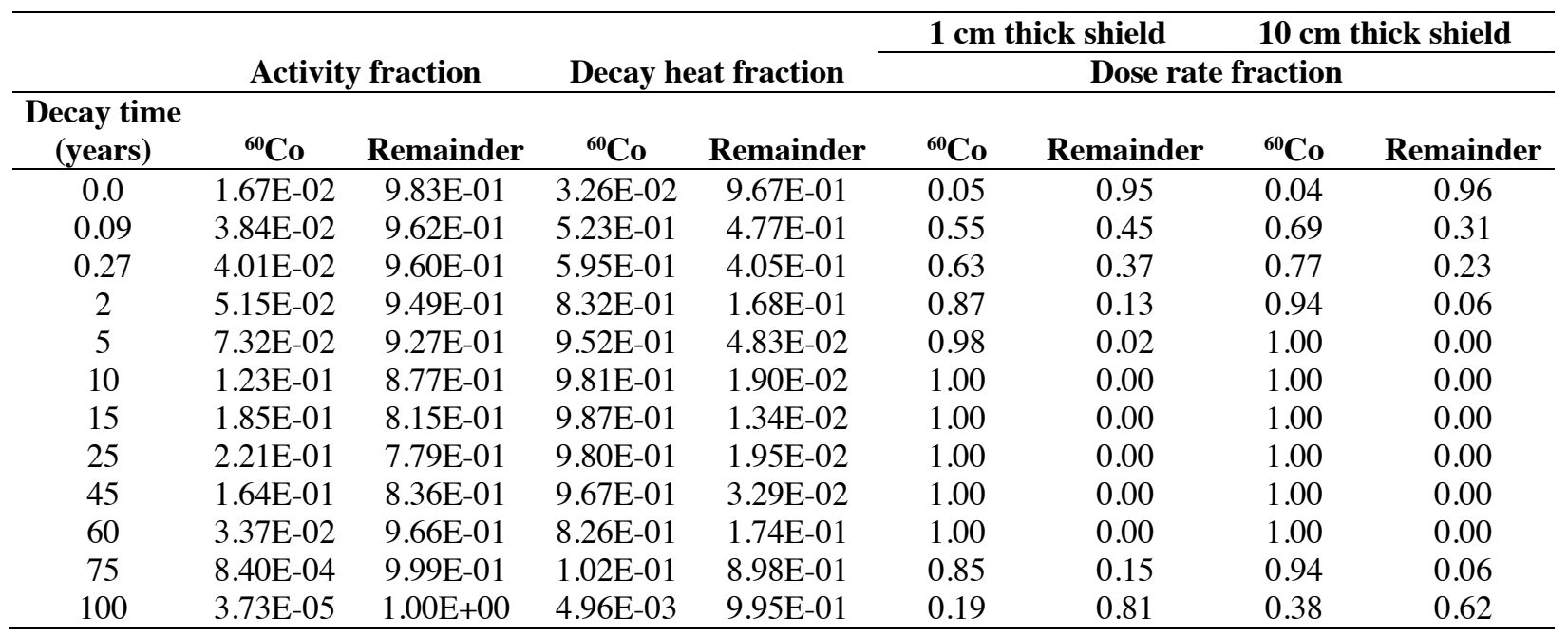

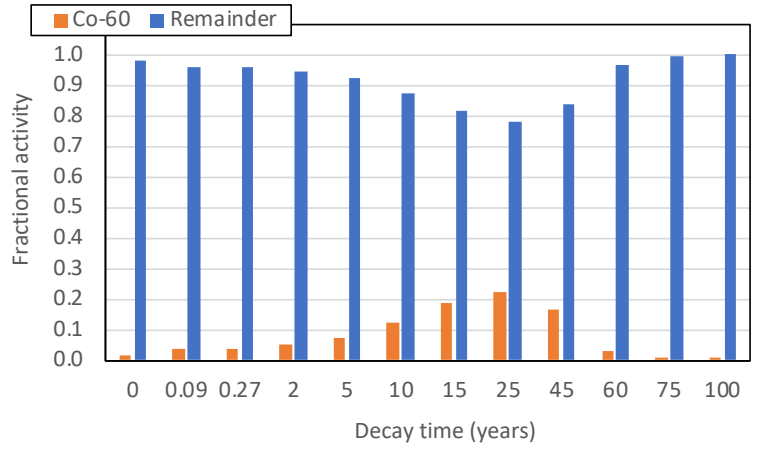

(a)

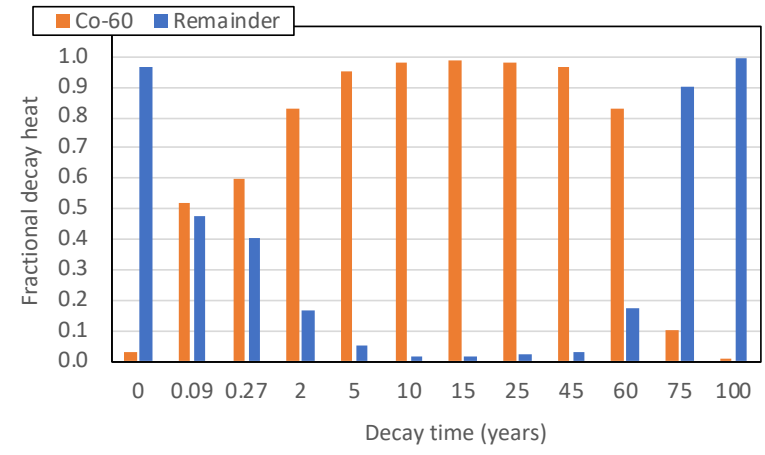

(b)

Figure 8. Fractional (a) activity and (b) decay heat for ${ }^{60} \mathrm{Co}$ and the remainder of radionuclides as a function of decay time for average vessel steel composition. 


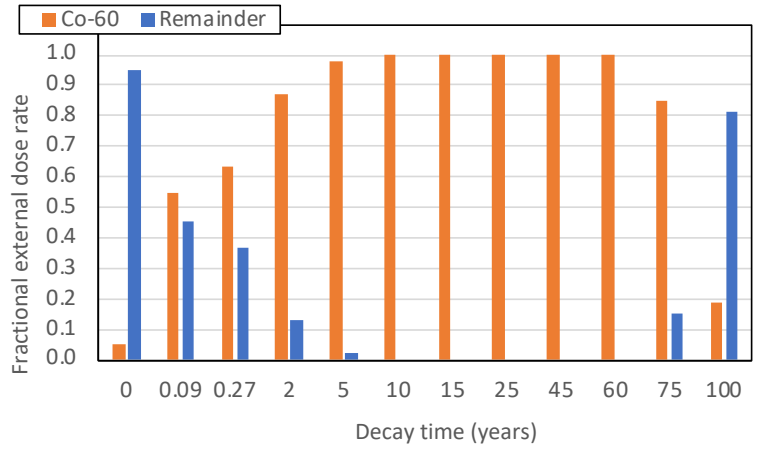

(a)

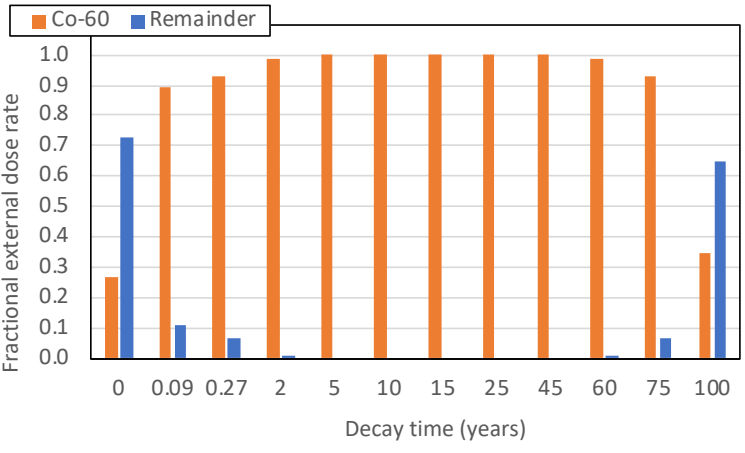

(b)

Figure 9. Fractional external dose rates for ${ }^{60} \mathrm{Co}$ and the remainder of radionuclides as a function of decay time for average vessel steel composition, assuming (a) $1 \mathrm{~cm}$ and (b) $10 \mathrm{~cm}$ thick steel cask shell.

\subsubsection{Minimum Initial Cobalt Impurity Concentration and Average Concentrations for the Remainder of Chemical Elements in Vessel Steel}

A similar analysis was also performed for the reactor vessel steel composition, assuming minimum initial cobalt impurity concentration (i.e., $93 \mathrm{ppm}$ ) and average concentrations for the remainder of the chemical elements in the composition. Fractional activities, decay heat, and dose rates from ${ }^{60} \mathrm{Co}$ and the remainder of radionuclides in irradiated reactor vessel steel are presented in Table 8 and illustrated in Figure 10 and Figure 11. The ${ }^{60} \mathrm{Co}$ contribution to dose rate was 99 to $100 \%$ within the time interval of 10 to 60 years after shutdown for the $1 \mathrm{~cm}$ thick shield and within the time interval of 5 to 60 years after shutdown for the $10 \mathrm{~cm}$ thick shield.

Table 8. Fractional activities, decay heat, and external package dose rates due to ${ }^{60} \mathrm{Co}$ and the remainder of radionuclides in irradiated vessel steel-minimum initial cobalt impurity concentration, average concentrations for the remainder of chemical elements

\begin{tabular}{|c|c|c|c|c|c|c|c|c|}
\hline & & & & & $1 \mathrm{~cm}$ & lick shield & $10 \mathrm{cr}$ & iick shield \\
\hline & Activi & $y$ fraction & Decay h & at fraction & & Dose ra & ractio & \\
\hline $\begin{array}{c}\text { Decay time } \\
\text { (years) }\end{array}$ & ${ }^{60} \mathrm{Co}$ & Remainder & ${ }^{60} \mathrm{Co}$ & Remainder & ${ }^{60} \mathrm{Co}$ & Remainder & ${ }^{60} \mathrm{Co}$ & Remainder \\
\hline 0.0 & $7.85 \mathrm{E}-03$ & 9.92E-01 & $1.37 \mathrm{E}-02$ & 9.86E-01 & 0.02 & 0.98 & 0.02 & 0.98 \\
\hline 0.09 & $2.99 \mathrm{E}-02$ & $9.70 \mathrm{E}-01$ & 4.54E-01 & $5.46 \mathrm{E}-01$ & 0.49 & 0.51 & 0.62 & 0.38 \\
\hline 0.27 & $3.13 \mathrm{E}-02$ & $9.69 \mathrm{E}-01$ & $5.29 \mathrm{E}-01$ & 4.71E-01 & 0.56 & 0.44 & 0.71 & 0.29 \\
\hline 2 & 4.03E-02 & $9.60 \mathrm{E}-01$ & 7.93E-01 & $2.07 \mathrm{E}-01$ & 0.84 & 0.16 & 0.92 & 0.08 \\
\hline 5 & $5.76 \mathrm{E}-02$ & $9.42 \mathrm{E}-01$ & $9.38 \mathrm{E}-01$ & $6.18 \mathrm{E}-02$ & 0.98 & 0.02 & 0.99 & 0.01 \\
\hline 10 & $9.72 \mathrm{E}-02$ & $9.03 \mathrm{E}-01$ & $9.76 \mathrm{E}-01$ & $2.43 \mathrm{E}-02$ & 1.00 & 0.00 & 1.00 & 0.00 \\
\hline 15 & $1.47 \mathrm{E}-01$ & $8.53 \mathrm{E}-01$ & $9.82 \mathrm{E}-01$ & $1.83 \mathrm{E}-02$ & 1.00 & 0.00 & 1.00 & 0.00 \\
\hline 25 & $1.66 \mathrm{E}-01$ & $8.34 \mathrm{E}-01$ & $9.71 \mathrm{E}-01$ & $2.90 \mathrm{E}-02$ & 1.00 & 0.00 & 1.00 & 0.00 \\
\hline 45 & $1.18 \mathrm{E}-01$ & $8.82 \mathrm{E}-01$ & $9.51 \mathrm{E}-01$ & 4.85E-02 & 1.00 & 0.00 & 1.00 & 0.00 \\
\hline 60 & 2.29E-02 & 9.77E-01 & $7.60 \mathrm{E}-01$ & $2.40 \mathrm{E}-01$ & 0.99 & 0.01 & 1.00 & 0.00 \\
\hline 75 & $5.64 \mathrm{E}-04$ & $9.99 \mathrm{E}-01$ & $6.99 \mathrm{E}-02$ & $9.30 \mathrm{E}-01$ & 0.71 & 0.29 & 0.86 & 0.14 \\
\hline 100 & $2.50 \mathrm{E}-05$ & $1.00 \mathrm{E}+00$ & $3.29 \mathrm{E}-03$ & $9.97 \mathrm{E}-01$ & 0.09 & 0.91 & 0.19 & 0.81 \\
\hline
\end{tabular}




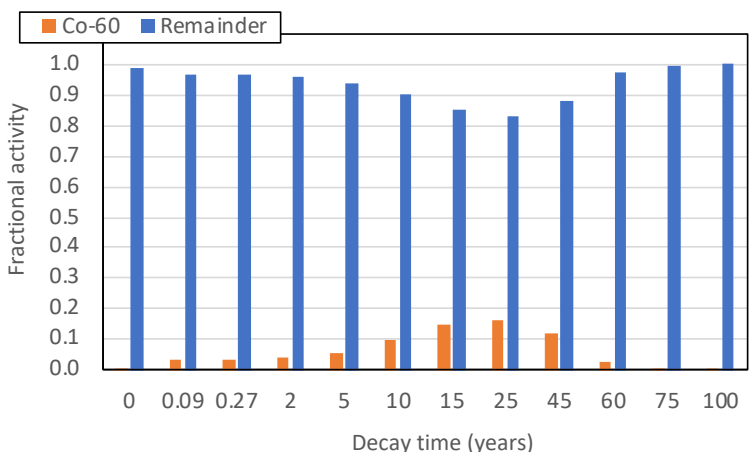

(a)

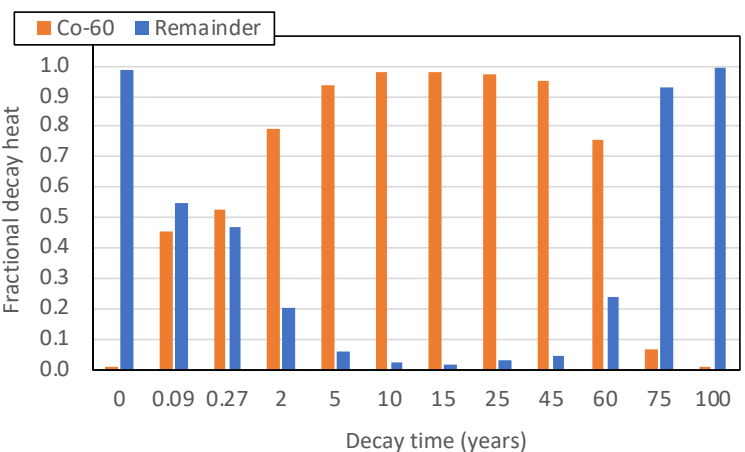

(b)

Figure 10. Fractional (a) activity and (b) decay heat for ${ }^{60} \mathrm{Co}$ and the remainder of radionuclides in irradiated vessel steel as a function of decay time, assuming minimum initial cobalt impurity concentration and average concentrations for the remainder of chemical elements.

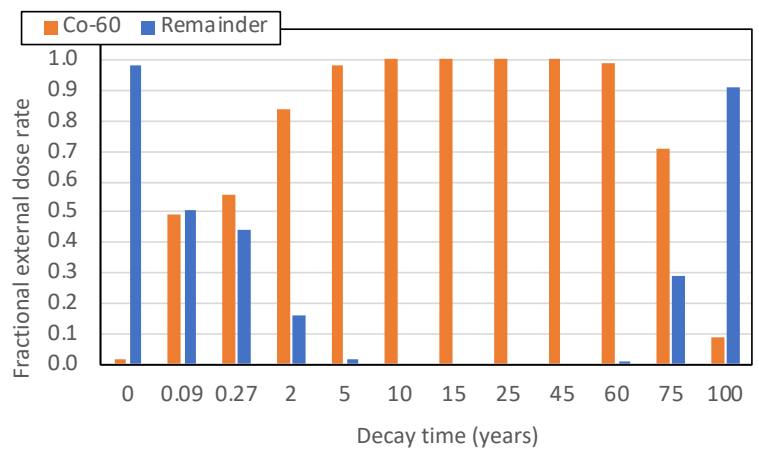

(a)

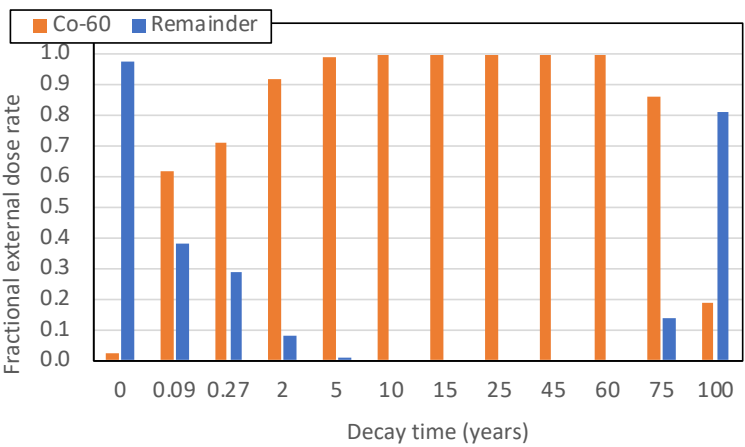

(b)

Figure 11. Fractional external dose rates for ${ }^{60} \mathrm{Co}$ and the remainder of radionuclides in irradiated vessel steel as a function of decay time assuming (a) $1 \mathrm{~cm}$ and (b) $10 \mathrm{~cm}$ thick steel cask shell—minimum initial cobalt impurity concentration and average concentrations for the remainder of chemical elements.

\subsection{INCONEL}

Inconel is a nickel alloy. The Inconel composition presented in Table 9, which includes major and minor elements, was used in ORIGEN activation calculations. This composition, taken from NUREG/CR-3474 [21], indicates a relatively low cobalt impurity concentration (i.e., 574 ppm) in Inconel. 
Table 9. Inconel composition from NUREG/CR-3474

\begin{tabular}{cccccc}
\hline Element & Unit & Concentration & Element & Unit & Concentration \\
\hline $\mathrm{Na}$ & $\mathrm{ppm}^{\mathrm{a}}$ & 4.1 & $\mathrm{Nb}$ & $\mathrm{ppm}$ & 385 \\
$\mathrm{Al}$ & $\mathrm{ppm}$ & 1,160 & $\mathrm{Mo}$ & $\%$ & 0.19 \\
$\mathrm{Cl}$ & $\mathrm{ppm}$ & 26 & $\mathrm{Ag}$ & $\mathrm{ppm}$ & 2 \\
$\mathrm{~K}$ & $\mathrm{ppm}$ & 40 & $\mathrm{Sb}$ & $\mathrm{ppm}$ & 2.3 \\
$\mathrm{Ti}$ & $\mathrm{ppm}$ & 2,280 & $\mathrm{Cs}$ & $\mathrm{ppm}$ & 20 \\
$\mathrm{~V}$ & $\mathrm{ppm}$ & 270 & $\mathrm{Ba}$ & $\mathrm{ppm}$ & 200 \\
$\mathrm{Cr}$ & $\%$ & 15.2 & $\mathrm{La}$ & $\mathrm{ppm}$ & 0.03 \\
$\mathrm{Mn}$ & $\%$ & 0.23 & $\mathrm{Ce}$ & $\mathrm{ppm}$ & 400 \\
$\mathrm{Fe}$ & $\%$ & 9.96 & $\mathrm{Sm}$ & $\mathrm{ppm}$ & 0.045 \\
$\mathrm{Co}$ & $\mathrm{ppm}$ & 574 & $\mathrm{Eu}$ & $\mathrm{ppm}$ & 0.05 \\
$\mathrm{Ni}$ & $\%$ & 74.5 & $\mathrm{~Tb}$ & $\mathrm{ppm}$ & 0.2 \\
$\mathrm{Cu}$ & $\mathrm{ppm}$ & 2,240 & $\mathrm{~Pb}$ & $\mathrm{ppm}$ & 0.5 \\
$\mathrm{Zn}$ & $\mathrm{ppm}$ & 9 & $\mathrm{Lu}$ & $\mathrm{ppm}$ & 2 \\
$\mathrm{Ga}$ & $\mathrm{ppm}$ & 13 & $\mathrm{Hf}$ & $\mathrm{ppm}$ & 1 \\
$\mathrm{As}$ & $\mathrm{ppm}$ & 33 & $\mathrm{Ta}$ & $\mathrm{ppm}$ & 0.9 \\
$\mathrm{Se}$ & $\mathrm{ppm}$ & 3 & $\mathrm{~W}$ & $\mathrm{ppm}$ & 1.2 \\
$\mathrm{Br}$ & $\mathrm{ppm}$ & 0.7 & $\mathrm{~Pb}$ & $\mathrm{ppm}$ & 2.8 \\
$\mathrm{Rb}$ & $\mathrm{ppm}$ & 11 & $\mathrm{Th}$ & $\mathrm{ppm}$ & 60 \\
$\mathrm{Y}$ & $\mathrm{ppm}$ & 11 & $\mathrm{U}$ & $\mathrm{ppm}$ & 1 \\
$\mathrm{Zr}$ & $\mathrm{ppm}$ & 8 & & & 0.8 \\
\hline
\end{tabular}

aarts per million (ppm).

At reactor shutdown, the main radionuclides in irradiated Inconel are ${ }^{63} \mathrm{Ni}\left(\mathrm{T}_{1 / 2}=100.1 \mathrm{y}\right),{ }^{58} \mathrm{Co}$ $\left(\mathrm{T}_{1 / 2}=70.88 \mathrm{~d}\right),{ }^{51} \mathrm{Cr}\left(\mathrm{T}_{1 / 2}=27.704 \mathrm{~d}\right),{ }^{58 \mathrm{~m}} \mathrm{Co}\left(\mathrm{T}_{1 / 2}=9.1 \mathrm{~h}\right),{ }^{56} \mathrm{Mn}\left(\mathrm{T}_{1 / 2}=2.579 \mathrm{~h}\right),{ }^{60} \mathrm{Co}\left(\mathrm{T}_{1 / 2}=5.271\right.$ $\mathrm{y})$, and ${ }^{55} \mathrm{Fe}\left(\mathrm{T}_{1 / 2}=2.73 \mathrm{y}\right)$. Fractional activities, decay heat, and dose rates for ${ }^{60} \mathrm{Co}$ and the remainder radionuclides in irradiated Inconel are presented in Table 10 and illustrated in Figure 12 and Figure 13. Cobalt-60 activity was approximately $5.6 \%$ of the total activity at shutdown, reached approximately $21.5 \%$ of the total activity at 2 years post shutdown, and decreased to negligible levels beyond 45 years after shutdown. However, ${ }^{60} \mathrm{Co}$ was a major decay heat contributor for irradiated Inconel up to 45 years after reactor shutdown and a major contributor to the external cask dose rate up to 75 years after reactor shutdown. The ${ }^{60} \mathrm{Co}$ contribution to the external package dose rate was approximately $27 \%$ (1 cm thick shield) and $33 \%$ (10 cm thick shield) of the total dose rate at shutdown. That contribution increased up to $98-100 \%$ within the time interval of 2 to 60 years after shutdown, and then it decreased to $6 \%$ ( $1 \mathrm{~cm}$ thick shield $)$ and $14 \%$ (10 cm thick shield) at 100 years post shutdown. 
Table 10. Fractional activities, decay heat, and dose rates because of ${ }^{60} \mathrm{Co}$ and the other radionuclides in irradiated Inconel

\begin{tabular}{|c|c|c|c|c|c|c|c|c|}
\hline \multirow{3}{*}{$\begin{array}{c}\begin{array}{c}\text { Decay time } \\
\text { (years) }\end{array} \\
\end{array}$} & \multirow{2}{*}{\multicolumn{2}{|c|}{ Activity fraction }} & \multirow{2}{*}{\multicolumn{2}{|c|}{ Decay heat fraction }} & \multicolumn{2}{|c|}{$1 \mathrm{~cm}$ thick shield } & \multicolumn{2}{|c|}{$10 \mathrm{~cm}$ thick shield } \\
\hline & & & & & \multicolumn{4}{|c|}{ Dose rate fraction } \\
\hline & ${ }^{60} \mathrm{Co}$ & Remainder & ${ }^{60} \mathrm{Co}$ & Remainder & ${ }^{60} \mathrm{Co}$ & Remainder & ${ }^{60} \mathrm{Co}$ & Remainder \\
\hline 0.0 & $5.58 \mathrm{E}-02$ & $9.44 \mathrm{E}-01$ & $2.22 \mathrm{E}-01$ & $7.78 \mathrm{E}-01$ & 0.27 & 0.73 & 0.33 & 0.67 \\
\hline 0.09 & $1.08 \mathrm{E}-01$ & $8.92 \mathrm{E}-01$ & $4.24 \mathrm{E}-01$ & $5.76 \mathrm{E}-01$ & 0.45 & 0.55 & 0.66 & 0.34 \\
\hline 0.27 & $1.58 \mathrm{E}-01$ & $8.42 \mathrm{E}-01$ & $5.72 \mathrm{E}-01$ & $4.28 \mathrm{E}-01$ & 0.60 & 0.40 & 0.78 & 0.22 \\
\hline 2 & $2.15 \mathrm{E}-01$ & $7.85 \mathrm{E}-01$ & $9.55 \mathrm{E}-01$ & $4.51 \mathrm{E}-02$ & 0.98 & 0.02 & 0.99 & 0.01 \\
\hline 5 & $1.72 \mathrm{E}-01$ & $8.28 \mathrm{E}-01$ & $9.60 \mathrm{E}-01$ & $4.03 \mathrm{E}-02$ & 0.99 & 0.01 & 1.00 & 0.00 \\
\hline 10 & $1.06 \mathrm{E}-01$ & $8.94 \mathrm{E}-01$ & $9.44 \mathrm{E}-01$ & $5.59 \mathrm{E}-02$ & 1.00 & 0.00 & 1.00 & 0.00 \\
\hline 15 & $6.07 \mathrm{E}-02$ & $9.39 \mathrm{E}-01$ & $9.06 \mathrm{E}-01$ & $9.41 \mathrm{E}-02$ & 1.00 & 0.00 & 1.00 & 0.00 \\
\hline 25 & $1.83 \mathrm{E}-02$ & $9.82 \mathrm{E}-01$ & 7.38E-01 & $2.62 \mathrm{E}-01$ & 1.00 & 0.00 & 1.00 & 0.00 \\
\hline 45 & $1.54 \mathrm{E}-03$ & $9.98 \mathrm{E}-01$ & $1.89 \mathrm{E}-01$ & $8.11 \mathrm{E}-01$ & 0.99 & 0.01 & 1.00 & 0.00 \\
\hline 60 & 2.38E-04 & $1.00 \mathrm{E}+00$ & $3.46 \mathrm{E}-02$ & $9.65 \mathrm{E}-01$ & 0.92 & 0.08 & 0.97 & 0.03 \\
\hline 75 & $3.66 \mathrm{E}-05$ & $1.00 \mathrm{E}+00$ & $5.50 \mathrm{E}-03$ & $9.95 \mathrm{E}-01$ & 0.63 & 0.37 & 0.80 & 0.20 \\
\hline 100 & $1.62 \mathrm{E}-06$ & $1.00 \mathrm{E}+00$ & $2.45 \mathrm{E}-04$ & $1.00 \mathrm{E}+00$ & 0.06 & 0.94 & 0.14 & 0.86 \\
\hline
\end{tabular}

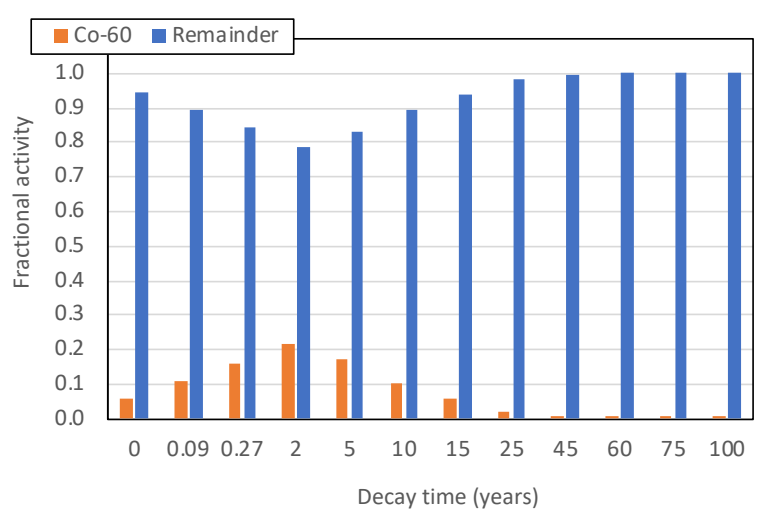

(a)

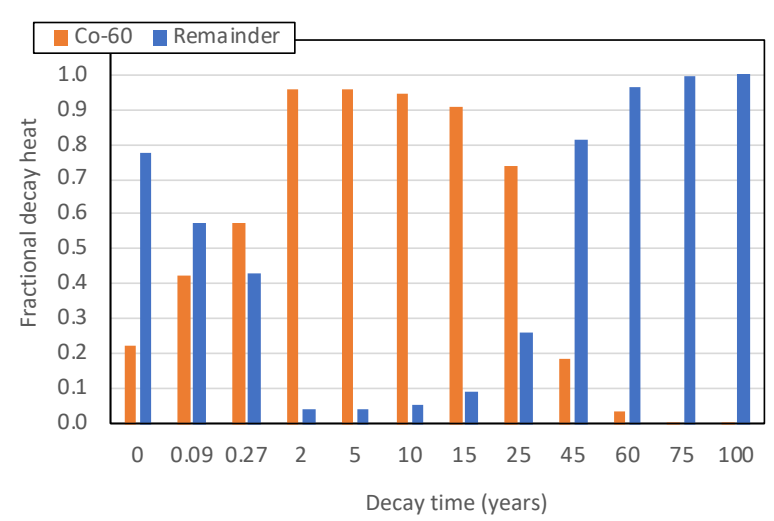

(b)

Figure 12. Fractional (a) activity and (b) decay heat for ${ }^{60} \mathrm{Co}$ and the remainder of radionuclides in irradiated Inconel as a function of decay time. 


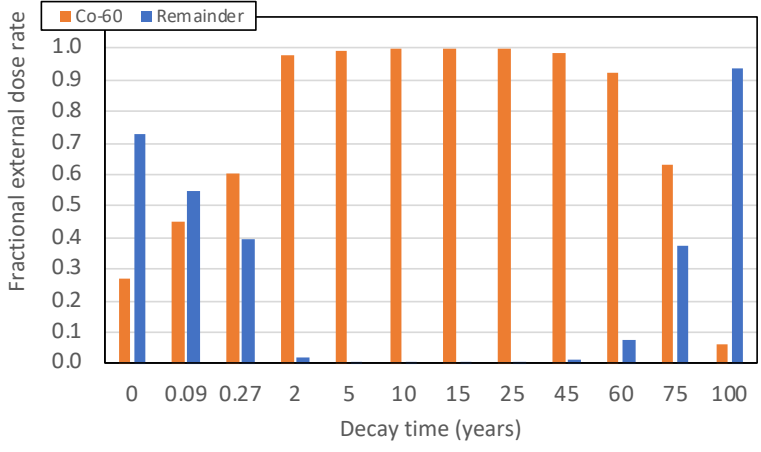

(a)

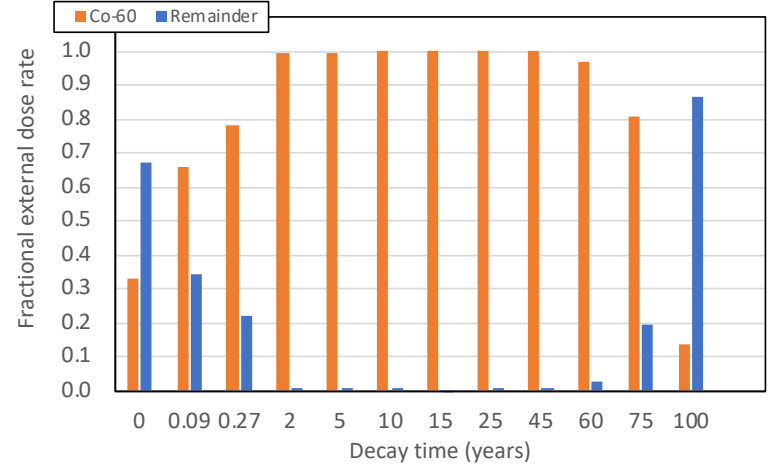

(b)

Figure 13. Fractional external dose rates for ${ }^{60} \mathrm{Co}$ and the remainder of radionuclides in irradiated Inconel as a function of decay time, assuming (a) $1 \mathrm{~cm}$ and (b) $10 \mathrm{~cm}$ thick steel cask shell.

\subsection{ACTIVATED METALS ANALYSIS SUMMARY}

Activated metals, including Type 304 stainless steel, reactor vessel steel (carbon steel), and Inconel, were analyzed with respect to external package dose rate in this report. Measured chemical compositions, including major constituents and impurities, of unirradiated metals from US LWRs, were obtained from NUREG/CR-3474 [21]. The greatest cobalt impurity levels were measured in Type 304 stainless steel, with up to 2,570 ppm, and the lowest cobalt impurity levels were measured in vessel steel (carbon steel), ranging from 93 to $151 \mathrm{ppm}$. The reported cobalt impurity concentration in the Inconel sample was $574 \mathrm{ppm}$. The Type 316 stainless steel was not analyzed in this report because stainless steel types 304 and 316 have similar initial elemental compositions and cobalt impurity concentrations [21]. Therefore, the results for Type 304 stainless steel are applicable to the Type 316 stainless steel.

The material compositions, including major constituents and impurities, were used in ORIGEN activation calculations to determine radionuclide activity, radiation source terms, and decay heat as a function of decay time up to 100 years post reactor shutdown. A generic neutron spectrum representative of a broad energy range - including thermal, epithermal, and fast neutron energies - was used in all activation calculations. The ORIGEN radiation source terms were used in a simplified cask model to determine total dose rate and the contribution of the major activation product ${ }^{60} \mathrm{Co}$ to the total dose rate as a function of decay time at a single location on the external radial surface of the cask.

Table 11 lists the main radionuclides with a half-life greater than 1 day identified in the activated metals found in reactor internals and pressure vessel along with their decay modes, the maximum energy of the beta particles for beta emitters, and the energy of principal gamma rays. The ORIGEN activation calculations showed that irradiated steel contains significant amounts of relatively short-lived radionuclides such as ${ }^{56} \mathrm{Mn}\left(\mathrm{T}_{1 / 2}=2.579 \mathrm{~h}\right)$ and ${ }^{51} \mathrm{Cr}\left(\mathrm{T}_{1 / 2}=27.704 \mathrm{~d}\right)$ at shutdown. Therefore, these radionuclides have negligible or small contributions to cask external dose rate after approximately 30 days to 1 year from reactor shutdown. Other activation products are pure beta emitters of low-energy electrons such as ${ }^{63} \mathrm{Ni}\left(\mathrm{T}_{1 / 2}=100.1 \mathrm{y}\right)$, or they emit weak $\mathrm{x}$ rays, such as ${ }^{55} \mathrm{Fe}\left(\mathrm{T}_{1 / 2}=2.73 \mathrm{y}\right)$. Irradiated steel also contains small amounts of the ${ }^{54} \mathrm{Mn}$ 
radionuclide $\left(\mathrm{T}_{1 / 2}=312.3 \mathrm{~d}\right)$, which is produced by the threshold reaction ${ }^{54} \mathrm{Fe}(\mathrm{n}, \mathrm{p})^{54} \mathrm{Mn}$ and whose decay produces gamma rays of $835 \mathrm{keV}$. The ORIGEN activation calculations showed that ${ }^{60} \mathrm{Co}$ is not a significant contributor to the total activity. However, ${ }^{60} \mathrm{Co}$ is a principal contributor to total decay heat and a major contributor to external package dose rate.

Table 11. Main radionuclides with a half-life greater than 1 day identified in reactor-activated metals

\begin{tabular}{ccccc}
\hline Nuclide & Half-life & Decay mode & $\boldsymbol{\beta}^{-}(\mathbf{k e V})$ & $\begin{array}{c}\text { Energy of principal gamma rays (keV) and } \\
\text { abundances }\end{array}$ \\
\hline${ }^{51} \mathrm{Cr}$ & $27.7025 \mathrm{~d}$ & $\mathrm{EC}^{a}$ & - & $320(9.8 \%)$ \\
${ }^{59} \mathrm{Fe}$ & $44.503 \mathrm{~d}$ & $\beta^{-}$ & 466 & $1,099(56 \%), 1292(44 \%), 192(3 \%)$ \\
${ }^{58} \mathrm{Co}$ & $70.86 \mathrm{~d}$ & $\mathrm{EC}+\beta^{+}$ & 474 & $511(30 \%), 811(99 \%), 864(1.4 \%), 1675(0.6 \%)$ \\
${ }^{54} \mathrm{Mn}$ & $312.3 \mathrm{~d}$ & $\mathrm{EC}$ & - & $835(100 \%)$ \\
${ }^{55} \mathrm{Fe}$ & $2.73 \mathrm{y}$ & $\mathrm{EC}$ & - & - \\
${ }^{60} \mathrm{Co}$ & $5.2714 \mathrm{y}$ & $\beta^{-}$ & 317.8 & $1,332.5(99.98 \%), 1173.2(99.92 \%)$ \\
${ }^{63} \mathrm{Ni}$ & $100.1 \mathrm{y}$ & $\beta^{-}$ & 66.945 & - \\
\hline
\end{tabular}

aElectron capture.

The graph presented in Figure 14 shows the ratio of ${ }^{60} \mathrm{Co}$ dose rate to total dose rate as a function of decay time for activated Type 304 stainless steel, vessel steel, and Inconel. The external package dose rate was dominated by short-lived radionuclides at shutdown, but the ${ }^{60} \mathrm{Co}$ contribution to external dose rate increased after reactor shutdown. At 30 days after shutdown, ${ }^{60} \mathrm{Co}$ contribution to the total external package dose rate varied from approximately $60 \%$ to $95 \%$, depending on material, initial cobalt impurity concentration, and shield thickness. Its maximum contribution of approximately $100 \%$ was reached within the time interval of 2 to 5 years after shutdown and was maintained for up to 45 to 60 years after shutdown, depending on material, initial cobalt impurity concentration, and shield thickness. Thereafter, ${ }^{60} \mathrm{Co}$ contribution to external dose rate decreased with increasing decay time. These findings are consistent with those in NUREG/CR-0130 and NUREG/CR-0672, which identified ${ }^{60} \mathrm{Co}$ as the major contributor to external package dose rate due to neutron-induced activation products in reactor pressure vessel and internal structural materials. 


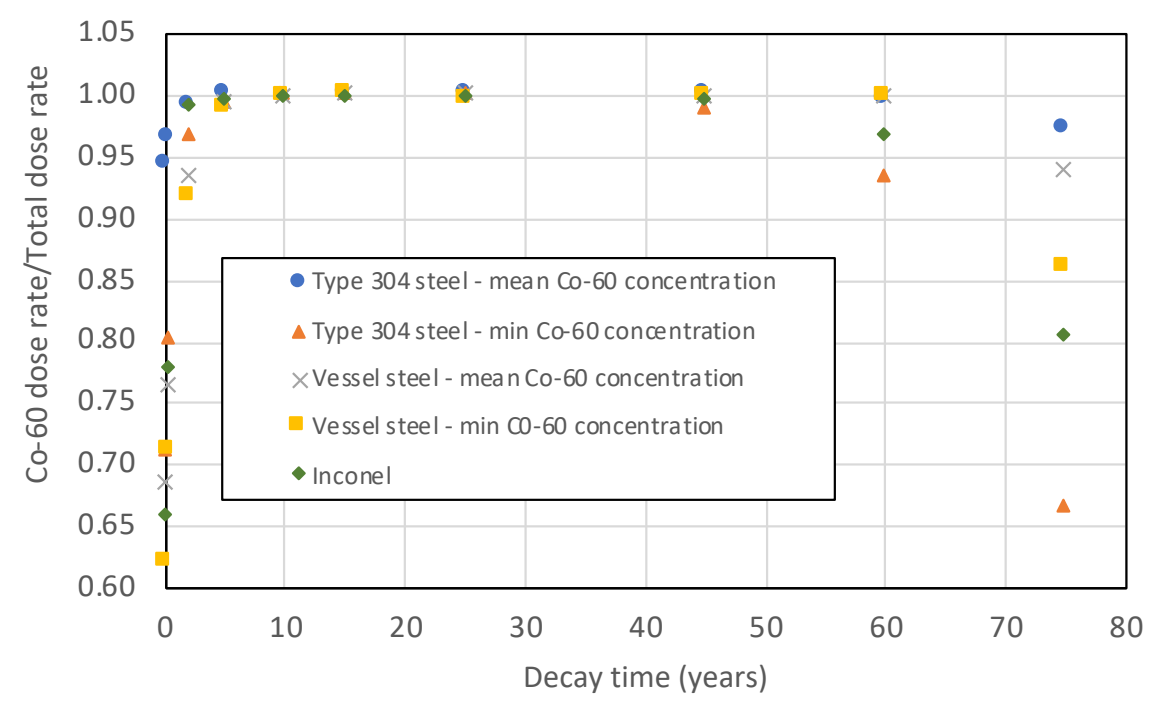

Figure 14. Ratio of ${ }^{60} \mathrm{Co}$ dose rate to total dose rate as a function of decay time for activated metals.

The analyses in this report support the approach of defining the contents of packages dedicated to shipment of activated metals from reactor internals and pressure vessel in terms of ${ }^{60} \mathrm{Co}$ activity/source strength. Representing other radionuclides that contribute to the external package dose rates as ${ }^{60} \mathrm{Co}$ is conservative because ${ }^{60} \mathrm{Co}$ gamma ray emissions are bounding in terms of radiation source energy and intensity (see Table 11). Examples of Certificate of Compliance $(\mathrm{CoC})$ certificates defining package contents in terms of ${ }^{60} \mathrm{Co}$ activity/source strength include the Nuclear Assurance Corporation-Storage Transport Cask (NAC-STC) and MAGNATRAN CoCs $[27,28]$. 


\section{CONTROL BLADES FROM BWRS}

The typical absorber material in $\mathrm{BWR}$ control blades is $\mathrm{B}_{4} \mathrm{C}$, which is used as compacted powder within stainless steel tubes. Some control blades may also contain hafnium rods at the top and/or edges of control rod blades [29]. The absorber rods are contained in stainless steel. Therefore, irradiated control blades contain activated stainless steel, which is analyzed in Section 5. Those analyses show that ${ }^{60} \mathrm{Co}$ produced by neutron activation of cobalt impurity in steel is a major contributor to external package dose rate due to activated steel. Additionally, measured ${ }^{60} \mathrm{Co}$ concentrations ( $\mathrm{pCi} / \mathrm{g}$ ) in irradiated $\mathrm{B}_{4} \mathrm{C}$ cruciform rod-bladed samples from the Duane Arnold Plant were one to three orders of magnitude greater than the measured concentrations of other important radionuclides (e.g., ${ }^{63} \mathrm{Ni},{ }^{93 \mathrm{~m}} \mathrm{Nb}$, and ${ }^{59} \mathrm{Ni}$ ) present in the samples at the time of measurement, which was approximately 5 years after discharge from the reactor [30].

Hafnium isotopes have strong epithermal resonance absorption cross section peaks [29]. Radiation sources associated with irradiated Hf control blades were determined from a SCALE/TRITON 2D depletion calculation of a General Electric 14 fuel assembly adjacent to a Hf control blade during irradiation. The assumed depleted fuel assembly burnup was 45 $\mathrm{GWd} / \mathrm{MTU}$. Table 12 shows the main radionuclides in irradiated $\mathrm{Hf}$ and their half-lives, decay modes, and the energy of emitted gamma rays. At discharge from the reactor, irradiated $\mathrm{Hf}$ contained many short- and medium-lived radionuclides, and its radioactivity decreased by more than 3 orders of magnitude at 2 years after discharge and by more than 6 orders of magnitude at 5 years after discharge. The cask model $(10 \mathrm{~cm}$ thick shield) illustrated in Figure 3 and the radiation source terms for irradiated stainless steel and $\mathrm{Hf}$ in the control blade were used to determine their associated external package dose rate. The external package dose rate resulting from the activated stainless steel was approximately 7 times higher at discharge and 100 times higher 2 years after discharge than the external package dose rate that resulted from the irradiated Hf rods at the same time intervals. This calculation shows that irradiated Hf absorber rods would have insignificant contributions to external package dose rate beyond 2 years after discharge from the reactor in comparison to the activated steel in the control blade. However, Hf radiation sources should be included in the total radiation sources of irradiated Hf control blades if the cooling time of the control blades is less than 2 years.

Table 12. Important radionuclides in irradiated $\mathrm{Hf}$ and their half-lives and gamma emissions

\begin{tabular}{cccc}
\hline Radionuclide & Half life & Decay mode & $\begin{array}{c}\text { Energy (keV) of } \\
\text { principal gamma rays }\end{array}$ \\
\hline${ }^{175} \mathrm{Hf}$ & $70 \mathrm{~d}$ & $\mathrm{EC}^{\mathrm{a}}$ & $343,89,433,230,114$ \\
${ }^{177} \mathrm{Lu}$ & $6.734 \mathrm{~d}$ & $\beta^{-}$ & $208,113,321,250,72$ \\
${ }^{179 \mathrm{~m} \mathrm{Hf}}$ & $18.67 \mathrm{~s}$ & $\mathrm{IT}^{\mathrm{b}}$ & $214,161,375$ \\
${ }^{180} \mathrm{Hf}$ & $5.5 \mathrm{~h}$ & $\mathrm{IT}^{-}$ & $391,450,351,234,104$ \\
${ }^{181} \mathrm{Hf}$ & $42.39 \mathrm{~d}$ & $\beta^{-}$ & $482,133,346,136,137$ \\
${ }^{182} \mathrm{Ta}^{\mathrm{c}}$ & $114.43 \mathrm{~d}$ & $\beta^{-}$ & $68,1121,1221,1189$, \\
& & $\beta^{-}$ & $784,73,459,398,1470$ \\
${ }^{183} \mathrm{Hf}$ & $1.067 \mathrm{~h}$ & $\beta^{-}$ & $246,354,108,161,244$ \\
${ }^{183} \mathrm{Ta}$ & $5.1 \mathrm{~d}$ & $\mathrm{IT}$ & $108,99,53,46,161$ \\
\hline
\end{tabular}

${ }^{\mathrm{a} E l e c t r o n}$ capture.

bIsomeric transition.

${ }^{\mathrm{c}}$ The abundances of the $1121,1221,1189$, and 1231 gamma rays are $~ 35 \%, 27 \%, 16 \%$, and $11 \%$, respectively. 


\section{SPENT RESINS FROM POWER PLANT OPERATIONS}

Resins contain a mixture of neutron-activated corrosion products and fission products. The major sources of the corrosion products are stainless steel and nickel-based alloys, Stellite and cobaltbearing components, fuel cladding, silver-indium-cadmium control rods, secondary start-up sources, etc. [31]. The magnitude of radionuclide loadings on spent resins varies as a function of power plant operating conditions. Levels of radionuclide loadings (in $\mu \mathrm{Ci} / \mathrm{g}$ ) on samples of spent resin from reactor coolant cleanup that were shipped for disposal were documented in NUREG/CR-2830 [32] and NUREG/CR-6567 [33]. The reported radionuclide loadings from six power plants are presented in Table 13. NUREG/CR-6567 [33] provides measured activities for the 10 CFR 61 [2] radionuclides and several additional long-lived radionuclides on a bead resin from Crystal River at 3.08 years after removal from service. The purpose of NUREG/CR-2830 [32] was to collect data on maximum radionuclide loadings on spent resins shipped for disposal. Therefore, the radionuclide loadings on spent resins for the plants other than Crystal River described in Table 13 are representative of the time of resin removal from service at US power plants during 1980 and 1981. The radionuclide compositions for those spent resins include, in addition to the long-lived radionuclides, ${ }^{137} \mathrm{Cs}\left(\mathrm{T}_{1 / 2}=30.07 \mathrm{y}\right)$ and ${ }^{60} \mathrm{Co}\left(\mathrm{T}_{1 / 2}=5.271 \mathrm{y}\right)$, other important gamma emitters that have shorter half-lives, such as ${ }^{134} \mathrm{Cs}\left(\mathrm{T}_{1 / 2}=2.0648 \mathrm{y}\right),{ }^{65} \mathrm{Zn}$ $\left(\mathrm{T}_{1 / 2}=244.26 \mathrm{~d}\right)$, and ${ }^{58} \mathrm{Co}\left(\mathrm{T}_{1 / 2}=70.86 \mathrm{~d}\right)$. However, the decay time for these resins was not provided in NUREG/CR-2830. NUREG/CR-2830 indicates that spent resins are shipped for disposal without storage in some plants, and the longest storage period seems to be about a year. Therefore, based on this statement and the reported radionuclide compositions, it can be assumed that the decay time for the radionuclide loadings on the spent resins reported in NUREG/CR2830 is less than 1 year.

The dominant fraction consists of fission products (e.g., ${ }^{134} \mathrm{Cs}$ and ${ }^{137} \mathrm{Cs}$ ) at some plants and activation products (e.g., ${ }^{60} \mathrm{Co}$ ) at other plants. It should be noted that ${ }^{137} \mathrm{Cs}$ is a pure beta emitter but $94.6 \%$ of its decay leads to ${ }^{137 \mathrm{~m}} \mathrm{Ba}\left(\mathrm{T}_{1 / 2}=2.552 \mathrm{~m}\right)$, which decays by emitting gamma rays of $662 \mathrm{keV}(89.9 \%)$. The available data show high variability in radionuclide levels on the spent resin samples from six power plants. Therefore, the levels of radionuclide loadings on the spent resins from six power plants that were analyzed in this report may not be representative of all/current spent resins discharged from US power plants. Distribution of the more prominent radionuclides at a given reactor depends on reactor operating conditions, development of fuel leaks, and chemical treatment of the coolant [32]. 
Table 13. Levels $(\mu \mathrm{Ci} / \mathrm{g})$ of radionuclides on resin samples from various power plants

\begin{tabular}{|c|c|c|c|c|c|c|c|}
\hline & Power plant & $\begin{array}{l}\text { Crystal } \\
\text { River }^{a}\end{array}$ & Hatch 1 & $\begin{array}{c}\text { Maine } \\
\text { Yankee }\end{array}$ & $\begin{array}{c}\text { Peach } \\
\text { Bottom }\end{array}$ & Trojan & $\begin{array}{c}\text { Vermont } \\
\text { Yankee }\end{array}$ \\
\hline Nuclide & Half-life & \multicolumn{6}{|c|}{ Activity $(\mu \mathrm{Ci} / \mathrm{g})$} \\
\hline${ }^{10} \mathrm{Be}$ & $1.5 \mathrm{E}+06 \mathrm{y}$ & $1.08 \mathrm{E}-04$ & - & - & - & - & - \\
\hline${ }^{36} \mathrm{Cl}$ & $3.01 \mathrm{E}+05 \mathrm{y}$ & 3.34E-03 & - & - & - & - & - \\
\hline${ }^{51} \mathrm{Cr}$ & $27.702 \mathrm{~d}$ & - & - & - & $2.06 \mathrm{E}-01$ & $1.21 \mathrm{E}-01$ & - \\
\hline${ }^{54} \mathrm{Mn}$ & $312.1 \mathrm{~d}$ & - & - & - & $1.10 \mathrm{E}-02$ & $2.78 \mathrm{E}+00$ & $5.98 \mathrm{E}+00$ \\
\hline${ }^{55} \mathrm{Fe}$ & $2.73 \mathrm{y}$ & $4.52 \mathrm{E}-01$ & - & - & 7.64E-01 & - & - \\
\hline${ }^{59} \mathrm{Fe}$ & $44.5 \mathrm{~d}$ & - & - & - & - & $5.87 \mathrm{E}-02$ & - \\
\hline${ }^{57} \mathrm{Co}$ & $271.8 \mathrm{~d}$ & - & - & - & - & $6.07 \mathrm{E}-02$ & - \\
\hline${ }^{58} \mathrm{Co}$ & $70.88 \mathrm{~d}$ & - & - & $1.70 \mathrm{E}+02$ & $1.05 \mathrm{E}-01$ & $5.32 \mathrm{E}-01$ & $5.88 \mathrm{E}+00$ \\
\hline${ }^{60} \mathrm{Co}$ & $5.271 \mathrm{y}$ & $6.54 \mathrm{E}+00$ & $3.01 \mathrm{E}+01$ & $9.76 \mathrm{E}+00$ & $6.64 \mathrm{E}-01$ & $4.57 \mathrm{E}+01$ & $3.05 \mathrm{E}+01$ \\
\hline${ }^{59} \mathrm{Ni}$ & $7.6 \mathrm{E}+04 \mathrm{y}$ & $2.0 \mathrm{E}-01$ & - & - & - & - & - \\
\hline${ }^{63} \mathrm{Ni}$ & $101 \mathrm{y}$ & $2.32 \mathrm{E}+01$ & - & - & $5.98 \mathrm{E}-01$ & - & - \\
\hline${ }^{65} \mathrm{Zn}$ & $243.8 \mathrm{~d}$ & - & $1.28 \mathrm{E}+02$ & - & $2.45 \mathrm{E}+00$ & $6.71 \mathrm{E}-02$ & $2.03 E+01$ \\
\hline${ }^{90} \mathrm{Sr}$ & $28.78 \mathrm{y}$ & $4.87 \mathrm{E}-01$ & - & - & $4.06 \mathrm{E}-03$ & - & - \\
\hline${ }^{95} \mathrm{Zr}$ & $64.02 \mathrm{~d}$ & - & - & - & - & - & $1.11 \mathrm{E}+01$ \\
\hline${ }^{93 \mathrm{~m}} \mathrm{Nb}$ & $16.1 \mathrm{y}$ & $5.3 \mathrm{E}-03$ & - & - & - & - & - \\
\hline${ }^{94} \mathrm{Nb}$ & $2.0 \mathrm{E}+04 \mathrm{y}$ & $7.4 \mathrm{E}-04$ & - & - & - & - & - \\
\hline${ }^{95} \mathrm{Nb}$ & $34.99 \mathrm{~d}$ & - & - & - & - & $2.26 \mathrm{E}-02$ & - \\
\hline${ }^{93} \mathrm{Mo}$ & $4 \mathrm{E}+03 \mathrm{y}$ & $1.6 \mathrm{E}-05$ & - & - & - & - & - \\
\hline${ }^{99} \mathrm{Tc}$ & $2.111 \mathrm{E}+05 \mathrm{y}$ & $13.0 \mathrm{E}-05$ & - & - & - & - & - \\
\hline${ }^{99 \mathrm{~m}} \mathrm{Tc}$ & $6.01 \mathrm{~h}$ & - & - & - & - & - & 4.19E-01 \\
\hline${ }^{106} \mathrm{Ru}$ & $1.02 \mathrm{y}$ & - & - & - & - & $1.95 \mathrm{E}-01$ & - \\
\hline${ }^{108 m} \mathrm{Ag}$ & $438 \mathrm{y}$ & $5.0 \mathrm{E}-02$ & - & - & - & - & - \\
\hline${ }^{110 \mathrm{~m}} \mathrm{Ag}$ & $249.8 \mathrm{~d}$ & - & - & - & - & 4.04E-02 & - \\
\hline${ }^{109} \mathrm{Cd}$ & $462.6 \mathrm{~d}$ & $9.0 \mathrm{E}-04$ & - & - & - & - & - \\
\hline${ }^{113 \mathrm{~m}} \mathrm{Cd}$ & $14.1 \mathrm{y}$ & 7.1E-03 & - & - & - & - & - \\
\hline${ }^{121 \mathrm{~m}} \mathrm{Sn}$ & $55 \mathrm{y}$ & $3.9 \mathrm{E}-04$ & - & - & - & - & - \\
\hline${ }^{124} \mathrm{Sb}$ & $60.2 \mathrm{~d}$ & - & - & - & - & $1.78 \mathrm{E}-02$ & - \\
\hline${ }^{125} \mathrm{Sb}$ & $2.7758 \mathrm{y}$ & - & - & - & - & $1.65 \mathrm{E}-01$ & - \\
\hline${ }^{129} \mathrm{I}$ & $1.57 \mathrm{E}+07 \mathrm{y}$ & $6.56 \mathrm{E}-05$ & - & - & - & - & - \\
\hline${ }^{131} \mathrm{I}$ & $8.02 \mathrm{~d}$ & - & - & - & $1.27 \mathrm{E}-01$ & - & $5.35 \mathrm{E}-01$ \\
\hline${ }^{134} \mathrm{Cs}$ & $2.065 \mathrm{y}$ & - & $5.46 \mathrm{E}+02$ & $1.11 \mathrm{E}+01$ & $2.86 \mathrm{E}-01$ & $5.13 \mathrm{E}+00$ & $1.78 \mathrm{E}+01$ \\
\hline${ }^{137} \mathrm{Cs}$ & $30.07 y$ & $2.32 \mathrm{E}+02$ & $7.57 \mathrm{E}+02$ & $2.11 \mathrm{E}+01$ & $4.06 \mathrm{E}-01$ & $1.26 \mathrm{E}+01$ & $4.84 \mathrm{E}+01$ \\
\hline${ }^{140} \mathrm{La}$ & $1.678 \mathrm{~d}$ & - & - & - & $2.60 \mathrm{E}-02$ & - & - \\
\hline${ }^{141} \mathrm{Ce}$ & $32.5 \mathrm{~d}$ & & & & & $1.26 \mathrm{E}-02$ & \\
\hline${ }^{144} \mathrm{Ce}$ & $284.6 \mathrm{~d}$ & - & - & - & - & $3.49 \mathrm{E}-01$ & - \\
\hline${ }^{234} \mathrm{U}$ & $2.455 \mathrm{E}+05 \mathrm{y}$ & $2.4 \mathrm{E}-05$ & - & - & - & - & - \\
\hline${ }^{235} \mathrm{U}$ & $7.038 \mathrm{E}+08 \mathrm{y}$ & $9.9 \mathrm{E}-06$ & - & - & - & - & - \\
\hline${ }^{238} \mathrm{U}$ & $4.468 \mathrm{E}+09 \mathrm{y}$ & $3.3 \mathrm{E}-06$ & - & - & - & - & - \\
\hline${ }^{238} \mathrm{Pu}$ & $87.7 \mathrm{y}$ & $1.26 \mathrm{E}-05$ & & & & & \\
\hline $\begin{array}{l}{ }^{239} \mathrm{Pu} \text { and/or } \\
{ }^{240} \mathrm{Pu}\end{array}$ & $\begin{array}{c}24110 y \\
6563 y\end{array}$ & $8.4 \mathrm{E}-06$ & - & - & - & - & - \\
\hline${ }^{241} \mathrm{Pu}$ & $14.35 \mathrm{y}$ & $6.9 \mathrm{E}-04$ & - & - & - & - & - \\
\hline${ }^{241} \mathrm{Am}$ & $432.2 \mathrm{y}$ & $3.35 \mathrm{E}-05$ & - & - & - & - & - \\
\hline${ }^{244} \mathrm{Cm}$ & $18.1 \mathrm{y}$ & $1.34 \mathrm{E}-05$ & - & - & - & - & - \\
\hline
\end{tabular}

${ }^{\mathrm{a}}$ Mean value plus uncertainty for radioisotopes in spent resin cooled for 3.08 years from NUREG/CR-6567 [33].

Activity, decay heat, and dose rate fractions as a function of decay time for ${ }^{137} \mathrm{Cs}$ and ${ }^{60} \mathrm{Co}$ for the Crystal River spent resin described in NUREG/CR-6567 are presented in Table 14. Dose rate 
was calculated at the external surface of the simplified cask model shown in Figure 3 . The dominant radionuclides with respect to dose rate for this spent resin with a cooling time of 3.08 years are ${ }^{137} \mathrm{Cs}$ and ${ }^{60} \mathrm{Co}$. Fractional external dose rates for ${ }^{137} \mathrm{Cs} /{ }^{137} \mathrm{ma}$ and ${ }^{60} \mathrm{Co}$ on the Crystal River spent resin described in NUREG/CR-6567 are illustrated in Figure 15. The contribution to dose rate from the remainder of radioisotopes is negligible (i.e., $<0.5 \%$ ). However, because ${ }^{137} \mathrm{Cs}$ has a much longer half-life than ${ }^{60} \mathrm{Co}$, the contribution of ${ }^{137} \mathrm{Cs} /{ }^{137 \mathrm{~m}} \mathrm{Ba}$ to dose rate increases with increasing decay time, whereas the contribution of ${ }^{60} \mathrm{Co}$ decreases with increasing decay time to negligible amounts beyond 45 years of cooling. From these dose rate calculations using two different thicknesses of the gamma shielding, it can be seen that the ${ }^{137} \mathrm{Cs} /{ }^{137 m} \mathrm{Ba}$ dose rate fraction decreases with increasing the shield thickness, whereas the ${ }^{60} \mathrm{Co}$ fraction increases with increasing the shield thickness because ${ }^{60} \mathrm{Co}$ emits more energetic gamma rays than ${ }^{137 \mathrm{~m}} \mathrm{Ba}$. Therefore, for thick shielding or deep penetration problems, ${ }^{60} \mathrm{Co}$ is more of a concern than ${ }^{137} \mathrm{Cs} /{ }^{137 \mathrm{~m}} \mathrm{Ba}$.

Table 14. Activity, decay heat, and dose rate fractions for ${ }^{137} \mathrm{Cs} /{ }^{137 \mathrm{~m}} \mathrm{Ba}$ and ${ }^{60} \mathrm{Co}$ on the Crystal River spent resin described in NUREG/CR-6567

\begin{tabular}{|c|c|c|c|c|c|c|c|c|c|c|}
\hline & \multicolumn{2}{|c|}{ Activity fraction a } & \multicolumn{2}{|c|}{ Decay heat fraction } & \multicolumn{3}{|c|}{$\begin{array}{c}\text { Dose rate fraction- } 1 \mathrm{~cm} \\
\text { steel shield }^{\mathrm{b}}\end{array}$} & \multicolumn{3}{|c|}{$\begin{array}{c}\text { Dose rate fraction - } 10 \mathrm{~cm} \\
\text { steel shield }^{b}\end{array}$} \\
\hline $\begin{array}{c}\text { time } \\
\text { (years) }\end{array}$ & ${ }^{137} \mathrm{Cs} /{ }^{137 \mathrm{~m}} \mathrm{Ba}$ & ${ }^{60} \mathrm{Co}$ & ${ }^{137} \mathrm{Cs} /{ }^{137 \mathrm{~mm}} \mathbf{B a}$ & ${ }^{60} \mathrm{Co}$ & ${ }^{137} \mathrm{Cs} /{ }^{137 \mathrm{~m}} \mathrm{Ba}$ & ${ }^{60} \mathrm{Co}$ & $\underset{\mathrm{c}}{\operatorname{Remainder}}$ & ${ }^{137} \mathrm{Cs} /{ }^{137 \mathrm{~m}} \mathrm{Ba}$ & ${ }^{60} \mathrm{Co}$ & Remainder \\
\hline 3.08 & $9.36 \mathrm{E}-01$ & $1.35 \mathrm{E}-02$ & $9.14 \mathrm{E}-01$ & $8.31 \mathrm{E}-02$ & $8.65 \mathrm{E}-01$ & $1.35 \mathrm{E}-01$ & $2.74 \mathrm{E}-05$ & $6.20 \mathrm{E}-01$ & $3.80 \mathrm{E}-01$ & $1.07 \mathrm{E}-04$ \\
\hline 5 & $9.36 \mathrm{E}-01$ & $1.10 \mathrm{E}-02$ & $9.26 \mathrm{E}-01$ & $6.84 \mathrm{E}-02$ & $8.87 \mathrm{E}-01$ & $1.13 \mathrm{E}-01$ & $5.46 \mathrm{E}-04$ & $6.66 \mathrm{E}-01$ & $3.32 \mathrm{E}-01$ & $1.32 \mathrm{E}-03$ \\
\hline 10 & $9.37 \mathrm{E}-01$ & $6.40 \mathrm{E}-03$ & $9.53 \mathrm{E}-01$ & 4.09E-02 & $9.31 \mathrm{E}-01$ & $6.87 \mathrm{E}-02$ & 4.92E-04 & 7.74E-01 & $2.25 \mathrm{E}-01$ & $9.67 \mathrm{E}-04$ \\
\hline 20 & $9.32 \mathrm{E}$ & $2.15 \mathrm{E}-$ & $9.80 \mathrm{E}-01$ & $1.42 \mathrm{E}-02$ & $9.75 \mathrm{E}$ & $2.43 \mathrm{E}$ & $5.43 \mathrm{E}$ & $9.10 \mathrm{E}$ & $8.92 \mathrm{E}$ & 1.25 \\
\hline 30 & $9.23 \mathrm{E}-01$ & $7.21 \mathrm{E}-04$ & $9.88 \mathrm{E}-01$ & 4.85E-03 & $9.91 \mathrm{E}-01$ & $8.36 \mathrm{E}$ & $5.12 \mathrm{E}$ & $9.65 \mathrm{E}-01$ & $3.20 \mathrm{E}-02$ & $3.39 \mathrm{E}-03$ \\
\hline 50 & 8.98E-01 & 8.01E-05 & $9.91 \mathrm{E}-01$ & $5.55 \mathrm{E}-04$ & $9.96 \mathrm{E}-01$ & $9.60 \mathrm{E}-04$ & $2.67 \mathrm{E}-03$ & $9.95 \mathrm{E}-01$ & $3.77 \mathrm{E}-03$ & $1.58 \mathrm{E}-03$ \\
\hline 65 & $8.74 \mathrm{E}-01$ & $1.53 \mathrm{E}-05$ & $9.90 \mathrm{E}-01$ & $1.09 \mathrm{E}-04$ & $9.98 \mathrm{E}-01$ & $1.89 \mathrm{E}-04$ & $2.26 \mathrm{E}-03$ & $9.98 \mathrm{E}-01$ & $7.42 \mathrm{E}-04$ & $1.31 \mathrm{E}-03$ \\
\hline 80 & $8.45 \mathrm{E}-01$ & $2.91 \mathrm{E}-06$ & 9.87E-01 & $2.14 \mathrm{E}-05$ & $9.95 \mathrm{E}-01$ & $3.70 \mathrm{E}-05$ & 4.79E-03 & 9.93E-01 & $1.45 \mathrm{E}-04$ & $6.93 \mathrm{E}-03$ \\
\hline 105 & 7.84E-01 & $1.79 \mathrm{E}-07$ & $9.82 \mathrm{E}-01$ & $1.41 \mathrm{E}-06$ & $9.95 \mathrm{E}-01$ & $2.46 \mathrm{E}-06$ & $4.89 \mathrm{E}-03$ & $9.91 \mathrm{E}-01$ & $9.63 \mathrm{E}-06$ & $8.77 \mathrm{E}-03$ \\
\hline
\end{tabular}

${ }^{a}$ One gram of resin contained $6.54 \mu \mathrm{Ci}$ of ${ }^{60} \mathrm{Co}$ and $232 \mu \mathrm{Ci}$ of ${ }^{137} \mathrm{Cs}$ at 3.08 years after discharge.

bDose rates at the external surface of the simplified cask model shown in Figure 3.

cThe remainder of radionuclides on the spent resin.

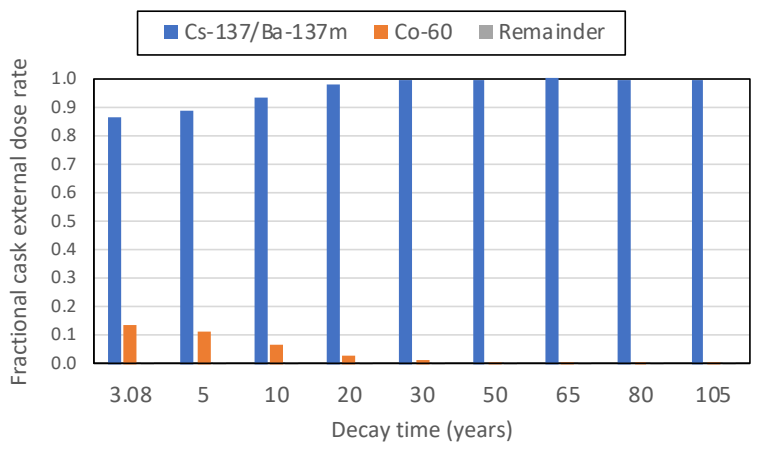

(a)

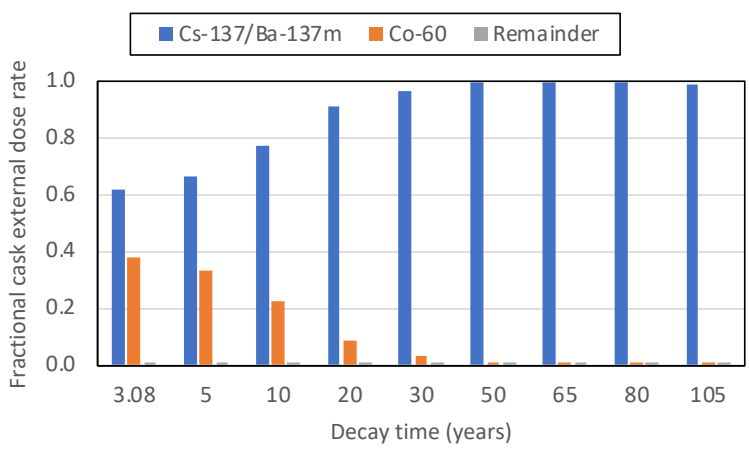

(b)

Figure 15. Fractional external dose rates for ${ }^{137} \mathrm{Cs} /{ }^{137 \mathrm{~m}} \mathrm{Ba}$ and ${ }^{60} \mathrm{Co}$ on the Crystal River spent resin described in NUREG/CR-6567, assuming the thickness of the cask steel shell is (a) $1 \mathrm{~cm}$ and (b) $10 \mathrm{~cm}$. 
Fractional external package dose rates for the ${ }^{137} \mathrm{Cs}\left(\mathrm{T}_{1 / 2}=30.07 \mathrm{y}\right),{ }^{60} \mathrm{Co}\left(\mathrm{T}_{1 / 2}=5.271 \mathrm{y}\right),{ }^{134} \mathrm{Cs}$ $\left(\mathrm{T}_{1 / 2}=2.0648 \mathrm{y}\right),{ }^{65} \mathrm{Zn}\left(\mathrm{T}_{1 / 2}=244.26 \mathrm{~d}\right)$, and ${ }^{58} \mathrm{Co}\left(\mathrm{T}_{1 / 2}=70.86 \mathrm{~d}\right)$ isotopes in the spent resins described in NUREG/CR-2830 are presented in Table 15 and illustrated in Figure 16. The contributions of these five radionuclides varied between $92.2 \%$ to $100 \%$ for the thin gamma shield (i.e., $1 \mathrm{~cm}$ ) and between $95.6 \%$ to $100 \%$ for the thick gamma shield (i.e., $10 \mathrm{~cm}$ ).

Table 15. Dose rate fractions for main radionuclides on spent resins with maximum loading (NUREG/CR2830)

\begin{tabular}{ccccccc}
\hline Nuclide & $\begin{array}{c}\text { Cs-137/ Ba- } \\
\mathbf{1 3 7 m}\end{array}$ & Co-60 & Cs-134 & Zn-65 & Co-58 & Other \\
\hline Reactor & \multicolumn{2}{c}{ Dose rate fractions assuming a 1 cm thick cask steel shell } \\
\hline Hatch1 & $2.84 \mathrm{E}-01$ & $6.26 \mathrm{E}-02$ & $5.96 \mathrm{E}-01$ & $5.80 \mathrm{E}-02$ & $0.00 \mathrm{E}+00$ & 0.00 \\
Maine Yankee & $4.79 \mathrm{E}-02$ & $1.23 \mathrm{E}-01$ & $7.34 \mathrm{E}-02$ & $0.00 \mathrm{E}+00$ & $7.56 \mathrm{E}-01$ & 0.00 \\
Peach Bottom & $4.90 \mathrm{E}-02$ & $4.44 \mathrm{E}-01$ & $1.00 \mathrm{E}-01$ & $3.57 \mathrm{E}-01$ & $2.48 \mathrm{E}-02$ & 0.03 \\
Trojan & $4.38 \mathrm{E}-02$ & $8.81 \mathrm{E}-01$ & $5.19 \mathrm{E}-02$ & $2.82 \mathrm{E}-04$ & $3.62 \mathrm{E}-03$ & 0.02 \\
Vermont Yankee & $1.46 \mathrm{E}-01$ & $5.11 \mathrm{E}-01$ & $1.56 \mathrm{E}-01$ & $7.40 \mathrm{E}-02$ & $3.47 \mathrm{E}-02$ & 0.08 \\
\hline Reactor & \multicolumn{7}{c}{ Dose rate fractions assuming a 10 cm thick cask steel shell } \\
\hline Hatch1 & $1.88 \mathrm{E}-01$ & $1.63 \mathrm{E}-01$ & $5.31 \mathrm{E}-01$ & $1.16 \mathrm{E}-01$ & $0.00 \mathrm{E}+00$ & 0.00 \\
Maine Yankee & $2.49 \mathrm{E}-02$ & $2.51 \mathrm{E}-01$ & $5.12 \mathrm{E}-02$ & $0.00 \mathrm{E}+00$ & $6.70 \mathrm{E}-01$ & 0.00 \\
Peach Bottom & $1.57 \mathrm{E}-02$ & $5.60 \mathrm{E}-01$ & $4.33 \mathrm{E}-02$ & $3.46 \mathrm{E}-01$ & $1.36 \mathrm{E}-02$ & 0.02 \\
Trojan & $1.21 \mathrm{E}-02$ & $9.59 \mathrm{E}-01$ & $1.93 \mathrm{E}-02$ & $2.36 \mathrm{E}-04$ & $1.71 \mathrm{E}-03$ & 0.01 \\
Vermont Yankee & $5.28 \mathrm{E}-02$ & $7.25 \mathrm{E}-01$ & $7.60 \mathrm{E}-02$ & $8.09 \mathrm{E}-02$ & $2.15 \mathrm{E}-02$ & 0.04 \\
\hline
\end{tabular}

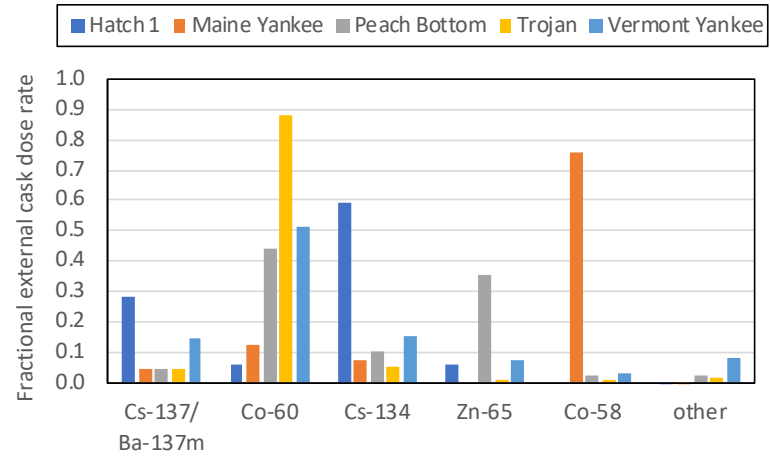

(a)

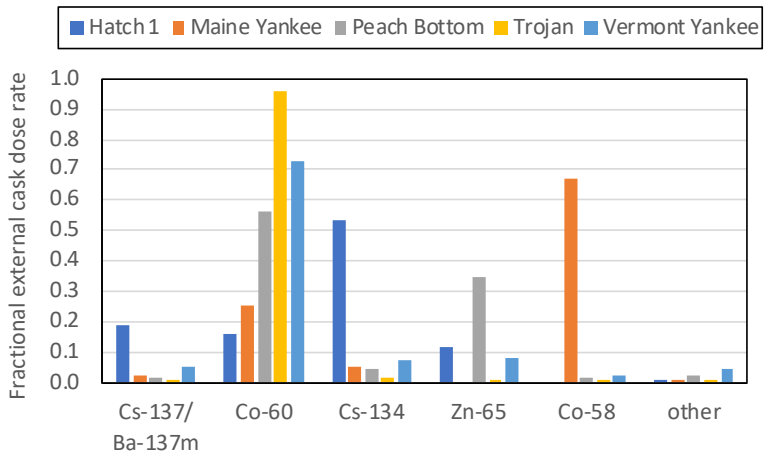

(b)

Figure 16. Fractional external package dose rates due to ${ }^{137} \mathrm{Cs} /{ }^{137 \mathrm{~m}} \mathrm{Ba},{ }^{60} \mathrm{Co},{ }^{134} \mathrm{Cs},{ }^{65} \mathrm{Zn}$, and ${ }^{58} \mathrm{Co}$ on the spent resins described in NUREG/CR-2830, assuming the thickness of the cask steel shell is (a) $1 \mathrm{~cm}$ and (b) $10 \mathrm{~cm}$.

In summary, based on reported maximum radionuclide loadings on spent resins from various power plants provided in NUREG/CR-2830 [32], the primary contributors to external package dose rate were ${ }^{137} \mathrm{Cs} /{ }^{137 m} \mathrm{Ba},{ }^{60} \mathrm{Co},{ }^{134} \mathrm{Cs},{ }^{65} \mathrm{Zn}$, and ${ }^{58} \mathrm{Co}$. These loadings contained both shortand long-lived radionuclides. For the Crystal River resin cooled for 3.08 years [33], the external package dose rate was essentially produced by the reported ${ }^{137} \mathrm{Cs}$ and ${ }^{60} \mathrm{Co}$ inventory. 


\section{NEUTRON SOURCES}

The decay of actinides present in waste may produce neutrons in addition to gamma radiation. Neutrons are produced by spontaneous fission of actinides and (alpha,n) reactions with light nuclei in the waste matrix. Thus, the neutron source depends on the actinides present in the waste and the waste elemental composition. A significant neutron source can be produced from ${ }^{17} \mathrm{O}$ $(\alpha, n)$ and ${ }^{18} \mathrm{O}(\alpha, \mathrm{n})$ reactions in the waste matrix material. The ${ }^{17} \mathrm{O}$ and ${ }^{18} \mathrm{O}$ nuclides have natural abundances of $0.038 \%$ and $0.205 \%$, respectively. ORIGEN has an option for the matrix material, which can be either $\mathrm{UO}_{2}$ (default option), borosilicate glass, or a case-specific mixture.

Spent organic ion exchange resins from nuclear power plants may contain low or undetectable levels of alpha emitters [32, Table 2.17]. Typical nuclear-grade resins have a matrix of polystyrene $\left(\mathrm{C}_{8} \mathrm{H}_{8}\right)_{n}$ cross-linked with divinylbenzene $\left(\mathrm{C}_{10} \mathrm{H}_{10}\right.$ or $\left.\mathrm{C}_{6} \mathrm{H}_{6}\left(\mathrm{CH}=\mathrm{CH}_{2}\right)_{2}\right)$ [34]. Residual water is removed from spent resins by dewatering and drying processes. However, spent resins may contain oxygen because the functional groups in ion exchange resins typically contain oxygen atoms (e.g., sulfonic acid $\left[\mathrm{S}\left(\mathrm{O}_{2}\right) \mathrm{OH}\right]$ ). The typical level of oxygen in spent resins could not be found from a literature review performed, but an evaluation of the neutron source and its importance to the shielding analyses is provided in this report. It was assumed that the resin matrix is polystyrene cross-linked with divinylbenzene and that this matrix contains $1 \%$ oxygen by weight. As presented in Table 16, NUREG/CR-2830 [32] provides alpha-emitting nuclide levels per gram of resin and associated photon sources and neutron source strengths from $(\alpha, n)$ reaction and spontaneous fission, as calculated with ORIGEN in this analysis. The neutron and photon sources were then used in a generic cask model illustrated in

Figure 3, assuming the thickness of the cask steel shell is $10 \mathrm{~cm}$, to calculate dose rate at the cask outer surface. The neutron and photon contributions to the total dose rate due to alpha-emitting nuclides are provided in the table below.

Table 16. Alpha-emitting nuclide levels on a resin sample and actinide neutron and gamma sources

\begin{tabular}{cc}
\hline Nuclide & Concentration on resin (nCi/g) \\
\hline${ }^{239} \mathrm{Pu},{ }^{240} \mathrm{Pu}$ & 11.4 \\
${ }^{238} \mathrm{Pu}$ & 3.0 \\
${ }^{241} \mathrm{Am}$ & 0.060 \\
${ }^{242} \mathrm{Cm},{ }^{243} \mathrm{Cm}$ & 0.073 \\
${ }^{244} \mathrm{Cm}$ & 0.006 \\
\hline \multicolumn{2}{c}{ Radiation levels for the actinides } \\
\hline \multicolumn{2}{c}{ Dose rate fractions } \\
Spontaneous fission neutron source \\
(neutrons/s/g) \\
Gamma source (photons/s/g) \\
\hline \multicolumn{2}{c}{ Neutrons } \\
\hline Secondary gamma rays \\
Primary gamma rays \\
\hline
\end{tabular}

This calculation shows that the neutron source, primarily from the (alpha,n) reactions, would contribute a small fraction (i.e., approximately $12 \%$ in this sample calculation) of the total dose rate due to actinides. However, the actinide radionuclide levels on spent resins is of the order of $\mathrm{nCi} / \mathrm{g}$, which is approximately three orders of magnitude lower that the reported levels of the 
${ }^{60} \mathrm{Co}$ nuclide (i.e., tens of $\mu \mathrm{Ci} / \mathrm{g}$ ) on spent resins [32]). Therefore, neutron and photon dose rates caused by actinides on spent resins are negligible compared to the total dose rate.

The DOE final environmental impact statement (EIS) report for GTCC waste [35] provides data for a conservative estimate of the actinide buildup in the crud and the radiation source terms as far as a shielding calculation is concerned. The neutron source associated with the EIS-0375 radionuclide inventory for rail shipments of activated metals ([35], Table B-13), presented in Table 17, was analyzed to determine the contribution of the neutron source to external package dose rate. This contribution was determined to be negligible as compared to the contribution of the gamma radiation from this inventory.

Table 17. EIS-0375 radionuclide inventory assumed for activation metals shipments and its gamma and neutron sources

\begin{tabular}{cc}
\hline Radionuclide & Activity (Ci) \\
\hline${ }^{241} \mathrm{Am}$ & $9.20 \mathrm{E}-02$ \\
${ }^{14} \mathrm{C}$ & $3.33 \mathrm{E}+01$ \\
${ }^{60} \mathrm{Co}$ & $9.35 \mathrm{E}+04$ \\
${ }^{137} \mathrm{Cs}$ & $1.98 \mathrm{E}+01$ \\
${ }^{3} \mathrm{H}$ & $1.03 \mathrm{E}+01$ \\
${ }^{129} \mathrm{I}$ & $2.74 \mathrm{E}-03$ \\
${ }^{55} \mathrm{Fe}$ & $6.13 \mathrm{E}+04$ \\
${ }^{54} \mathrm{Mn}$ & $1.05 \mathrm{E}+02$ \\
${ }^{59} \mathrm{Ni}$ & $1.78 \mathrm{E}+02$ \\
${ }^{63} \mathrm{Ni}$ & $2.58 \mathrm{E}+04$ \\
${ }^{94} \mathrm{Nb}$ & $1.07 \mathrm{E}+00$ \\
${ }^{238} \mathrm{Pu}$ & $1.28 \mathrm{E}-03$ \\
${ }^{239} \mathrm{Pu}$ & $6.48 \mathrm{E}+00$ \\
${ }^{241} \mathrm{Pu}$ & $3.67 \mathrm{E}-02$ \\
${ }^{90} \mathrm{Sr}$ & $1.75 \mathrm{E}+01$ \\
${ }^{99} \mathrm{Tc}$ & $6.48 \mathrm{E}+00$ \\
\hline \multicolumn{2}{c}{ Radiation levels } \\
\hline Neutron source & $1.8 \mathrm{E}+00$ \\
(neutrons/s) & \\
Actinide gamma & $7.1 \mathrm{E}+09$ \\
source (photons/s) & \\
Total gamma & $7.1 \mathrm{E}+15$ \\
source (photons/s) & \\
\hline \multicolumn{2}{c}{ Dose rate fraction } \\
\hline Neutrons \\
Actinide photons \\
Total photons & $3.0 \mathrm{E}-14$ \\
\hline \multicolumn{2}{c}{1.0} \\
\hline
\end{tabular}

The neutron dose rate contribution to the total dose from all sources of radiation on spent resins or activated metals was demonstrated to be negligible. The results of this neutron source analysis are in agreement with the results of the neutron source analysis for model 8-120B Type B shipping packaging, the contents of which included dewatered resins [7]. 


\section{ANALYSIS OF SOURCE GEOMETRY AND SPATIAL DISTRIBUTION MODELS}

The shapes and spatial source distributions of individual activated metal pieces loaded into a transportation cask may exhibit variations that cannot be easily characterized and considered in the safety analysis models. Therefore, safety analyses typically use idealized bounding geometry and spatial source distribution models. The effects of idealized source geometry and spatial distributions on external package dose rates were analyzed based on dose rate calculations for the simplified cask models described in Section 9.1. Self-shielding effects associated with various idealized material representations and source geometry configuration are analyzed in Section 9.2. The effects of spatial radiation source variation on external package dose rate are analyzed in Section 9.3 .

\subsection{SIMPLIFIED PACKAGE MODEL}

The simplified transportation cask model described in Table 18 and illustrated in Figure 17 was used to analyze the effects of various source geometry and radiation spatial distributions on external package dose rates. This cask model features carbon steel structural walls and lid, a lead layer in the cask radial shell and base for additional shielding, and two upper steel trunnions penetrating the lead shield material. This cask model was assumed to contain 15,000 kg Type 304 stainless steel with an arbitrary ${ }^{60}$ Co source.

Table 18. Characteristics of the simplified cask model

\begin{tabular}{lccl}
\hline \multicolumn{1}{c}{ Cask model component } & Characteristics & Value $(\mathbf{c m})$ & Material \\
\hline Cavity & Radius & 75.00 & N/A \\
& Height & 195.00 & N/A \\
Structural shell & Thickness & 5.08 & Carbon steel \\
Radial gamma shield & Thickness & 5.08 & Lead \\
& Height & 200 & Lead \\
Outer shell & Thickness & 2.54 & Carbon steel \\
Base & Thickness & 3.81 & Carbon steel \\
Bottom gamma shield & Thickness & 5.08 & Lead \\
Bottom plate & Thickness & 3.81 & Carbon steel \\
Top lid & Thickness & 15.24 & Carbon steel \\
Top trunnions & Radius & 5.50 & Stainless steel \\
Waste & Height & 195 & Type 304 stainless steel \\
\hline
\end{tabular}




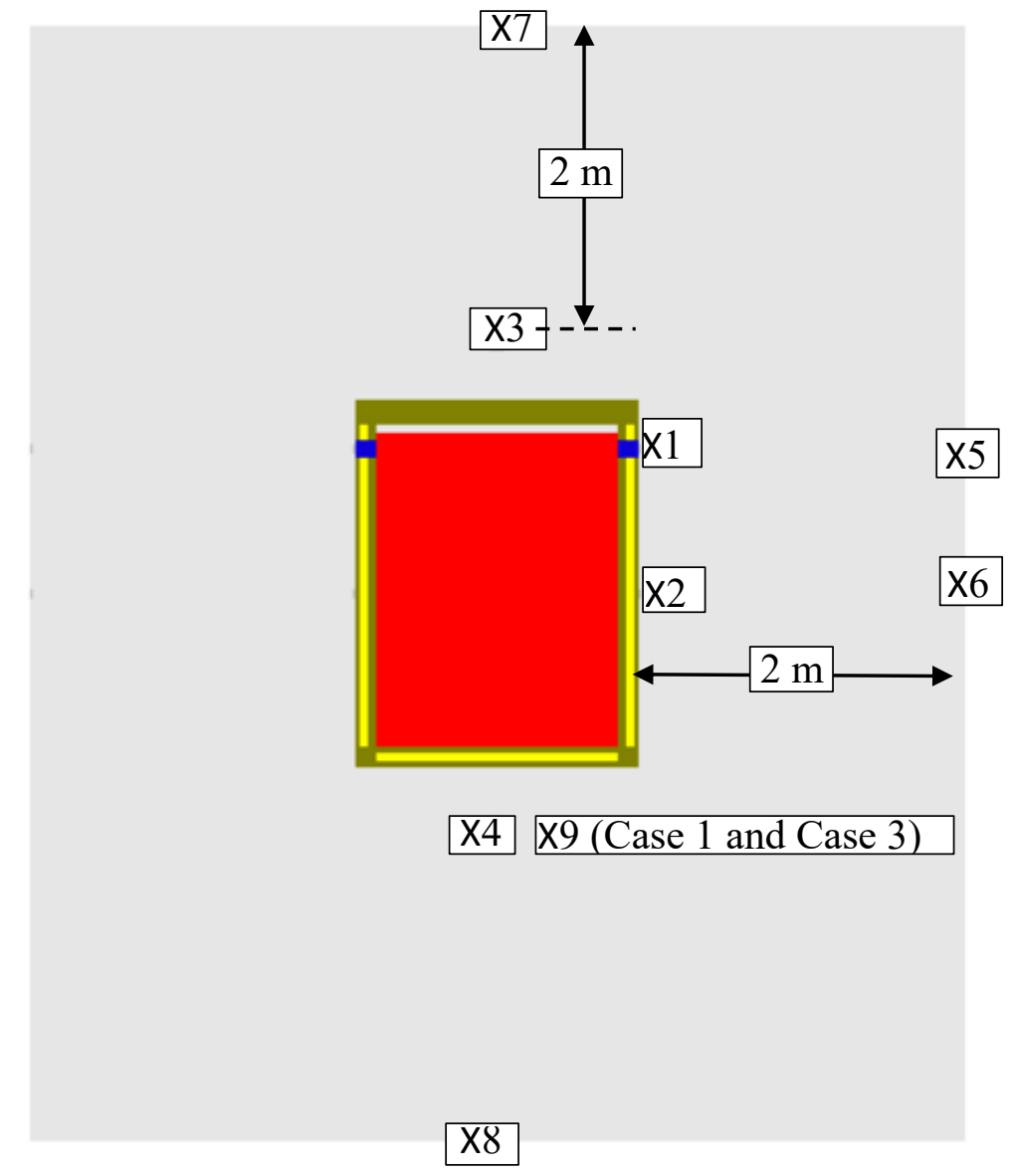

Figure 17. Axial dose rate detector locations for the cask model under NCT.

Four different waste geometry configurations were analyzed to determine the effect of waste geometry configuration and material self-shielding on external package dose rate for the simplified transport cask model described in Table 18. The four geometry configurations, referred to as Case 1, Case 2, Case 3, and Case 4, are illustrated in Figure 18. The assumed waste material was Type 304 stainless steel and the assumed total weight was $15,000 \mathrm{~kg}$ for all four configurations. The Case 1 model describes the waste as a rectangular array of 21 cuboids with mass density of $8.00 \mathrm{~g} / \mathrm{cm}^{3}$. Case 2 is similar to Case 1 , except that the 21 cuboids are wider and have a mass density of $5.86 \mathrm{~g} / \mathrm{cm}^{3}$. In Case 3 , the waste is represented as seven identical cylinders with a mass density of $6.07 \mathrm{~g} / \mathrm{cm}^{3}$. In Case 4, the waste is modeled as a homogeneous mixture of $4.35 \mathrm{~g} / \mathrm{cm}^{3}$ radially extending to the cask inner shell. The Case 4 geometry model is often used in safety analyses because it is considered to produce bounding dose rates caused by (1) reduced self-shielding and (2) closer source proximity to dose rate locations than other geometry models.

For these studies, the regulatory dose rates under NCT were assumed to be most limiting. External dose rate was calculated at either 8 (Case 2 and Case 4) or 9 (Case 1 and Case 3) different detector locations in air (see Table 19, Figure 17, and Figure 18). Figure 17 shows the 
axial locations of dose rate detectors. Detector locations \# 1,3, 4, 5, 6, 7, and 8 are in the same vertical plane through the cask vertical axis. The radial locations of detector \#2 for Case 1 through Case 4 are illustrated on Figure 18. The radial location of detector \#9 corresponds to a gap between waste blocks, which is also illustrated on Figure 18.

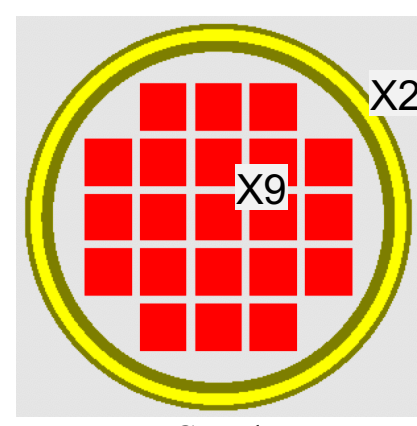

Case 1

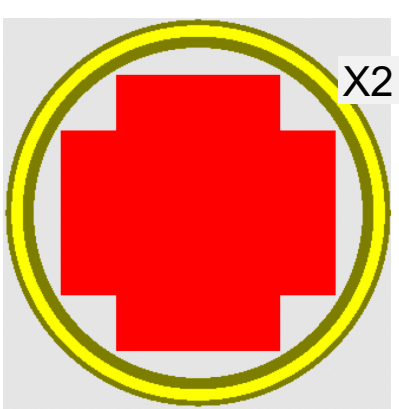

Case 2

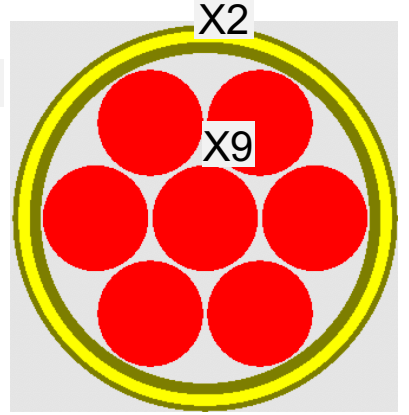

Case 3

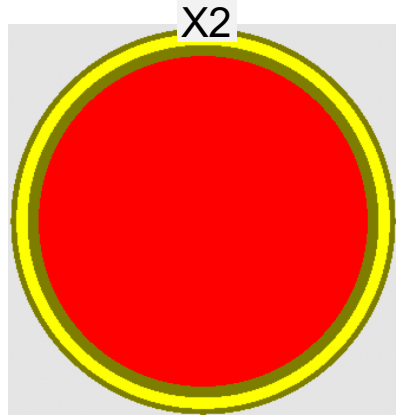

Case 4

Figure 18. Horizontal cross-sectional view of assumed source geometry models, radial locations of detector \#2, and radial location of the projection of detector $\# 9$ onto waste horizontal cross section.

Table 19. Description of dose rate detector locations for the cask at NCT

\begin{tabular}{|c|c|c|}
\hline Detector \# & Radial location & Axial location \\
\hline 1 & Radial outer surface & Trunnion axis \\
\hline 2 & Radial outer surface & Fuel midplane \\
\hline 3 & Cask vertical axis & $\begin{array}{l}\text { Top of impact limiter assumed to be } 30 \mathrm{~cm} \text { from cask top } \\
\text { surface }\end{array}$ \\
\hline 4 & Cask vertical axis & $\begin{array}{l}\text { Bottom of impact limiter assumed to be } 30 \mathrm{~cm} \text { from cask } \\
\text { bottom surface }\end{array}$ \\
\hline 5 & $1 \mathrm{~m}$ from outer radial cask surface & Trunnion axis \\
\hline 6 & $1 \mathrm{~m}$ from outer radial cask surface & Fuel midplane \\
\hline 7 & Cask vertical axis & $2 \mathrm{~m}$ from Detector $\# 3$ \\
\hline 8 & Cask vertical axis & $2 \mathrm{~m}$ from Detector $\# 4$ \\
\hline 9 & $\begin{array}{l}\text { Projection of detector location onto } \\
\text { waste horizontal cross section } \\
\text { corresponds to a gap (see Figure 18) }\end{array}$ & $\begin{array}{l}\text { Bottom of impact limiter assumed to be } 30 \mathrm{~cm} \text { from cask } \\
\text { bottom surface }\end{array}$ \\
\hline
\end{tabular}

${ }^{\mathrm{a}} \mathrm{An}$ impact limiter was not modeled, but its physical location was considered in the model.

\subsection{SELF-SHIELDING EFFECTS ASSOCIATED WITH ANALYSIS MODELS}

\subsubsection{Material Considerations}

A transportation cask may be designed to transport various waste streams with different material compositions. The waste weight limit assumed for each waste stream was $15,000 \mathrm{~kg}$. The selfshielding effects of various materials with adjusted densities to the maximum acceptable content weight of $15,000 \mathrm{~kg}$ was evaluated using the simplified transport cask model described in Table 18 and a uniform volumetric source configuration, i.e., Case 4 in Figure 18. Dose rate values at the detector locations 1 through 8 shown in Figure 17 were calculated assuming that the cask homogeneous material is Type 304 stainless steel, zirconium, or aluminum with a mass density of $4.35 \mathrm{~g} / \mathrm{cm}^{3}$. These dose rate values normalized to the dose rate values obtained for $\mathrm{Al}$ are 
presented in Table 20. The ratio between dose rate, assuming $\mathrm{Zr}$ as the waste material, appears to be slightly higher than the dose rates based on the assumption that the waste material is either Al or stainless steel. However, the dose rate values for all cases were typically within the 3 sigma statistical uncertainty and the three materials with adjusted density based on package content weight are considered equivalent with respect to external dose rate.

Table 20. External cask dose rate for various materials normalized to dose rate based on Al material

\begin{tabular}{cccccc}
\hline & Al & \multicolumn{2}{c}{ Type 304 stainless steel } & \multicolumn{2}{c}{$\mathbf{Z r}$} \\
\hline Detector location & Dose rate ratio $^{\boldsymbol{a}}$ & Dose rate ratio $^{\boldsymbol{a}}$ & $\mathbf{R E}^{b}$ & Dose rate ratio $^{\boldsymbol{a}}$ & $\mathbf{R E}^{b}$ \\
\hline 1 & 1.00 & 1.01 & 0.04 & 1.05 & 0.07 \\
2 & 1.00 & 1.01 & 0.08 & 1.07 & 0.15 \\
3 & 1.00 & 1.02 & 0.03 & 1.07 & 0.06 \\
4 & 1.00 & 1.03 & 0.05 & 1.06 & 0.08 \\
5 & 1.00 & 1.01 & 0.07 & 1.07 & 0.13 \\
6 & 1.00 & 1.02 & 0.07 & 1.07 & 0.12 \\
7 & 1.00 & 1.02 & 0.03 & 1.07 & 0.05 \\
8 & 1.00 & 1.02 & 0.05 & 1.05 & 0.08 \\
\hline
\end{tabular}

${ }^{\mathrm{a}}$ Dose rates values normalized to dose rate for $\mathrm{Al}$.

${ }^{\mathrm{b}}$ Relative error (3 sigma) due to statistical uncertainty.

\subsubsection{Self-Shielding Effects Associated with Waste Geometry Model}

The effects of the idealized waste geometry model on external package dose rate were evaluated assuming the same arbitrary source strength for all cases and a uniform volumetric source distribution. The dose rate at each detector location produced by each geometry model was normalized to the dose rate produced by the Case 4 model at that detector location. These values, presented in Table 21, show that the Case 4 model, the configuration with least material selfshielding and closer source proximity to external dose rate locations, is most conservative of the four cases analyzed.

Table 21. Effects of geometry models Case 1, 2, and 3 on external package dose rate relative to Case 4uniform volumetric source distribution

\begin{tabular}{|c|c|c|c|c|c|c|c|}
\hline \multirow[b]{2}{*}{$\begin{array}{l}\text { Detector } \\
\text { location }\end{array}$} & \multicolumn{2}{|c|}{ Case 1} & \multicolumn{2}{|c|}{ Case 2} & \multicolumn{2}{|c|}{ Case 3} & \multirow{2}{*}{$\begin{array}{c}\text { Case } 4 \\
\text { Dose rate } \\
\text { ratio }^{\text {a }}\end{array}$} \\
\hline & $\begin{array}{c}\text { Dose rate } \\
\text { ratio }^{\text {a }}\end{array}$ & $\begin{array}{c}\text { Relative } \\
\text { error }(\%)\end{array}$ & $\begin{array}{c}\text { Dose rate } \\
\text { ratio }^{\text {a }}\end{array}$ & $\begin{array}{c}\text { Relative } \\
\text { error }(\%)\end{array}$ & $\begin{array}{c}\text { Dose rate } \\
\text { ratio }^{\text {a }}\end{array}$ & $\begin{array}{c}\text { Relative } \\
\text { error }(\%)\end{array}$ & \\
\hline 1 -side & 0.83 & 0.79 & 0.87 & 0.66 & 0.98 & 0.68 & 1.00 \\
\hline 2 -side & 0.98 & 2.04 & 1.01 & 1.52 & 0.99 & 1.38 & 1.00 \\
\hline 3 -top & 0.94 & 1.55 & 0.96 & 0.51 & 0.96 & 0.69 & 1.00 \\
\hline 4 -bottom & 0.94 & 0.85 & 0.97 & 0.70 & 0.97 & 0.77 & 1.00 \\
\hline 5 -side & 0.95 & 1.12 & 0.99 & 1.03 & 1.00 & 1.25 & 1.00 \\
\hline 6 -side & 0.95 & 1.38 & 0.98 & 1.10 & 0.99 & 1.17 & 1.00 \\
\hline 7 -top & 0.80 & 3.10 & 0.83 & 0.43 & 0.87 & 0.83 & 1.00 \\
\hline 8 -bottom & 0.77 & 0.76 & 0.82 & 0.71 & 0.87 & 1.45 & 1.00 \\
\hline $9^{\mathrm{b}}$-bottom & 0.95 & 2.69 & - & - & 0.92 & 0.75 & 1.00 \\
\hline
\end{tabular}

${ }^{a}$ Dose rates values normalized to dose rate for Case 4.

${ }^{b}$ Dose rate for Case 1 and Case 3 normalized to dose rate for Case 4 at detector location \#4. 


\subsection{SOURCE SPATIAL DISTRIBUTIONS}

\subsubsection{Spatial Distribution of Activation Products in Reactor Vessel and Internals}

Various reactor analyses $[21,36,37]$ have shown that the neutron flux and spectrum exhibit axial, radial, and azimuthal variations outside the reactor core region. In addition, the ${ }^{60} \mathrm{Co}$ impurity concentration may significantly vary as a function of metal alloy. Therefore, nuclide activity densities (i.e., Ci per gram of material) are expected to widely vary within activated metals from decommissioned reactors.

High-fidelity, detailed reactor analyses [38] determined that $99.9 \%$ of the activity inventory at 3 years after shutdown was in the activated internal structural materials and the remainder was equally distributed between the pressure vessel and the biological shield. The study by P-W Phlippen et al. (2018) [38] has shown that the specific activities of activation products ${ }^{60} \mathrm{Co}$ and ${ }^{55} \mathrm{Fe}$ were much higher in the pressure vessel liner than within the pressure vessel. These specific activities further decreased with increasing depth within the pressure vessel up to a certain depth and then slightly increased near the outer surface because of neutron streaming in the annulus region between the pressure vessel and the biological shielding. Therefore, specific activity of activation products is expected to vary as a function of depth within reactor vessel and structural materials.

The analyses in NUREG/CR-0130 [23] and NUREG/CR-0672 [22] have shown that the external dose rates due to activation products at the inner surface of the activated shroud, core barrel, and pressure vessel are higher than the external dose rates at the outer surfaces of these reactor components. The dose rates were computed at a distance of $1 \mathrm{~cm}$ from the surface of the activated material, at the vertical center line of the reactor core. The thicknesses of pressure vessel liner of the reference pressurized water reactor (PWR) and BWR reactors were $4 \mathrm{~mm}$ and $3 \mathrm{~mm}$, respectively. The thickness of the reactor pressure vessel was $21.6 \mathrm{~cm}$ (PWR) or $17.1 \mathrm{~cm}$ (BWR). For the ${ }^{60} \mathrm{Co}$ in the pressure vessels of the reference PWR and BWR reactors, the dose rate at the inner surface of the activated material was approximately two orders of magnitude higher than the dose rate at the outer surface of the activated material. This is an indication that the specific activity of ${ }^{60} \mathrm{Co}$ significantly decreases from the inner to outer surface of the pressure vessel. For the core shroud and core barrel, which are thinner than the reactor pressure vessel, the ratio between the dose rate at the inner surface to the dose rate at the outer surface was from approximately 2 to 3.6 .

Based on these previous analyses, activity densities (i.e., Ci per gram of material) of radionuclides in activated metals may vary by orders of magnitude, depending on their location in the reactor and material compositions. Therefore, limits on maximum activity densities of various nuclides may be specified for a package to ensure compliance with regulatory dose rate limits.

Using average nuclide activity and a uniform volumetric source distribution in safety analyses may underpredict external package dose rate values. The effects on the external package dose rate of spatial variations in ${ }^{60} \mathrm{Co}$ specific activity were analyzed using idealized probability density functions (pdfs) for the axial and radial source distributions. The total source strength was constant for all analyzed spatial source distributions. The intent of the study was to 
determine the effects of localized source peaks on external package dose rate relative to uniform volumetric source models.

\subsubsection{Idealized Axial Source Distributions}

Figure 19 shows three different axial source strength distributions that were analyzed: (1) uniform axial source strength distribution (pdf 1), (2) source strength increasing from the lower end to the upper end (pdf 2), and (3) source strength peaking at the midplane (pdf 3 ). The effects on external package dose rates of pdf 2 and pdf 3 were evaluated relative to pdf 1 for Case 4 illustrated in Figure 18 and are presented in Table 22. The table presents the ratio of dose rate value for pdf 2 and pdf 3 to dose rate value for pdf 1 at each dose rate detector location. The dose rate increased at detector locations in the proximity of the source strength peak relative to the uniform source distribution. This increase was by a factor approximately equal to the ratio of the peak source strength to average source strength (i.e., 1.8) at detector locations \# 1, 3, and 7 for pdf 2 and detector location \#2 for pdf 3.

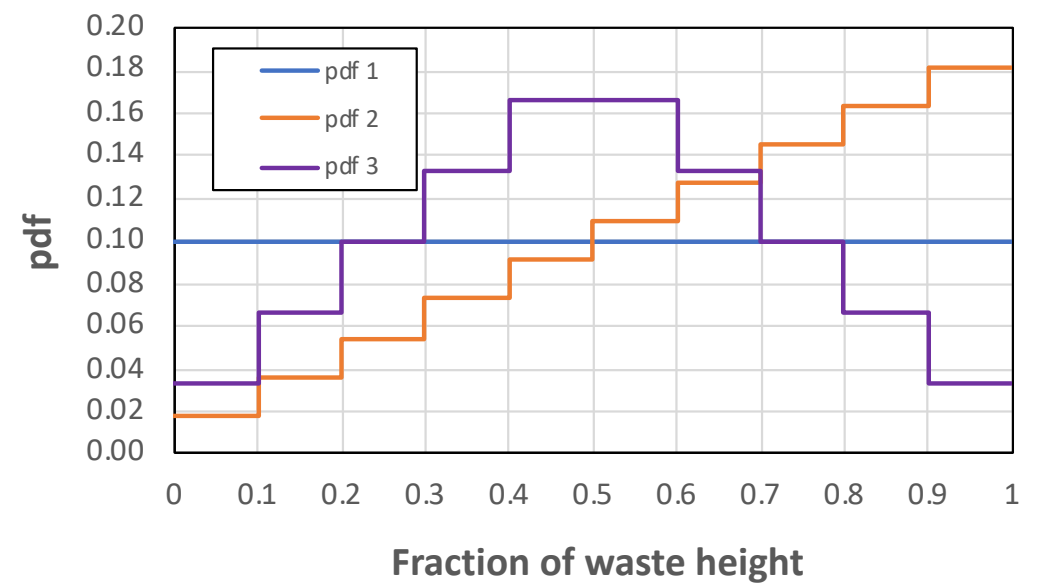

Figure 19. Probability density functions assumed for the source strength axial distribution.

Table 22. Effects on cask external dose rate of pdf 2 and pdf 3 axial source strength distributions relative to uniform source distribution pdf 1

\begin{tabular}{ccccc}
\hline & \multicolumn{2}{c}{ pdf 2 } & \multicolumn{2}{c}{ pdf 3 } \\
\hline $\begin{array}{c}\text { Detector } \\
\text { location }\end{array}$ & $\begin{array}{c}\text { Dose rate } \\
\text { ratio }\end{array}$ & $\begin{array}{c}\text { Relative } \\
\text { error (\%) }\end{array}$ & $\begin{array}{c}\text { Dose rate } \\
\text { ratio }\end{array}$ & $\begin{array}{c}\text { Relative } \\
\text { error (\%) }\end{array}$ \\
\hline 1 & 1.83 & 1.00 & 0.37 & 0.26 \\
2 & 0.97 & 1.42 & 1.66 & 1.66 \\
3 & 1.81 & 0.78 & 0.34 & 0.18 \\
4 & 0.18 & 0.30 & 0.34 & 0.30 \\
5 & 1.32 & 1.35 & 0.95 & 0.82 \\
6 & 1.03 & 1.21 & 1.08 & 1.01 \\
7 & 1.82 & 0.77 & 0.34 & 0.17 \\
8 & 0.19 & 0.30 & 0.34 & 0.29 \\
\hline
\end{tabular}

a Ratio of dose rate value for pdf 2 or pdf 3 to dose rate value for pdf 1 at the detector location. 


\subsubsection{Idealized Radial Source Distributions}

Three different idealized radial source distributions were analyzed to further illustrate the effects of source spatial strength distribution on cask external dose rate relative to the uniform volumetric source volume. These source distributions were applied to the source geometry model identified as Case 1 in Figure 18, which consists of 21 identical sources represented as cuboids in a rectangular array. The three scenarios assume that $90 \%$ of the total source strength is uniformly distributed in one of the following ways: (1) within one cuboid at the peripheral location (pdf 4), (2) within the 12 cuboids at peripheral locations (pdf 5), or (3) within the 9 inner cuboids (pdf 6). The analysis also assumes that $10 \%$ of the source strength is equally distributed among the remainder of cuboids (see Figure 20). The effects of radial source distributions pdf 4, pdf 5, and pdf 6 relative to the uniform source distribution (pdf 1) for Case 1 at detector locations 1 through 9 (see Figure 17) are illustrated in the graph shown in Figure 21. This graph presents the ratios of dose rates based on pdf 4, pdf 5, and pdf 6 source distributions to dose rate based on pdf 1 (uniform distribution) at each detector location.

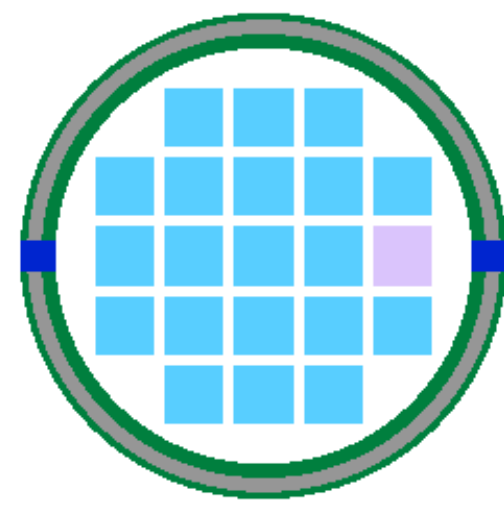

pdf 4

Strength fraction $=0.900$

Strength fraction $=0.005$

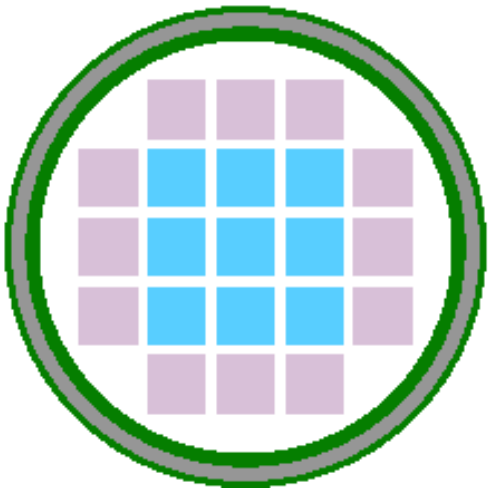

pdf 5

Strength fraction $=0.0750$

Strength fraction $=0.011$

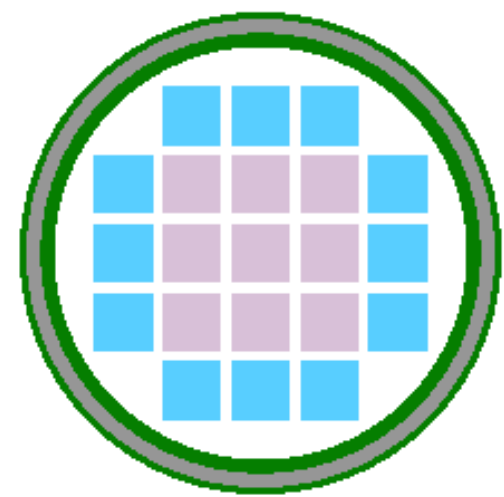

pdf 6

Strength fraction $=0.1000$

Strength fraction $=0.0083$

Figure 20. Source distributions assumed for the radial source profile. 


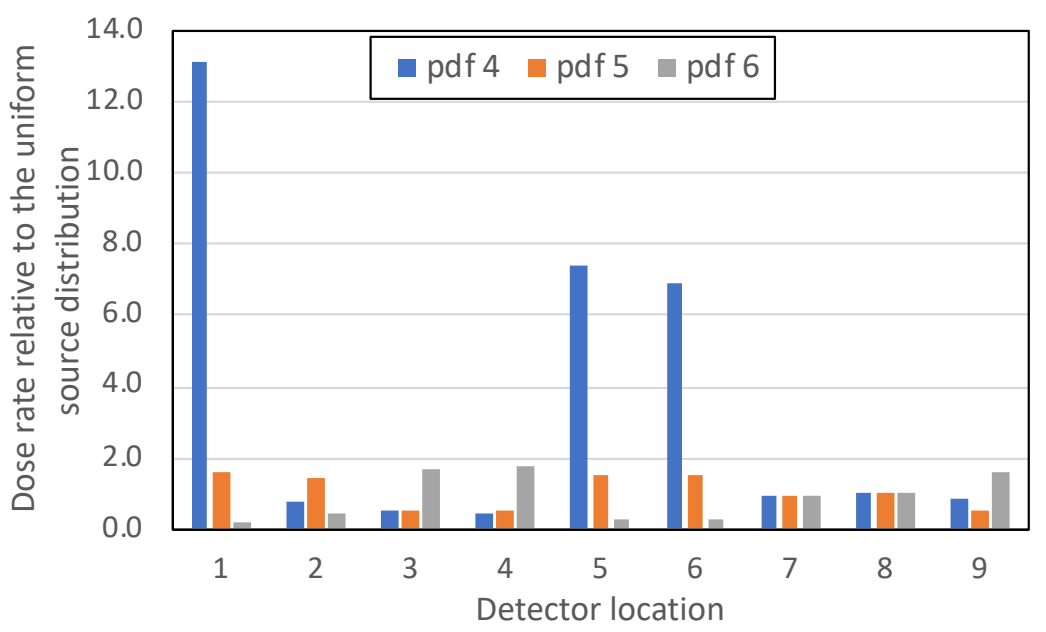

Figure 21. Effects of radial source distributions pdf 4, pdf 5, and pdf 6 relative to the uniform source distribution (pdf 1) at detector locations 1 through 9.

Waste configurations with higher ${ }^{60} \mathrm{Co}$ source strength/activity density located at peripheral source regions (pdf 4 and pdf 5) produced higher radial dose rates relative to the uniform source distribution. For pdf 4, which has most of the source strength concentrated in the cuboid located near the cask inner radial shell, the relative increase was by a factor 13 at detector location \#1 near the upper trunnion, and by a factor of approximately 7 at detector locations \#5 and \#6. The dose rate decreased at detector location \#2 because sources with lower activity density/source strength were located near this detector location. For pdf 5, the relative increase in radial dose rate was proportional to the increase in the source strength at the peripheral locations relative to that of the uniform source distribution, i.e., $0.075 / 0.048=1.56$, where 0.048 is the source strength fraction for each individual source cuboid assuming uniform source distribution (i.e., $1 / 21=0.0476$ ). The waste configuration with higher source strength placed on the inner source regions (pdf 6) produced higher dose rates at the cask top and bottom surfaces relative to the uniform source distribution. All three distributions produced approximately the same dose rates at $2 \mathrm{~m}$ from the cask top and bottom surfaces (i.e., detectors \#7 and \#8).

This study shows that the uniform volumetric source distribution would not be conservative if individual waste units exhibit significantly localized peaks of activity density/source strength and emphasizes the need for accurate characterization of the peak source activities for the waste stream expected to be loaded in the cask. A simple modeling approach would be to assume that the entire waste has an activity density equal to the localized specific activity peak. External package dose rates may then be determined using a uniform source distribution with an activity density equal to the localized peak. Limits on nuclide activity density $(\mathrm{Ci} / \mathrm{g})$ or on gamma source strength density (photons/s/g) may be specified for package contents to ensure compliance with regulatory dose rate limits. This analysis approach was used in the MAGNATRAN safety analysis [5]. 


\section{NEUTRON-ACTIVATED CORROSION PRODUCTS ON REACTOR INTERNAL SURFACES}

The composition and amount of radionuclides found on reactor internals depend on structural material composition; reactor size, design, and operating history; and reactor fuel conditions [23]. Reference fractional radioactivity levels on surfaces of PWR and BWR piping, equipment, and fuel at shutdown are provided in Table 23. The data on neutron-activated corrosion products were provided in NUREG/CR-0130 [22] and NUREG/CR-0672 [23] and the data for crud (Chalk River unidentified deposits) were provided in Ref. [39]. Larger amounts of ${ }^{58} \mathrm{Co}$, a shortlived ( $\mathrm{T}_{1 / 2}=70.85$ days) activation product in Inconel, are found in PWRs. Larger amounts of ${ }^{60} \mathrm{Co}\left(\mathrm{T}_{1 / 2}=5.271 \mathrm{y}\right)$, an activation product in stainless steel and Inconel, are found in BWRs. Fission products were primarily measured on internally contaminated equipment. The analysis presented in Section 8 shows that neutron sources that might exist on the surface of activated metals have negligible contributions to the external package dose rate.

Table 23. Reference fractional radioactivity levels on internal surfaces at reactor shutdown.

\begin{tabular}{ccccccc}
\hline & \multicolumn{2}{c}{$\begin{array}{c}\text { Corrosion products on } \\
\text { piping }\end{array}$} & \multicolumn{2}{c}{$\begin{array}{c}\text { Surface contamination for } \\
\text { reference reactor }\end{array}$} \\
\hline Radioisotope & PWR $^{a}$ & BWR $^{b}$ & PWR $^{a}$ & BWR $^{b}$ & PWR $^{c}$ & BWR $^{c}$ \\
\hline${ }^{51} \mathrm{Cr}$ & $2.4 \mathrm{E}-02$ & $2.1 \mathrm{E}-02$ & $6.9 \mathrm{E}-04$ & $2.1 \mathrm{E}-02$ & $1.48 \mathrm{E}-01$ & $1.63 \mathrm{E}-02$ \\
${ }^{54} \mathrm{Mn}$ & $3.6 \mathrm{E}-02$ & $3.9 \mathrm{E}-01$ & $1.4 \mathrm{E}-03$ & $3.9 \mathrm{E}-01$ & $1.44 \mathrm{E}-01$ & $2.91 \mathrm{E}-01$ \\
${ }^{55} \mathrm{Fe}$ & - & - & $2.2 \mathrm{E}-02$ & - & - & - \\
${ }^{59} \mathrm{Fe}$ & $8.2 \mathrm{E}-03$ & $2.5 \mathrm{E}-02$ & $8.7 \mathrm{E}-04$ & $2.5 \mathrm{E}-02$ & $1.13 \mathrm{E}-01$ & $4.05 \mathrm{E}-02$ \\
${ }^{58} \mathrm{Co}$ & $4.6 \mathrm{E}-01$ & $9.3 \mathrm{E}-03$ & $7.5 \mathrm{E}-03$ & $9.3 \mathrm{E}-03$ & $5.29 \mathrm{E}-01$ & $2.94 \mathrm{E}-02$ \\
${ }^{60} \mathrm{Co}$ & $3.2 \mathrm{E}-01$ & $4.7 \mathrm{E}-01$ & $7.5 \mathrm{E}-02$ & $4.7 \mathrm{E}-01$ & $5.29 \mathrm{E}-02$ & $5.82 \mathrm{E}-01$ \\
${ }^{89} \mathrm{Sr}$ & - & - & $1.2 \mathrm{E}-03$ & - & - & - \\
${ }^{90} \mathrm{Sr}$ & - & - & $6.9 \mathrm{E}-04$ & - & - & - \\
${ }^{90} \mathrm{Y}$ & - & - & $6.9 \mathrm{E}-04$ & - & - & - \\
${ }^{95} \mathrm{Zr}$ & $5.6 \mathrm{E}-02$ & $6.1 \mathrm{E}-03$ & $2.5 \mathrm{E}-04$ & $4.0 \mathrm{E}-03$ & - & - \\
${ }^{95} \mathrm{Nb}$ & $5.6 \mathrm{E}-02$ & - & $2.5 \mathrm{E}-04$ & $4.0 \mathrm{E}-03$ & $1.36 \mathrm{E}-02$ & $1.40 \mathrm{E}-02$ \\
${ }^{103} \mathrm{Ru}$ & $2.6 \mathrm{E}-02$ & - & - & $2.3 \mathrm{E}-03$ & - & - \\
${ }^{106} \mathrm{Ru}$ & - & - & - & $2.8 \mathrm{E}-03$ & - & - \\
${ }^{129 \mathrm{~m} \mathrm{Te}}$ & - & - & $3.1 \mathrm{E}-04$ & - & - & - \\
${ }^{131} \mathrm{I}$ & - & - & $1.4 \mathrm{E}-02$ & - & - & - \\
${ }^{134} \mathrm{Cs}$ & - & - & $1.2 \mathrm{E}-01$ & $1.9 \mathrm{E}-02$ & - & - \\
${ }^{136} \mathrm{Cs}$ & - & - & $1.1 \mathrm{E}-03$ & - & - & - \\
${ }^{137} \mathrm{Cs}$ & $1.2 \mathrm{E}-03$ & $6.9 \mathrm{E}-02{ }^{d}$ & $7.5 \mathrm{E}-01$ & $3.4 \mathrm{E}-02$ & - & - \\
${ }^{141} \mathrm{Ce}$ & $6.6 \mathrm{E}-02$ & - & - & $3.0 \mathrm{E}-03$ & - & - \\
${ }^{144} \mathrm{Ce}$ & - & - & - & $8.1 \mathrm{E}-03$ & - & - \\
\hline
\end{tabular}

${ }^{a}$ R. I. Smith et al. (1978) [22].

bH. D. Oak et al. (1979) [23].

'R. P. Sandoval et al. (1992) [39].

${ }^{\mathrm{d}}$ Total fission products represented as ${ }^{137} \mathrm{Cs}$.

Approaches for modeling the neutron-activated corrosion products that may be attached to activated reactor components were analyzed in this report. The reference fractional radioactivity levels presented in Table 23 were used in ORIGEN decay calculations to determine photon source terms for $1 \mathrm{Ci}$ of neutron-activated corrosion products. For the cask model at NCT (see Figure 17), the corrosion products were modeled as (1) a uniform volumetric source within the 
waste volume (Case 4 in Figure 18) and (2) a uniform surface source on the outer waste surfaces. An arbitrary radiation source strength was used for the total amount of neutron-activated corrosion products for each of the reference compositions presented in Table 23. The absolute value of the source strength is not important because relative dose rate effects are presented in this report. Dose rates were calculated at the detector locations 1 through 8 shown in Figure 17. The surface source produced much higher external dose rates than the volumetric source. For the cask model used in this analysis, this increase was similar among the 6 sets of activated corrosion products analyzed and the increase varied from approximately 4.2 to 7.4 , depending on detector location, as illustrated in Figure 22. Homogenization of the neutron-activated corrosion products within the waste material is not recommended because this modeling approach would result in an underestimation of cask external dose rate caused by self-shielding effects.

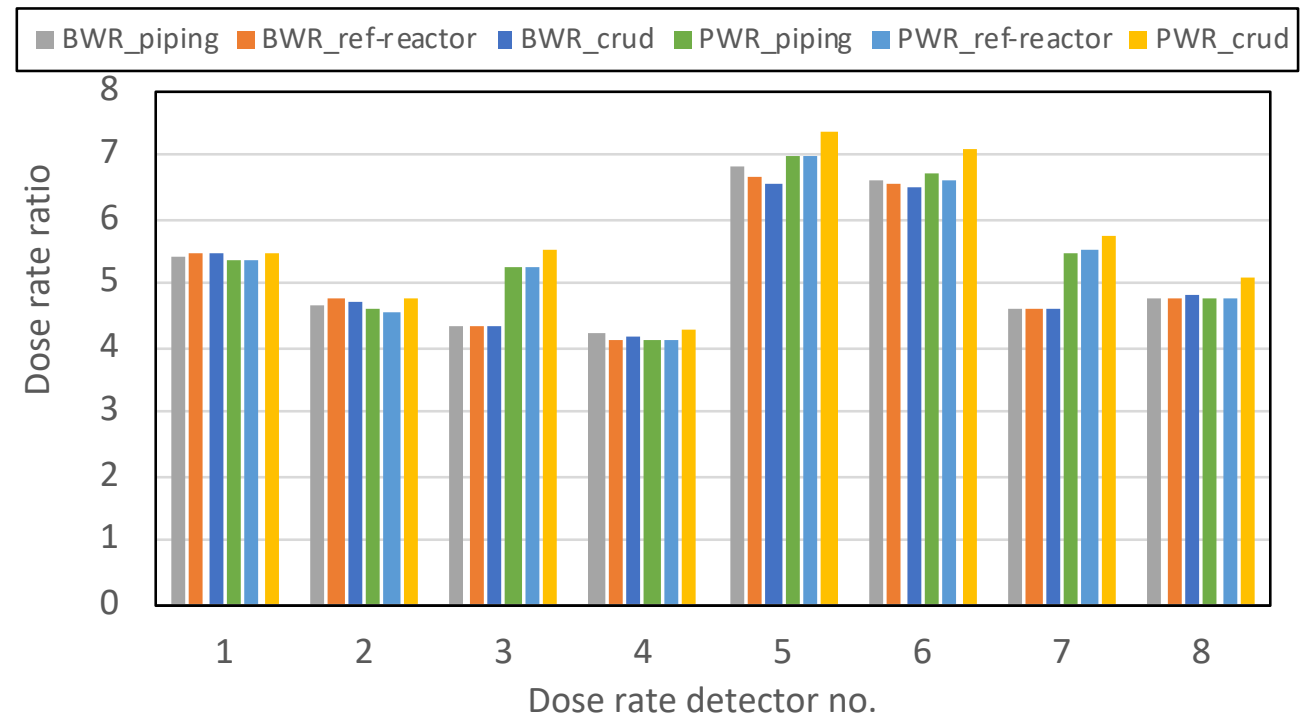

Figure 22. Ratio of dose rate based on a surface source model to dose rate based on a uniform volumetric source model as a function of detector location for various neutron-activated corrosion product sources. 


\section{CONCLUSIONS AND RECOMMENDATIONS}

This report presents a series of analyses intended to (1) identify radioisotopes in various non-fuel waste streams produced by power plant operations that are major contributors to external package dose rates, (2) evaluate self-shielding effects associated with various idealized representations of source materials and geometry, (3) evaluate effects of localized peak source strength on external package dose rates, and (4) investigate possible ways to reduce the complexity of radiation source term and shielding analyses based on the results of these studies. The following non-fuel waste streams were analyzed to identify the radionuclides with greatest effects on external package dose rates:

- Activated metals, including Type 304 stainless steel, reactor vessel steel, and Inconel from decommissioned commercial power reactors.

- Activated BWR control blades.

- Neutron-activated corrosion products on reactor internal surfaces.

- Spent resins from power plant operation.

Cobalt-60 in activated metals is a major contributor to external package dose rate and the package contents are often specified in term of maximum ${ }^{60} \mathrm{Co}$ activity per package. Activated metals, including Type 304 stainless steel, reactor vessel steel (carbon steel), and Inconel, were analyzed with respect to the external package dose rate. Measured chemical compositions, including major constituents and impurities, of unirradiated metals from US LWRs were obtained from NUREG/CR-3474 [21]. The greatest cobalt impurity levels were measured in Type 304 stainless steel, with up to $2,570 \mathrm{ppm}$, and the lowest cobalt impurity levels were measured in vessel steel (carbon steel), which ranged from $93 \mathrm{ppm}$ to $151 \mathrm{ppm}$. The reported cobalt impurity concentration in the Inconel samples was 574 ppm. The Type 316 stainless steel was not analyzed in this report because stainless steel types 304 and 316 have similar initial elemental compositions and cobalt impurity concentrations [21], and the results for Type 304 stainless steel are applicable to the Type 316 stainless steel. The external package dose rate was dominated by short-lived radionuclides at shutdown, but the ${ }^{60} \mathrm{Co}$ contribution to the external package dose rate increased after reactor shutdown. At 30 days after shutdown, ${ }^{60} \mathrm{Co}$ contribution to the total external package dose rate varied from approximately $60 \%$ to $95 \%$, depending on material, initial cobalt impurity concentration, and shield thickness. Its maximum contribution of approximately $100 \%$ was reached within the time interval of 2 to 5 years after shutdown and was maintained for up to 45 to 60 years after shutdown, depending on material, initial cobalt impurity concentration, and shield thickness. Thereafter, ${ }^{60} \mathrm{Co}$ contribution to external package dose rate decreased with increasing decay time. These findings are consistent with those in NUREG/CR0130 and NUREG/CR-0672, which identified ${ }^{60} \mathrm{Co}$ as the major contributor to external dose rate because of neutron-induced activation products in reactor pressure vessel and internal structural materials.

Approaches for modeling the neutron-activated corrosion products that may be attached to activated reactor components were analyzed in this report. Data on neutron-activated corrosion products were provided in NUREG/CR-0130 [22] and NUREG/CR-0672 [23], and data for crud were provided in Ref. [39]. Using a simplified cask model, the corrosion products were modeled 
as (1) a uniform volumetric source within the waste volume and (2) a uniform surface source on the outer waste surfaces. The surface source produced higher external dose rates by a factor greater than four than a uniform volumetric source for the cask model used in the analysis. Therefore, it was demonstrated that a surface source is more conservative than a uniform volumetric source for the treatment of neutron-activated corrosion products with respect to external package dose rates.

The radionuclide loadings on spent resins reported in NUREG/CR-2830 [32] for US power plants were analyzed with respect to external package dose rate using a simplified cask model. Based on the reported maximum radionuclide loadings on spent resins [32], the primary contributors to dose rate were ${ }^{137} \mathrm{Cs}\left(\mathrm{T}_{1 / 2}=30.07 \mathrm{y}\right),{ }^{60} \mathrm{Co}\left(\mathrm{T}_{1 / 2}=5.271 \mathrm{y}\right),{ }^{134} \mathrm{Cs}\left(\mathrm{T}_{1 / 2}=2.0648 \mathrm{y}\right)$, ${ }^{65} \mathrm{Zn}\left(\mathrm{T}_{1 / 2}=244.26 \mathrm{~d}\right)$, and ${ }^{58} \mathrm{Co}\left(\mathrm{T}_{1 / 2}=70.86 \mathrm{~d}\right)$. For a resin cooled for 3.08 years [33], the external package dose rate was entirely produced by the reported ${ }^{137} \mathrm{Cs}$ and ${ }^{60} \mathrm{Co}$ inventory. Therefore, the study has identified primary contributors to external dose rate for packages loaded with spent resins from power plant operations. The neutron sources from actinides found on spent resins or crud [35] attached to activated metals were shown to produce negligible dose rates and may be ignored.

The materials, geometry shapes, and spatial source distributions of individual waste pieces loaded into a transportation cask may not be easily characterized and considered in the safety analysis models. Therefore, safety analyses typically determine maximum external package dose rate using idealized bounding material, geometry, and spatial source distribution models. Effects of idealized waste source geometry and spatial distributions on external package dose rates were determined based on dose rate calculations using a simplified cask model under NCT. Four different waste geometry configurations providing different mass densities from $4.35 \mathrm{~g} / \mathrm{cm}^{3}$ to $8.00 \mathrm{~g} / \mathrm{cm}^{3}$ were analyzed. As expected, the geometry configuration with a mass density of 4.35 $\mathrm{g} / \mathrm{cm}^{3}$ (i.e., minimum self-shielding effect among the four cases) was most conservative. For material modeling effects, the assumed waste materials were Type 304 stainless steel, zirconium, and aluminum with the same source strength and their adjusted mass density based on an assumed maximum acceptable content weight. These three different materials with adjusted mass densities produced identical external package dose rates within the statistical uncertainties of the dose rate estimates.

Previous reactor analyses indicate that radionuclide activity densities in activated metals (i.e., $\mathrm{Ci}$ per gram of metal) may vary by orders of magnitude, depending on the activated material and their location in the reactor. The effects on the external package dose rate of localized ${ }^{60} \mathrm{Co}$ source peaks were analyzed using idealized axial and radial source distributions while maintaining the total source strength for all analyzed spatial source distributions constant. The intent of the study was to evaluate the effects of various source distributions relative to the uniform volumetric distribution, which is often used in safety analyses. The study showed that spatial source distributions that better represent localized peak source strength values would be more conservative than a uniform volumetric source distribution, assuming same total source strength per package. A simple modeling approach would be to assume that the entire waste has an activity density equal to the localized activity peak. External package dose rates may then be determined using a uniform source distribution with an activity density equal to the localized peak. Limits on nuclide activity density $(\mathrm{Ci} / \mathrm{g})$ or on gamma source strength density (photons/s/g) may be specified for package contents to ensure compliance with regulatory dose rate limits. 
The following recommendations are provided based on the analyses presented in this report:

- Bremsstrahlung (i.e., photon radiation) produced by the slowing down of pure beta emitters in waste materials, may be calculated with ORIGEN by specifying either $\mathrm{UO}_{2}$ (default option, for conservative sources) or water matrix. A different method (e.g., analytical formula) may be used with proper justification/validation if the $\mathrm{UO}_{2}$ option in ORIGEN is too conservative or if the $\mathrm{H}_{2} \mathrm{O}$ option in ORIGEN yields underestimated quantities.

- The neutron sources associated with actinides on spent resins or neutron sources that might exist on the surface of activated metals may be neglected because of their negligible contribution to external package dose rate.

- The analyses in this report support the approach of defining the contents of packages dedicated to shipment of activated stainless steel, carbon steel, Inconel, and Stellite from reactor internals and pressure vessel in terms of ${ }^{60} \mathrm{Co}$ activity/source strength or equivalent activity/source strength. Representing other important short- and long-lived radionuclides, such as ${ }^{59} \mathrm{Fe}$ and ${ }^{54} \mathrm{Mn}$, that contribute to the external package dose rates as ${ }^{60} \mathrm{Co}$ would be conservative because ${ }^{60} \mathrm{Co}$ gamma ray emissions were shown to be bounding in terms of source energy.

- The activation sources for control blades with $\mathrm{B}_{4} \mathrm{C}$ absorber or $\mathrm{Hf}$ absorber rods cooled for more than 2 years may be treated as activated stainless steel radiation sources alone. However, Hf radiation sources should be included in the total radiation sources of irradiated Hf control blades if the cooling time of the control blades is less than 2 years.

- If the gamma radiation source from corrosion products that might exist on the surface of activated metals is shown to be a significant contributor to external package dose rate, this radiation source should be modeled as a surface source. Homogenization of the neutron-activated corrosion products within the waste material is not recommended because this modeling approach would result in an underestimation of cask external dose rate due to self-shielding effects.

- For maximum radionuclide loadings on spent resins (i.e., resins containing short- and long-lived radionuclides), ${ }^{137} \mathrm{Cs},{ }^{60} \mathrm{Co},{ }^{134} \mathrm{Cs},{ }^{65} \mathrm{Zn}$, and ${ }^{58} \mathrm{Co}$ were identified as primary contributors to external package dose rates. For resins cooled for more than three years, the inventory may be limited to ${ }^{137} \mathrm{Cs}$ and ${ }^{60} \mathrm{Co}$. However, note that these conclusions were based on a limited number of spent resins from six power plants that were shipped for disposal and may not be applicable to all spent resins.

- Concerning idealized source geometry models, a homogeneous mixture radially extending to the cask inner shell may be used for slightly conservative external package dose rates as compared to other shapes with higher mass densities.

- Common non-fuel reactor materials such as aluminum, steel, and Zircaloy may be modeled as any of these materials with an adjusted mass density that produces the same weight per package to obtain the same external dose rate values.

- For waste-exhibiting localized source peaks, the entire waste volume may be assumed to have an activity density equal to the localized specific activity peak. External package dose rates may then be determined using a uniform source distribution with an activity density equal to the localized peak. Limits on nuclide activity density $(\mathrm{Ci} / \mathrm{g})$ or on gamma source strength density (photons/s/g) may be specified for package contents to ensure compliance with regulatory dose rate limits. 


\section{ACKNOWLEDGMENTS}

The work described in this paper was accomplished with funding provided by the US Nuclear Regulatory Commission. 


\section{REFERENCES}

1. US Code of Federal Regulations, "Packaging and Transportation of Radioactive Material," Part 71, Title 10, "Energy."

2. US Code of Federal Regulations, "Licensing Requirements for Land Disposal of Radioactive Waste" Part 61, Title 10, "Energy."

3. RT-100 Type B Cask Safety Analysis Report, Docket Number 71-9365, Rev. 7, Robatel Technologies (2018).

4. Safety Analysis Report for the UMS ${ }^{\circledast}$ Universal Transport Cask Docket No. 71-9270 Revision 2, Nuclear Assurance Corporation International (2005).

5. NAC-STC NAC Storage Transport Cask Safety Analysis Report, Rev. 15, Nuclear Assurance Corporation International (2004).

6. MAGNATRAN, Safety Analysis Report Rev. 0, Nuclear Assurance Corporation International (2019).

7. Safety Analysis Report for Model 8-120B Type B Shipping Packaging, Rev. 10, EnergySolutions (2016).

8. Enclosure 3 of E-41950, Changed Pages, TN-RAM SAR, Revision 14, ML15162A173, AREVA Inc. (2015).

9. “RAMPAC: Radioactive Material Packaging," US Office of Environmental Management, Rampac.energy.gov, accessed July 2020.

10. Certificate of Compliance for Radioactive Material Packages No. 9168, Package Identification Number USA/9168/B(U)-96, US Nuclear Regulatory Commission (2017).

11. Model 2000 Radioactive Material Transport Package Safety Analysis Report, GE-Hitachi Nuclear Energy Americas, LLC (2017).

12. B. T. Rearden and M. A. Jessee, Eds. 2016. SCALE Code System, ORNL/TM-2005/39, Version 6.2.1, Oak Ridge National Laboratory. Available from the Radiation Safety Information Computational Center as CCC-834.

13. R. B. Firestone, C. M. Baglin (Editor), S. Y. Frank Chu (CD-ROM Editor), Table of Isotopes: 1999 Update, $8^{\text {th }}$ Edition, WILEY (1999).

14. D. E. Peplow. 2011. "Monte Carlo Shielding Analysis Capabilities with MAVRIC." Nucl. Technol. 174 (2): 289-313.

15. J. C. Wagner, D. E. Peplow, and S. W. Mosher. 2014. "FW-CADIS Method for Global and Regional Variance Reduction of Monte Carlo Radiation Transport Calculations." Nucl. Sci. Eng., 176 (1): 37-57.

16. T. M. Evans, A. S. Stafford, R. N. Slaybaugh, and K. T. Clarno. 2010. "Denovo: A New Three-Dimensional Parallel Discrete Ordinates Code In SCALE.” Nucl. Technol. 171 (2): 171-200. 
17. American National Standard Neutron and Gamma-Ray Flux-to-Dose-Rate Factors, ANSI/ANS 6.1.1-1977 American Nuclear Society (1977).

18. P. J. Karpius, Beta Emission and Bremsstrahlung, LA-UR-17-30388, Los Alamos National Laboratory (2017).

19. 8-120B Safety Analysis Report, Docket Number 71-9168, Revision 10, Energy Solutions (2016).

20. H. H. Grady III, Enhanced Electron-Photon Transport in MCNP6, LA-UR-13-20564, Los Alamos National Laboratory (2013).

21. J. C. Evans et al., Long-Lived Activation Products in Reactor Materials, NUREG/CR-3474, US Nuclear Regulatory Commission (1984).

22. R. I. Smith, G. J. Konzek, and W. E. Kennedy, Jr., Technology, Safety and Costs of Decommissioning a Reference Pressurized Water Reactor Power Station, NUREG/CR-0130 Vol1, Battelle Pacific Northwest Laboratory, prepared for US Nuclear Regulatory Commission (1978).

23. H. D. Oak et al., Technology, Safety and Costs of Decommissioning a Reference Boiling Water Reactor Power Station, NUREG/CR-0672 Vol2, Battelle Pacific Northwest laboratory, prepared for US Nuclear Regulatory Commission (1979).

24. W. Gunther and K. Sullivan, Aging Assessment of the Westinghouse PWR Control Rod Drive System, NUREG/CR-5555, US Nuclear Regulatory Commission (1990).

25. M. S. Hasan et al., "The Basics of Stellites in Machining Perspective," International Journal of Engineering Materials and Manufacture (2016) 1(2).

26. Radioactive Waste Management, Volume 96, Issues 1-4, DOE/RWM-96/1, US Department of Energy (1996).

27. Certificate of Compliance for Radioactive Material Packages No. 9235, Package Identification Number USA/9235/B(U)F-96, US Nuclear Regulatory Commission (2019).

28. Certificate of Compliance for Radioactive Material Packages No. 9356, Package Identification Number USA/9356/B(U)F-96, US Nuclear Regulatory Commission (2019).

29. General Electric System Technology Manual, Chapter 2.2, "Fuel and Control Rods System," ML11258A302.pdf, US Nuclear Regulatory Commission.

30. E. A. Lepel et al., Radiological Characterization of Spent Control Rod Assemblies, NUREG/CR-6390, US Nuclear Regulatory Commission (1995).

31. Radiation Protection Aspects of Primary Water Chemistry and Source-term Management, NEA/CRPPH/R(2014)2, Nuclear Energy Agency, Organisation for Economic Co-operation and Development (2014).

32. D. R. MacKenzie, M. Lin, and R. E. Barletta, Permissible Radionuclide Loadings for Organic Ion Exchange Resins from Nuclear Power Plants, NUREG/CR-2830, US Nuclear Regulatory Commission (1983). 
33. D. E. Robertson et al., Low-Level Radioactive Waste Classification, Characterization, and Assessment: Waste Stream and Neutron-Activated Metals, NUREG/CR-6567, US Nuclear Regulatory Commission (2000).

34. Chapter 1, Ref. 08 - Resin and Filter Handbook - Primers and Product Information, https://www.nrc.gov/docs/ML1407/ML14079A369.pdf

35. Final Environmental Impact Statement for the Disposal of Greater-Than-Class C (GTCC) Low-Level Radioactive Waste and GTCC-Like Waste (DOE/EIS-0375), Volume 2: Chapter 9 through Appendix I, US Department of Energy (2016).

36. J. F. Carew et al., PWR and BWR Pressure Vessel Fluence Calculation Benchmark Problems and Solutions, NUREG/CR-6115, Brookhaven National Laboratory, prepared for US Nuclear Regulatory Commission (2001).

37. M. P. Garces, Activation Neutronics for the Swiss Nuclear Power Plants, PhD Dissertation (2013).

38. P-W Phlippen et al., "Numeric Determination and Validation of Neutron-Induced Radioactive Nuclide Inventories for Decommissioning and Dismantling of Light Water Reactor," Nucl.Technol., 201, (2018): 66-79.

39. R. P. Sandoval et al., "Estimate of the CRUD Contribution to Shipping Cask Containment Requirements," Nucl. Technol., Vol. 98 (1992). 